\title{
Fatores associados à qualidade da dieta de adultos residentes na região metropolitana de São Paulo
}

\author{
Juliana Masami Morimoto
}

Dissertação apresentada ao Programa de Pós-Graduação em Saúde Pública da Faculdade de Saúde Pública da Universidade de São Paulo para obtenção do título de Mestre em Saúde Pública.

Área de concentração: Nutrição

Orientadora: Prof $^{a} \mathrm{Dr}^{\mathrm{a}}$ Regina Mara Fisberg 


$$
45815 / 2005 \text { dre }
$$

Autorizo, exclusivamente para fins acadêmicos e científicos, a reprodução total ou parcial desta dissertação, por processos fotocopiadores.

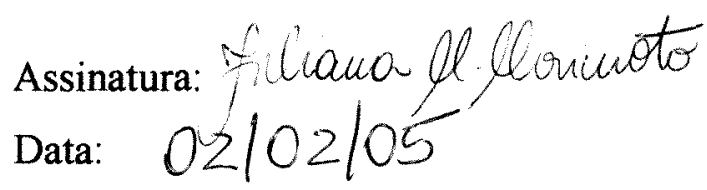


"A vida não é um corredor reto e tranqüilo que nós percorremos livrese sem empecifhos, mas um labirinto de passagens, pelas quais nós devemos procurar nosso caminho, perdidos e confusos, de vez em quando presos em um beco sem saída. Porém, se tivermos fé, uma porta sempre será aberta para nós, não talvez aquela sobre a qual nós mesmos nunca pensamos, mas aquela que definitivamente se revelará 6oa para nós." (A. J. Cronin) 
DEDICATÓRIA 
Aos meus pais, Takashi e Sueko, que sempre se esforçaram para garantir a maior heranfa que poderiam deixar aos seus filfios: a educação.

Ao meu irmão Emesto, que me encorajou a buscar a realização dos sonfios em minfa vida.

Ao Ivan, companfeiro e amigo, presente em todos os momentos de minha vida, sempre apoiando minhas decisões mais importantes. 
À REGINA MARA FISBERG, orientadora e amiga, pela confiança, amizade, carinho e os incontáveis ensinamentos sobre Nutrição e sobre a vida, que contribuíram decisivamente para a minha formação profissional e crescimento pessoal.

À DIRCE MARIA LOBO MARCHIONI, BETZABETH SLATER e LIGIA ARAÚJO MARTINI, pelos ensinamentos e incentivos constantes que colaboraram imensamente para a realização deste trabalho, minha formação profissional e desenvolvimento individual.

À MARIA DO ROSÁRIO DIAS DE OLIVEIRA LATORRE, pelos ensinamentos e orientação na análise estatística e nas coisas da vida, que contribuíram para o meu aprendizado, para o aprimoramento deste trabalho e para o desenvolvimento pessoal.

Ao CHESTER LUIZ GALVÃO CESAR, pela oportunidade de participação na pesquisa, o que possibilitou a concretização deste trabalho.

À FERNANDA, SORAYA e SAMANTHA, pela dedicação e esforço em uma das partes mais trabalhosas desta pesquisa e que foi de fundamental importância para a qualidade dos resultados deste estudo.

À TATYANA e JAQUELINE, alunas de iniciação científica, que sempre ofereceram auxílio durante a realização deste trabalho.

À MILENA, amiga e companheira de estudos, pela amizade sincera e pelos ensinamentos fundamentais para a realização das análises estatísticas deste trabalho.

À ANA CAROLINA e ROBERTA, amigas de longa data, pelo incentivo e amizade que foram muito importantes para o meu crescimento profissional e pessoal.

Ao professor JOSÉ ALFREDO GOMES ARÊAS, pelo constante incentivo na busca do conhecimento científico.

Aos professores do Departamento de Nutrição da Faculdade de Saúde Pública da USP pelo carinho durante a convivência conjunta em todos estes anos.

Aos amigos FABIANA, RICARDO, JOSÉ ALEXANDRE, ALINE, FERNANDO, pelo incentivo e apoio, que estimularam o meu ingresso no Mestrado e na carreira acadêmica.

À MÁRCIA, ANA PAULA, RITA DE CÁSSIA, GIANA, PRISCILA, PATRÍCIA, BÁRBARA, RAQUEL, LUANA, NATACHA, SILVIA, BETH, ILANA, FLÁVIA e demais colegas de curso, pela convivência sadia na Faculdade de Saúde Pública.

AO CONSELHO NACIONAL DE DESENVOLVIMENTO CIENTÍFICO E TECNOLÓGICO - CNPq - pela bolsa de estudos concedida desde o início deste Programa de Pós-Graduação. 
Morimoto JM. Fatores associados à qualidade da dieta de adultos residentes na região metropolitana de São Paulo. São Paulo; 2004. [Dissertação de Mestrado Faculdade de Saúde Pública da Universidade de São Paulo].

Objetivo: Avaliar os fatores demográficos, socioeconômicos e de estilo de vida associados à qualidade da dieta de adultos residentes na região metropolitana de São Paulo. Metodologia: Utilizaram-se dados de adultos de 20 anos ou mais, de ambos os sexos $(n=1840)$ da pesquisa "Inquérito de Saúde do Estado de São Paulo - ISASP”. É um estudo transversal, por meio de inquérito domiciliar, de base populacional, realizado no distrito do Butantã e nos municípios de Itapecerica da Serra, Embu e Taboão da Serra. Aplicou-se um questionário e o Método Recordatório de 24 horas por entrevistadores previamente treinados. A qualidade da dieta foi avaliada através do Índice de Qualidade da Dieta (IQD) adaptado para a realidade local. O IQD é constituído por 10 componentes, sendo que 6 medem o grau de adequação do consumo de cada um dos 6 principais grupos de alimentos, outros 3 medem a ingestão de gordura total, de colesterol e de sódio, respectivamente, e o último mede a variedade da dieta. Foi utilizada análise de regressão linear para avaliar a relação entre o IQD e as demais variáveis. Resultados: A média do IQD foi de 60 pontos, sendo que a maioria da população (75\%) possuía dieta que necessita de melhora. Os valores médios dos componentes do IQD apresentaram-se baixos para frutas, verduras e legumes, leite e produtos lácteos e elevadas para carnes e ovos e colesterol. $\mathrm{Na}$ análise de regressão múltipla, ingestão de energia, número de bens de consumo duráveis, escolaridade do chefe da familia e faixa etária (60 anos ou mais) associaram-se ao IQD. Foram observadas diferenças entre homens e mulheres após estratificação do modelo final. Conclusão: Quanto maior a ingestão de energia ou maior o número de bens de consumo duráveis ou maior a escolaridade do chefe da família ou estar na faixa etária de 60 anos ou mais, maior é o IQD. Para as mulheres apenas o efeito da ingestão de energia e da faixa etária foi mantido, enquanto que para os homens todas as variáveis permaneceram significativas.

Palavras chave: índice de qualidade da dieta, qualidade da dieta, nutrição, consumo alimentar. 
Morimoto JM. Factors associated with dietary quality for adults living in metropolitan region of Sao Paulo. São Paulo; 2004. [Master's Degree Dissertation - School of Public Health / Sao Paulo University].

Objective: The purpose of this study was to evaluate the demographic, socioeconomic and life style factors associated to diet quality of adults residents in the metropolitan area of Sao Paulo. Methods: Data from "Health Survey of State of Sao Paulo - ISA-SP" research about adults from both sexes with 20 years old or more $(n=1840)$ were used. It was a transversal study, by domiciliar survey, population based carried out in district of Butanta and Itapecerica da Serra, Embu and Taboao da Serra towns. A questionary and one 24-hour Recall were applied by previously trained interviewers. Dietary quality was evaluated by the Healthy Eating Index (HEI) adapted to local reality. HEI comprises ten components: six measures the degree of suitability of the intake of each of the six major grups of foods, other three measure fat, cholesterol and sodium intake, respectively, and the last component evaluates the variety of food consumed. Linear regression analysis was used to evaluate the relationship between $\mathrm{HEI}$ and other variables. Results: Average overall score was 60 points. The majority of individuals $(75 \%)$ had diets rated as "needs improvement". Mean scores for the index components were low to fruits, vegetables, and milk and dairy products and they were high to meat and eggs, and cholesterol. Energy intake, number of durable goods, highest level of education of the head of the family and age equal or superior to 60 years old associated to HEI in multiple regression analysis. We observed differences between men and women after the final model was stratified by sex. Conclusion: The higher energy intake or the number of durable goods or level of education of the head of the family or to have age equal ou superior to 60 years, the higher HEI will be. For women, just energy intake and age remained in the model, while for men all variables remained significant.

Key words: healthy eating index, dietary quality, nutrition, food intake. 
ÍNDICE 


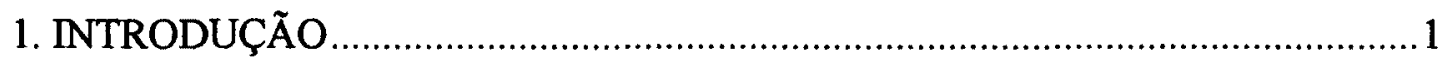

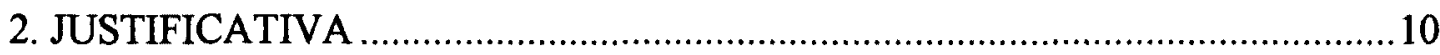

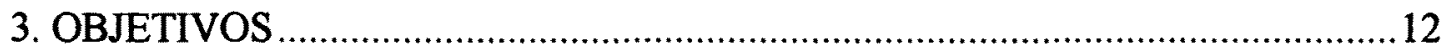

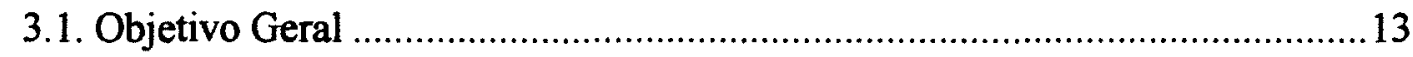

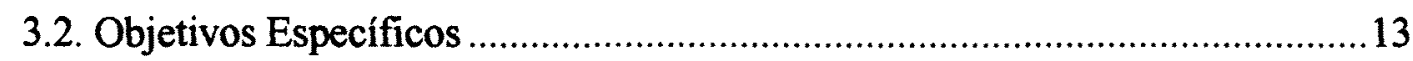

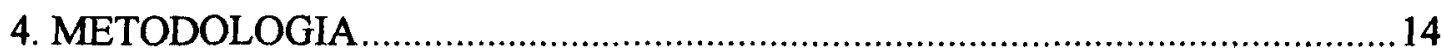

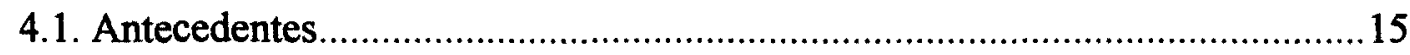

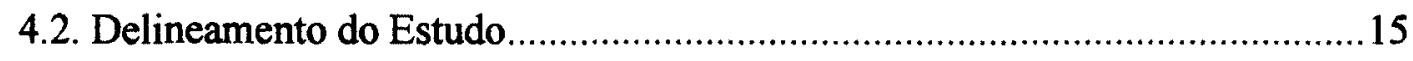

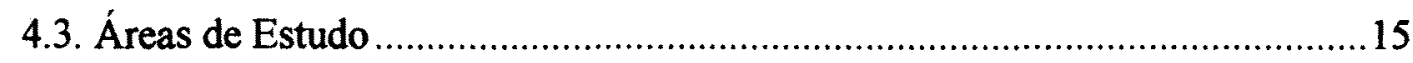

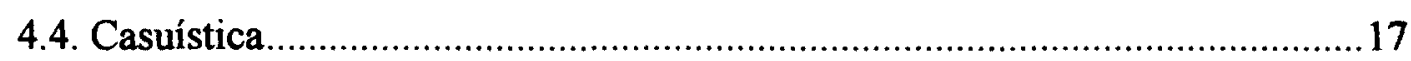

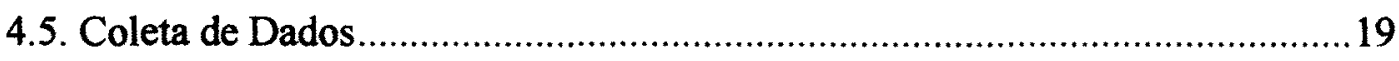

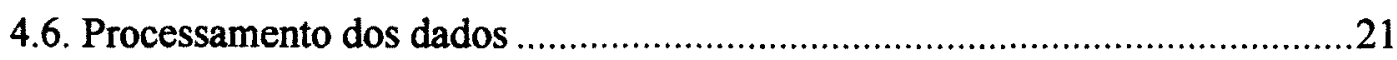

4.6.1. O Índice de Qualidade da Dieta (IQD) ...............................................22

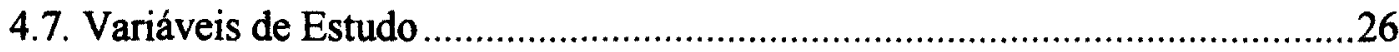

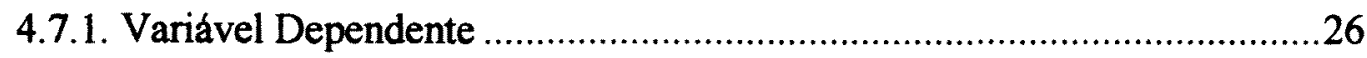

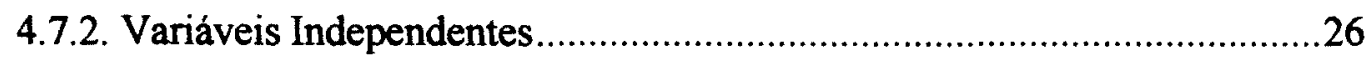

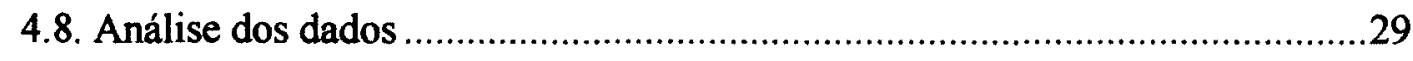

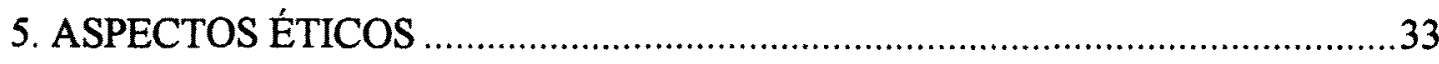

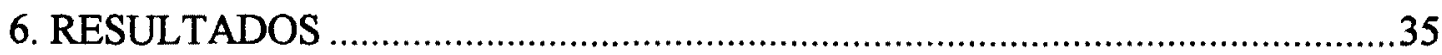

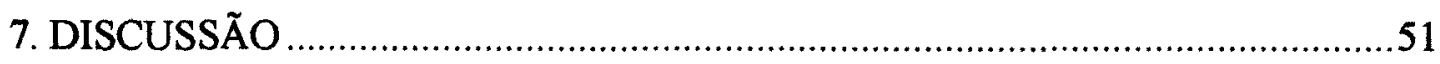

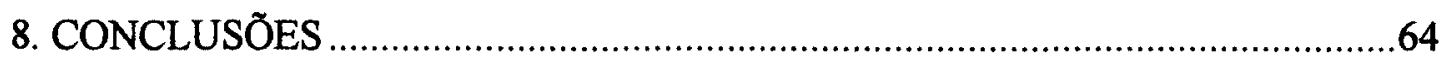

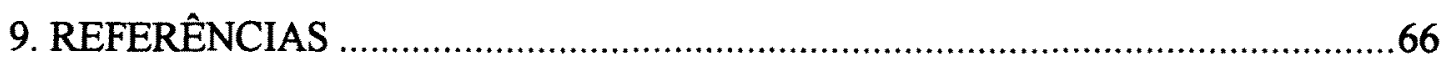
ANEXOS 


\section{LISTA DE ANEXOS}


Anexo 1 - Questionário da pesquisa "Inquérito de Saúde do Estado de São Paulo".

Anexo 2 - Manual do entrevistador para preenchimento do Recordatório de 24 horas.

Anexo 3 - Teste de Kolmogorov-Smirnov e gráfico QQPLOT do Índice de Qualidade da Dieta (IQD).

Anexo 4 - Histogramas de distribuição das variáveis quantitativas em sua unidade original e transformadas em seu logaritmo natural.

Anexo 5 - Gráficos QQPLOTs das variáveis quantitativas.

Anexo 6 - Parecer do Comitê de Ética em Pesquisa da FSP/USP do Projeto de Pesquisa Principal “Inquérito de Saúde do Estado de São Paulo - ISASP".

Anexo 7 - Parecer do Comitê de Ética em Pesquisa da FSP/USP deste subprojeto de pesquisa.

Anexo 8 - Termo de consentimento livre e esclarecido do Projeto de Pesquisa Principal.

Anexo 9 - Análise de resíduos do modelo final de regressão linear múltipla para o índice de Qualidade da Dieta na população total estudada e segundo sexo. 
LISTA DE TABELAS 
Tabela 1 - Estatística descritiva para as variáveis quantitativas. São Paulo, $2001 / 2002$ 36

Tabela 2 - Distribuição do número e porcentagem de indivíduos, segundo variáveis demográficas e de estilo de vida qualitativas. São Paulo, 2001/2002 ....37

Tabela 3 - Distribuição do número e porcentagem de indivíduos, segundo variáveis socioeconômicas e de do domicílio qualitativas. São Paulo, 2001/2002.

Tabela 4 - Estatística descritiva para os escores de cada componente do Índice de Qualidade da Dieta (IQD) e percentual de indivíduos que obtiveram pontuação mínima (zero) ou máxima (dez). São Paulo 2001/2002 .......40

Tabela 5 - Correlação entre ingestão de nutrientes em valores brutos e ajustados e escores do Índice de Qualidade da Dieta. São Paulo, 2001/2002

Tabela 6 - Estatísticas descritivas da ingestão de nutrientes segundo tercis do Índice de Qualidade da Dieta (IQD) e teste estatístico em relação ao tercil inferior do IQD. São Paulo, 2001/2002.

Tabela 7 - Estatística descritiva do Índice de Qualidade da Dieta (IQD) segundo variáveis demográficas e de estilo de vida. São Paulo, 2001/2002

Tabela 8 - Estatística descritiva do Índice de Qualidade da Dieta (IQD) segundo variáveis socioeconômicas e do domicílio. São Paulo, 2001/2002 .45

Tabela 9 - Análise de regressão linear simples: coeficiente de correlação de Pearson, beta e intervalo de confiança de 95\% (IC 95\%) da análise de regressão simples entre o Índice de Qualidade da Dieta e cada variável independente quantitativa. São Paulo, 2001/2002. .46

Tabela 10 - Resultado da análise de regressão múltipla do Índice de Qualidade da Dieta (pontos) e as características demográficas, de estilo de vida e socioeconômicas da população estudada. São Paulo, 2001/2002 48 
Tabela 11 - Resultado da análise de regressão múltipla final estratificada por sexo.

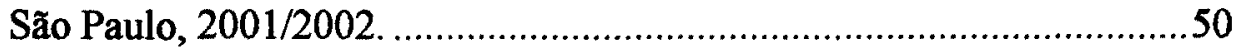




\section{LISTA DE QUADROS}


Quadro 1 - Valor energético por porção de cada grupo de alimentos da Pirâmide Alimentar.

Quadro 2 - Descrição, variação da pontuação e critérios para pontuação máxima e mínima de cada componente do IQD. ..............................................25

Quadro 3 - Seleção e ordenação das variáveis para entrada no modelo múltiplo......47 


\section{LISTA DE FIGURAS}


Figura 1 - Mapa de localização das regiões de estudo. São Paulo, 2001/2002 _........ 17

Figura 2 - Percentual de indivíduos segundo categorias do Índice de Qualidade da Dieta. São Paulo, 2001/2002 ............................................................39

Figura 3 - Valor médio do percentual de macronutrientes em relação à ingestão de energia segundo tercis do Índice de Qualidade da Dieta (IQD). São Paulo, 2001/2002 ..........................................................................4 
1. INTRODUÇÃO 
É necessário conhecer o consumo alimentar da população e quais de seus segmentos podem estar em risco nutricional pelo baixo consumo (por exemplo, deficiência de micronutrientes) ou consumo excessivo (por exemplo, alta ingestão de gordura ou colesterol) de algum nutriente da dieta. Desta forma, a coleta de dados de consumo alimentar em nível populacional é essencial para a estimativa da ingestão de alimentos da população (MURPHY e col. 1992).

Os dados de consumo alimentar podem ser coletados usando uma grande variedade de métodos e procedimentos, a fim de atender a inúmeras razões. Podem ser coletados em levantamentos que monitoram o estado nutricional e de saúde da população, como estudos epidemiológicos ou em ensaios clínicos. Podem ser usados para avaliar a adequação das dietas, a efetividade de programas de assistência em alimentação e a segurança de alimentos (GUENTHER e col. 1997).

No Brasil, assim como nos países em desenvolvimento, são escassas as fontes de dados sobre consumo alimentar da população. Em nível nacional, o Estudo Nacional sobre Despesa Familiar (ENDEF) foi um inquérito dietético realizado em meados da década de 70 pelo Instituto Brasileiro de Geografia e Estatística (IBGE). $O$ ENDEF constituiu-se em uma pesquisa domiciliar que utilizou uma amostra probabilística de 55 mil domicílios de todo o país. O consumo médio per capita diário das famílias foi determinado através do método da pesagem direta dos alimentos aplicado durante sete dias consecutivos (VASCONCELLOS 2000). Também existem três Pesquisas de Orçamento Familiar (POF) realizadas nas décadas de 1960, 1980 e 1990, respectivamente. As POFs representam uma boa alternativa na ausência de inquéritos dietéticos e são caracterizadas pela pesquisa domiciliar, com o objetivo principal de obtenção de informaç̃̃es sobre a estrutura de orçamentos das famílias residentes nas áreas urbanas das Regiões Metropolitanas de Belém, Fortaleza, Recife, Salvador, Belo Horizonte, Rio de Janeiro, São Paulo, Curitiba, Porto Alegre, Brasília e Goiânia. Constituem uma fonte importante de informações sobre consumo alimentar, estimado através do levantamento das despesas efetuadas com a compra de alimentos e que permitem estimar a disponibilidade individual de alimentos de cada família (MONDINI e MONTEIRO 1995; MONTEIRO e col. 2000; SILVA 2000). Outra fonte de dados é o Estudo Multicêntrico sobre Consumo Alimentar, realizado em 1996 pelo Instituto Nacional 
de Alimentação e Nutrição (INAN) do Ministério da Saúde (MS) e coordenado pelo Núcleo de Estudos e Pesquisas em Alimentação (NEPA) em cinco cidades do país. $\mathrm{O}$ objetivo deste estudo foi o dimensionamento da disponibilidade familiar de cem gêneros alimentícios, proporcionando informação sobre o consumo alimentar familiar (GALEAZZI e col. 1997).

Os métodos de consumo alimentar apresentam vantagens e desvantagens. Os inquéritos dietéticos, como o realizado no ENDEF, apresentam como principal vantagem o fornecimento de uma medida direta e precisa do consumo alimentar em nivel individual (MAJEM e BARTRINA 1995). Suas limitaçðes são caracterizadas pela dificuldade em se captar a grande variabilidade do consumo alimentar em um período curto de tempo e o custo elevado da pesquisa domiciliar. Já as POFs têm dentre suas limitaç̃es a ausência de informaçð̃es sobre o consumo alimentar de cada integrante dos domicílios e a impossibilidade de se avaliar a fração desperdiçada dos alimentos. Quando as pesquisas de avaliação do consumo alimentar são realizadas com regularidade, propiciam a formação de séries temporais, essenciais para a identificação de mudanças no padrão alimentar por estratos socioeconômicos e diferenças geográficas, a fim de, posteriormente, formular políticas nutricionais em saúde pública (MONDINI e MONTEIRO 1995; MONTEIRO e col. 2000). As pesquisas domiciliares representaram um grande avanço para os estudos do consumo alimentar no país através de sua contribuição para o aumento da precisão das estimativas da ingestão de alimentos (LUSTOSA 2000).

Uma dieta adequada quantitativa e qualitativamente fornece ao indivíduo energia, nutrientes e componentes dietéticos necessários para o bom funcionamento de seu organismo e manutenção do estado de saúde. Assim, há tempos são conhecidos os danos para a saúde que podem decorrer do consumo insuficiente ou do consumo excessivo de alimentos (MONDINI e MONTEIRO 1995; MONTEIRO e col. 2000).

Alteraçð̃es na dieta podem ter efeitos tanto positivos como negativos, durante toda a vida, podendo não apenas influenciar a saúde do indivíduo no presente, mas, também, aumentar a probabilidade de desenvolver ou não alguma doença em idade mais tardia, como câncer, doença cardiovascular e diabetes mellitus (WHO 2003). 
Grandes mudanças na composição da dieta vêm ocorrendo e refletindo nos desfechos nutricionais, como as mudanças na estatura média e na composição corporal da população. As sociedades modernas estão convergindo para um padrão alimentar com alto conteúdo de gordura saturada, açúcar e alimentos refinados, além de pobre em fibra alimentar, geralmente denominada "Dieta Ocidental", a qual têm se associado com a ocorrência de doenças crônicas não transmissíveis (DCNT). A identificação das principais mudanças nos padrões alimentares e de suas relações com fatores econômicos, sociais, demográficos e de saúde pode auxiliar o entendimento das causas e consequuências das mudanças que vêm ocorrendo na dieta (POPKIN 1993).

A dieta pode ser descrita através de sua composição em nutrientes ou em termos de alimentos ou grupos de alimentos. Analisá-la através dos nutrientes possui a vantagem de que a informação pode ser diretamente relacionada ao conhecimento biológico. Por exemplo, em um estudo é possivel que a ingestão de gordura total possa estar claramente associada com o risco de uma doença, enquanto a contribuição de cada alimento isoladamente para a ingestão de gordura pode não estar significativamente relacionada com a doença. Entretanto a abordagem baseada em alimentos tem várias vantagens práticas. A investigação das relações de alimentos ou grupos de alimentos com o risco de doenças pode conduzir a hipóteses relacionando a doença a um componente químico específico. Por exemplo, os achados de que a ingestão de vegetais crucíferos foi inversamente relacionada ao risco de câncer de cólon sugerem que compostos contidos nestes vegetais podem ter ação protetora (WILLETT 1998).

Além disso, no estudo da dieta, deve-se também considerar que os indivíduos ingerem os nutrientes necessários a partir da escolha dos alimentos, que é influenciada por inúmeros fatores: culturais, sociais, demográficos e sazonais. Assim, a abordagem da dieta baseada em alimentos, do que apenas em nutrientes, pode trazer importantes contribuições (MERTZ 1984; WILLETT 1998).

Segundo DREWNOWSKI e POPKIN (1997) a qualidade da dieta deve ser avaliada usando ferramentas mais complexas. Novas medidas da totalidade da dieta e dos hábitos alimentares saudáveis devem começar a se basear em parâmetros de equilíbrio, moderação e variedade. Por exemplo, dietas pobres em gordura não são 
necessariamente as mais saudáveis, já que a gordura faz parte da composição normal da dieta. Em muitos paises de baixa renda, dietas ricas em gorduras e açúcares são também mais variadas e contêm uma grande proporção de proteína de origem animal de boa qualidade. VARIYAM e colaboradores (1998) definiram qualidade da dieta como o resultado final dos alimentos consumidos, técnicas de preparo utilizadas e outros fatores que influenciam o conteúdo de nutrientes das refeições.

Dada a complexidade da dieta humana, os resultados de estudos sobre o efeito do consumo de um único nutriente, alimento ou componente da dieta sobre um efeito específico para a saúde podem ser enganosos. Por isso, torna-se conveniente a utilização de índices que reflitam a ingestão global de alimentos e nutrientes e que incluam vários aspectos da ingestão dietética simultaneamente (KANT 1996). Os indices de qualidade da dieta têm sido desenvolvidos para se obter uma medida resumo das principais características da dieta, facilitando a avaliação da qualidade da mesma em populações ou grupos de indivíduos.

Vários índices de qualidade da dieta têm sido propostos e descritos na literatura científica. A forma como estes índices definem qualidade da dieta varia de acordo com os atributos selecionados e de quando cada um foi elaborado. Por exemplo, no passado, uma dieta era considerada de boa qualidade se alcançasse a necessidade de proteína ou de algumas vitaminas ou minerais em determinado nivel de ingestão de energia. Portanto, os primeiros índices de qualidade da dieta basearam-se neste conceito. Os índices mais recentes definem a qualidade da dieta em termos de proporcionalidade (consumir mais porções de certos grupos de alimentos e menos de outros), moderação (limitação da ingestão de alimentos e bebidas que contribuem para o consumo excessivo de gordura, colesterol, açúcares de adição, sódio e álcool) e variedade (exposição a vários componentes alimentares). Os primeiros índices tendem a focar na prevenção de doenças decorrentes de deficiências nutricionais, enquanto os indices mais recentes tendem a direcionar para a prevenção do risco de DCNT (HAINES e col. 1999; LEE e NIEMAN 2003).

Os indices de qualidade da dieta seguem basicamente três abordagens principais: 1) comparar a ingestão de determinados nutrientes e componentes alimentares a um padrão; 2) comparar a ingestão de alimentos ou grupos de alimentos com um padrão; e 3) avaliar tanto a ingestão de nutrientes e alimentos ou 
grupos de alimentos com um padrão (KANT 1996; LEE e NIEMAN 2003). Porém, poucos dos índices publicados foram validados contra parâmetros bioquímicos, antropométricos e clínicos do estado nutricional. KANT (1996) sugere que para estudos epidemiológicos sobre a relação entre dieta e doença, a medida da qualidade global da dieta deve ser considerada como uma alternativa que considera a multicolinearidade das diversas variáveis dietéticas.

Segundo WILLETT (1998), uma ótima abordagem para análises epidemiológicas da dieta é considerar seus nutrientes, alimentos e grupos de alimentos, pois, desta forma, pode se obter o máximo de informaçðes sobre a dieta. Com isso, os índices de qualidade da dieta baseados em alimentos e nutrientes podem ser mais promissores, pois retêm a complexidade dos alimentos e permitem uma avaliação indireta de componentes nutrientes e não nutrientes sem reduzir a avaliação a um único componente isolado (KANT 1996).

Dentre os vários índices de qualidade da dieta propostos na literatura, o Diet Quality Index - DQI (PATTERSON e col. 1994), Diet Quality Index Revised - DQI$R$ (HAINES e col. 1999) e o Healthy Eating Index - HEI (KENNEDY e col. 1995) merecem destaque, pois utilizam a estimativa quantitativa da ingestão de nutrientes e alimentos e são baseados nos princípios de proporcionalidade, moderação e variedade da dieta.

O DQI é um instrumento desenvolvido para medir a qualidade global da dieta que reflete um gradiente de risco para DCNT relacionadas com a alimentação. Foi originalmente desenvolvido com base nas recomendações do Committee on Diet and Health of the National Research Council, Food and Nutrition Board e consiste em 8 componentes dietéticos: gordura total, gordura saturada, colesterol, frutas e hortaliças, grãos e legumes, proteína, sódio e cálcio (PATTERSON e col. 1994). Após a alteração das orientaçð̃es dietéticas nacionais dos Estados Unidos (Food Guide Piramide, Dietary Guidelines for Americans e Dietary Reference Intakes), HAINES e colaboradores (1999) fizeram uma revisão do DQI, alterando-o de 8 para 10 componentes e atualizando o uso das recomendaçðes a partir de Dietary Reference Intakes - DRI (YATES e col. 1998). O DQI-R é constituído de 10 indicadores de qualidade da dieta, sendo que três representam a ingestão de macronutrientes, três refletem as recomendações da Pirâmide Alimentar Americana 
sobre o consumo de frutas, vegetais e grãos, dois baseiam-se nas recomendações para cálcio e ferro a partir das DRIs, e os dois últimos refletem a importância da variedade da dieta e da moderação com relação à ingestão de açúcar, gordura, sódio e bebidas alcoólicas.

O Healthy Eating Index (HEI), desenvolvido por KENNEDY e colaboradores (1995), avalia a adequação e variedade da dieta, possibilitando a avaliação de possíveis mudanças nos padrões dietéticos. É constituído por um sistema de 10 componentes: cinco grupos de alimentos (cereais, pães, tubérculos e raizes; verduras e legumes; frutas; leite e produtos lácteos; carnes, ovos e leguminosas), quatro nutrientes (níveis de ingestão de gordura total, gordura saturada, colesterol e sódio) e uma medida da variedade da dieta. Este índice é obtido por uma pontuação distribuída em dez componentes que caracterizam diferentes aspectos de uma dieta saudável. Em estudo norte-americano, o HEI foi recentemente validado através de marcadores bioquímicos, no qual observou-se que dietas com altos escores do índice tiveram correlação significativa com concentraç̃̃es plasmáticas de vários carotenóides e vitamina C. Sabe-se que a ingestão dietética de frutas e vegetais, que são a fonte primária destes nutrientes, está associada com redução do risco de doenças (HANN e col. 2001). WEINSTEIN e colaboradores (2004), em estudo semelhante, verificaram que o HEI correlacionou-se com vários nutrientes sanguíneos, sendo que as correlações mais fortes ocorreram com marcadores bioquímicos da ingestão de frutas e hortaliças. Os estudos de HANN e colaboradores (2001) e WEINSTEIN e colaboradores (2004) representam importantes etapas para a validação do HEI, demonstrando que este índice pode ser uma boa ferramenta para uso em estudos sobre nutrição e saúde.

Estudo no qual o DQI foi utilizado como medida da qualidade da dieta, aplicado em uma amostra de adultos norte-americanos do Nationwide Food Consumption Survey (1987-88 NFCS), encontrou altos escores de DQI em individuos do sexo feminino, com idade por volta de 40 anos, maior renda $e$ escolaridade, o que é consistente com o estudo de PATTERSON e colaboradores (1994). Resultados semelhantes foram encontrados por KANT e colaboradores (2000), os quais observaram que altos escores de qualidade da dieta estavam associados a um maior número de anos de estudo, hábito de não fumar, prática de 
atividade física e uso de suplementos vitamínicos. Neste estudo foi utilizado o Recommended Foods Score (RFS), um índice de qualidade baseado no consumo de alimentos recomendados pelas atuais orientações dietéticas dos Estados Unidos.

POPKIN e colaboradores (2003) observaram que, entre 1965 e 1996, a qualidade da dieta melhorou nos grupos étnicos e socioeconômicos dos Estados Unidos, ou seja, a média global do DQI-R e o percentual de indivíduos que ingere uma dieta pobre em gordura e em colesterol, rica em grãos, vegetais e com grande variedade de alimentos aumentou. Porém, alguns componentes do índice indicaram que os norte-americanos não estão consumindo dietas tão saudáveis, pois houve declínio da adequação da ingestão de cálcio, pouca melhora no consumo de frutas e pouca alteração no componente que representa moderação (inclui o consumo de açúcar de adição, sal, bebida alcoólica e gordura). As dietas avaliadas por renda e escolaridade indicaram que indivíduos com maiores níveis de escolaridade melhoraram a qualidade da dieta. Os dados sugerem que possivelmente o maior nível de conhecimentos está relacionado a dietas mais saudáveis.

VARIYAM e colaboradores (1998) investigaram a influência de características socioeconômicas e conhecimento a respeito de nutrição, saúde e doença sobre a qualidade da dieta, medida pelo HEI. Efeitos positivos da renda e escolaridade sobre a qualidade da dieta foram observados neste estudo, ou seja, indivíduos com maior renda ou nível de escolaridade possuíam mais informação sobre nutrição e, conseqüentemente, consumiam dietas de melhor qualidade. Também foram observados efeitos das variáveis sexo e etnia sobre escores do $\mathrm{HEI}$ : mulheres tiveram médias do HEI superiores em 5 pontos em relação aos homens; negros e hispânicos obtiveram escores menores do que brancos e não-hispânicos; fumantes tiveram HEI mais baixo do que não fumantes. Os autores sugeriram que ao estudar a influência das variáveis sociodemográficas sobre a qualidade da dieta deve se considerar o conhecimento sobre nutrição dos individuos.

Periodicamente, o Center for Nutrition Policy and Promotion do United States Department of Agriculture utiliza o HEI com o objetivo de avaliar e monitorar a dieta dos norte-americanos. BOWMAN e colaboradores (1998) utilizaram os dados do Continuing Survey of Food Intakes by Individuals (CSFII) do periodo de 1994 a 1996 e observaram que a maioria da população possuía uma dieta que 
necessitava de melhora, sendo que o consumo de frutas, leite e derivados deveria ser aumentado. As dietas com pior qualidade foram observadas em indivíduos afroamericanos, com baixa renda e menor escolaridade. Resultados semelhantes foram observados por BASIOTIS e colaboradores (2002) ao aplicar o HEI nos dados do National Health and Nutrition Examination Survey (NHANES) de 1999 a 2000. Os dados sugerem que, durante o intervalo de três anos entre um estudo e outro, a dieta dos norte-americanos continua "necessitando de melhora".

Estudo realizado na Finlândia para avaliar a ingestão de grupos de alimentos e nutrientes de acordo com nível de escolaridade e renda familiar, utilizando um índice proposto, observou que a melhor condição socioeconômica, medida pela escolaridade e renda, esteve associada com um padrão de consumo alimentar próximo das orientações dietéticas deste país (ROOS e col. 1996).

Outra variável que tem sido relacionada com a qualidade da dieta é a urbanização. STOOKEY e colaboradores (2000) observaram que os indivíduos residentes em áreas urbanas têm mais problemas relacionados tanto à desnutrição quanto ao consumo excessivo de alimentos e/ou nutrientes do que os residentes em áreas rurais da China. Já CABALLERO e RUBINSTEIN (1997) verificaram que, em países em desenvolvimento, a migração de pessoas das áreas rurais para áreas urbanas leva à ingestão excessiva de gordura, vida sedentária e hábito de fumar e, conseqüentemente, todos estes fatores de risco aumentam a mortalidade por doenças coronarianas.

Muitos estudos mostram a relação entre saúde e renda sendo os segmentos mais pobres da população os mais vulneráveis. Populações carentes têm desvantagem social em termos de incidência aumentada de DCNT e acesso precário ao seu tratamento, além de taxas mais baixas de aceitação de comportamentos de promoção da saúde comparados aos outros segmentos da sociedade. Assim, as políticas públicas precisam favorecer a população com condição socioeconômica desfavorável e ter alvos apropriados, já que esta está em maior risco e tem menor poder para efetuar mudança (WHO 2003). 
2. JUSTIFICATIVA 
O Índice de Qualidade da Dieta classifica os individuos em categorias de consumo alimentar o que permite agrupá-los em segmentos semelhantes para possíveis associaçðes com outros fatores, como sexo, idade, escolaridade, renda, consumo de bebida alcoólica e hábito de fumar. No Brasil, até o momento, nenhum estudo com este enfoque foi realizado. Através do estudo da relaçăo entre qualidade da dieta e características socioeconômicas, demográficas e de estilo de vida, podem ser identificados os segmentos da população que possuem risco de ter a dieta deficiente em algum nutriente ou grupo de alimentos. Conseqüentemente, torna-se possível adaptar políticas e programas de nutrição para atingir as necessidades dos segmentos da população realmente em risco. 
3. OBJETIVOS 


\subsection{Objetivo Geral}

Avaliar os fatores demográficos, socioeconômicos e de estilo de vida associados à qualidade da dieta de adultos residentes na região metropolitana de São Paulo.

\subsection{Objetivos Especificos}

* Avaliar a qualidade da dieta da população de estudo segundo o Índice de Qualidade da Dieta.

Descrever a pontuação de cada um dos componentes do Índice de Qualidade da Dieta.

Analisar a relação entre o Índice de Qualidade da Dieta e características demográficas, socioeconômicas e de estilo de vida da população de estudo. 
4. METODOLOGIA 


\subsection{Antecedentes}

Este estudo utilizou dados da pesquisa "Inquérito de Saúde do Estado de São Paulo (ISA-SP) - Inquérito Domiciliar, de Saúde, de Base Populacional, em Municípios do Estado de São Paulo, 1999-2000", financiado pela Fundação de Amparo à Pesquisa do Estado de São Paulo (FAPESP - Processo nº 98/14099-7).

O projeto principal tem o objetivo de analisar as condiçð̃es de vida, a situação de saúde e o uso de serviços de saúde em quatro diferentes áreas do Estado de São Paulo, sendo duas no interior (Botucatu e Campinas) e outras duas na Região Metropolitana de São Paulo (distrito do Butantã e parte da região sudoeste da Grande São Paulo). Outro propósito deste estudo é estimar a magnitude das desigualdades em saúde, analisar o potencial e os limites dos métodos e técnicas utilizados, contribuindo para $o$ aprimoramento da metodologia dos inquéritos de saúde populacionais e para o planejamento de políticas públicas locais e regionais.

\subsection{Delineamento do Estudo}

Este é um estudo transversal, por meio de inquérito domiciliar com base populacional.

\section{3. Áreas de Estudo}

Foram estudados parte da região sudoeste da Grande São Paulo, constituida pelos municípios de Taboão da Serra, Embu e Itapecerica da Serra, e o distrito do Butantã, pertencente ao município de São Paulo. Estas regiðes fazem parte da Região Metropolitana de São Paulo segundo Lei Complementar Federal nº 14, de 8/06/1973 e Lei Complementar Estadual n94, de 29/05/1974 (Figura 1).

Os municípios de Taboão da Serra e Embu foram desmembrados de Itapecerica da Serra em 1959, quando passaram a ser municípios autônomos. Taboão da Serra, com $20 \mathrm{~km}^{2}$ de extensão, é delimitado pela região sudoeste da cidade de São Paulo. Sua população em 2004 foi estimada em 215.652 habitantes, a densidade 
demográfica em 10.782,60 hab/ $\mathrm{km}^{2}$ e a taxa de crescimento entre 2000 e 2004 foi de 2,26\% ao ano (FUNDAÇÃO SEADE 2004).

O Município de Embu está a $27 \mathrm{~km}$ da cidade de São Paulo e possui uma extensão territorial de $68 \mathrm{~km}^{2}$. Em 2004 a população residente era de 232.165 habitantes, a densidade demográfica de $3.414,19 \mathrm{hab} / \mathrm{km}^{2}$ e a taxa de crescimento populacional entre 2000 e 2004 foi de 2,90\% ao ano (FUNDAÇÃO SEADE 2004).

O Município de Itapecerica da Serra fica a $33 \mathrm{~km}$ da capital. Tem um território de $136 \mathrm{~km}^{2}$ e, em 2004, tinha uma população de 155.171 habitantes e uma densidade demográfica de $1.140,96 \mathrm{hab} / \mathrm{km}^{2}$. A taxa de crescimento populacional entre 2000 e 2004 foi de 4,69\% (FUNDAÇÃO SEADE 2004).

Estes municípios apresentam diferenças tanto no que se refere à condição socioeconômica, quanto na organização dos serviços de saúde, sendo que Taboão da Serra destacou-se por Ter melhores condiç̃̃es socioeconômicas. Em 2000, mais de $85 \%$ dos moradores dos três municípios eram atendidos pela rede geral de água e por coleta de lixo. A proporção de rede de esgoto sanitário foi de $24,9 \%$ para Itapecerica da Serra, 57,8\% para Embu e 84,8\% para Taboão da Serra, em 2000. Em 2003, o coeficiente de mortalidade infantil por 1.000 nascidos vivos em Taboão da Serra foi de 11,82 óbitos, no Embu foi de 16,44 e em Itapecerica de 11,65 (FUNDAÇÃO SEADE 2004).

O distrito do Butantã está inserido no município de São Paulo, com 12,50 $\mathrm{km}^{2}$, população estimada em 2004 de 50.737 habitantes, densidade demográfica de $4.058,96 \mathrm{hab} / \mathrm{km}^{2}$. Entre 2000 e 2004 , a taxa de crescimento populacional foi negativa, de $-0,95 \%$. A taxa de mortalidade infantil é baixa quando comparada aos coeficientes de Taboão da Serra, Itapecerica e Embu, sendo que em 2003 foi de 6,86 óbitos por 1.000 nascidos vivos (FUNDAÇÃO SEADE 2004). 


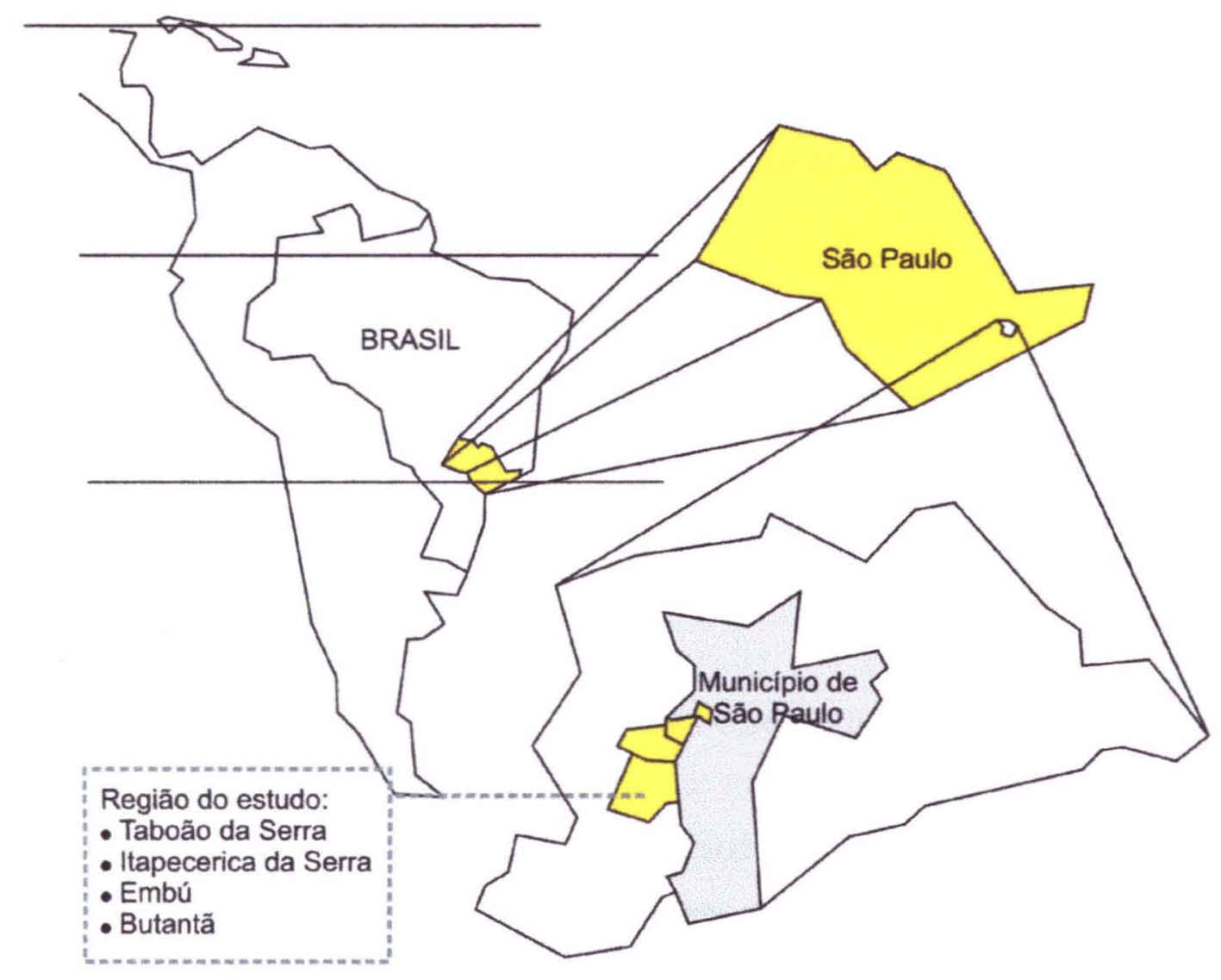

Figura 1 - Mapa de localização das regiões de estudo. São Paulo, 2001/2002.

\subsection{Casuística}

Foram definidos grupos de idade e sexo, denominados domínios amostrais, para os quais foram garantidos números mínimos na amostra que permitam análises posteriores em cada uma das áreas de estudo. Os quatro domínios amostrais foram: 20 a 59 anos do sexo masculino, 20 a 59 anos do sexo feminino, 60 anos e mais do sexo masculino e 60 anos e mais do sexo feminino.

Para o cálculo do tamanho da amostra utilizou-se a fórmula:

$$
\mathrm{n}_{0}=\frac{\mathrm{P} \cdot(1-\mathrm{P})}{(d / z)^{2}} \cdot d e f f
$$


Onde:

$\mathrm{P}=$ proporção de indivíduos a ser estimada

$\mathrm{z}=$ valor na curva normal reduzida correspondente ao nível de confiança utilizado na determinação de $P$.

$\mathrm{d}=$ erro de amostragem

deff $=$ efeito do delineamento

Considerou-se que:

- Proporção a ser estimada nos subgrupos populacionais é de $50 \%(\mathrm{P}=0,50)$ por ser a variabilidade máxima, que leva a obtenção de tamanhos de amostras conservadores;

- Coeficiente de confiança de $95 \%(z=1,96)$ na determinação dos intervalos de confiança das estimativas;

- Erro de amostragem de $10 \%$, indicando que a estimativa da amostra e o parâmetro populacional não deveriam exceder esse valor $(d=0,10)$;

- Efeito do desenho (deff) igual a 2.

O número de indivíduos a ser entrevistado em cada domínio foi calculado em 200. Esperando-se um taxa de $80 \%$ de cobertura e resposta, foram sorteados, em cada domínio, 250 indivíduos para obter-se aproximadamente as 200 entrevistas (CESAR e col. 1996).

Assim, estimou-se que a população de estudo seria composta por aproximadamente 1600 adultos de ambos sexos com idade acima de 20 anos.

Para cada área (distrito do Butantã e região sudoeste da Grande São Paulo) foi determinado o número de domicílios a serem sorteados. Calculou-se a razão do número médio de indivíduos pelo número de domicílio em cada domínio amostral $\left(\mathrm{r}_{\mathrm{i}}\right)$. O número de domicílios que deveria ser sorteado para que fossem incluidos na amostra os 250 de cada grupo populacional foi calculado por $250 / \mathrm{r}_{\mathrm{i}}$.

Os setores censitários foram divididos segundo nivel de escolaridade do chefe de família. Foram formados 3 estratos segundo percentual de chefes de famílias com nível universitário no setor: menos de $5 \%$; de 5 a $25 \%$ e com $25 \%$ ou mais. Em cada um dos estratos foi sorteado $1 / 3$ dos domicílios. Essa estratificação visou aumentar a 
probabilidade de que pessoas do estrato mais rico da população pertencessem à amostra. Informações sobre a escolaridade dos chefes das famílias estavam disponíveis na contagem da população feita pelo Instituto Brasileiro de Geografia e Estatística (IBGE) em 1996, fato que, acrescido da existência de relação entre nível socioeconômico e escolaridade justificou a escolha desta variável para orientar a estratificação das áreas. Esta técnica é utilizada para garantir a presença de determinados segmentos da população que poderiam estar presentes em pequeno número ou ausentes (PEREIRA 2002).

O sorteio da amostra calculada foi por conglomerado em dois estágios, estratificada segundo nível socioeconômico. Os setores censitários constituíram as unidades primárias de amostragem (UPAS) e os domicílios as secundárias. Os dados de população basearam-se no censo do IBGE de 1996.

As unidades primárias de amostragem foram sorteadas com probabilidade proporcional ao seu tamanho por sorteio sistemático em cada estrato. Os domicílios foram sorteados com probabilidade inversamente proporcional ao tamanho da UPAS a partir de listagens feitas em visitas aos setores sorteados. O sorteio com probabilidade proporcional ao tamanho foi adotado por se constituir no tipo de sorteio mais utilizado em inquéritos domiciliares. Pelo mesmo motivo, foram utilizados como unidades de amostragem, setores censitários e domicílios (ALVES 2002).

Considerando que não se desejava fazer sorteio dentro de cada domićlio e que se pretendia incluir na amostra 250 pessoas de cada domínio, foram sorteadas sub-amostras de domicílios, nos quais os indivíduos dos distintos grupos de sexo e idade deveriam ser entrevistados. Assim sendo em alguns domicílios foram entrevistados todos moradores, e em outros, os que pertenciam a determinado grupo.

Desta forma, o tamanho da amostra deste estudo resultou em 1904 indivíduos, de ambos os sexos, com idade de 20 anos ou mais.

\subsection{Coleta de Dados}

Os dados foram coletados no período de abril de 2001 a setembro de $2002 \mathrm{em}$ seis cortes, ao longo de doze meses. 
As informações foram obtidas através de questionários (Anexo 1) aplicados em visita domiciliar por entrevistados previamente treinados, sendo respondidos diretamente pelos moradores sorteados, garantindo-se assim maior confiabilidade das informaçðes.

O questionário, previamente testado em estudo piloto, foi organizado em blocos segundo áreas temáticas, com a maioria das questões fechadas, com altemativas pré-definidas.

No presente estudo foram utilizadas as informações referentes às características demográficas, socioeconômicas, da família, do domićlio e de estilo de vida (Blocos A, B, L, O, P e Q do questionário principal).

A seguir estão descritos os diversos blocos que compõem o questionário e que foram utilizados para este estudo:

O BLOCO A refere-se a informações gerais sobre a composição familiar necessária para estabelecer os primeiros elementos das condições de vida.

O BLOCO B constitui-se em instrumento de controle para a realização das visitas, registrando-se as razões para eventuais não realização das entrevistas.

No BLOCO $L$ são exploradas as questões referentes ao estilo de vida, aprofundados em quatro de seus tradicionais capítulos: atividade física, hábitos alimentares, fumo e consumo de álcool. Para avaliação da atividade física foi utilizado o questionário validado International Physical Activity (IPAC) resumido. O consumo alimentar foi medido por meio da aplicação do Método Recordatório de 24 horas (R24h) nos indivíduos selecionados. Foi utilizado o método passo a passo, adaptado de THOMPSON e BYERS (1994). Para padronização na coleta de dados foi realizado treinamento dos entrevistadores, com utilização de formulário padrão para aplicação de $R 24 h$ (Anexo 1) e manual explicativo para o seu preenchimento (Anexo 2). Além dos dados de ingestão alimentar do Recordatório de 24 horas, foram utilizadas as informações sobre altura e peso referidos desta parte do questionário.

Os BLOCOS $\boldsymbol{O}$ e $\boldsymbol{Q}$ estão voltados para a caracterização socioeconômica do entrevistado (O) e do chefe da família (Q), e o BLOCO P descreve as características da familia e do domicílio. Conjuntamente com as informações colhidas no BLOCO $A$ é possível descrever, com esses quatros blocos, as condições de vida dos 
individuos entrevistados, variável essencial para entender a distribuição das doenças, bem como 0 acesso às respostas sociais.

\subsection{Processamento dos dados}

Os dados do questionário principal foram codificados diretamente nos questionários e digitados em máscara do programa EPI INFO (versão 6.04d, 2001, Center for Disease Control and Prevention, Atlanta, Geórgia, EUA).

Previamente à digitação dos dados de consumo alimentar foi realizada crítica de todos os Recordatórios de 24 horas coletados. O objetivo da crítica foi identificar as principais e importantes falhas do entrevistador na obtenção da informação sobre consumo alimentar. Falhas relacionadas à descrição do alimento ou preparações consumidas, porcionamento e quantificação de cada item do Recordatório de 24 horas são erros que devem ser corrigidos para tornar os dados confiáveis e viabilizar a análise de uma dieta próxima do real. Também foi realizada conferência do valor nutritivo de alimentos de consumo mais freqüente, principalmente quanto aos nutrientes considerados de maior contribuição (fonte) para o valor nutritivo de cada alimento (por exemplo, cálcio em leite e produtos lácteos; ferro em carnes; sódio em embutidos, entre outros). Desta forma, houve a tentativa de minimizar um dos erros que ocorre na estimativa da ingestão de nutrientes.

O cálculo do valor nutritivo dos alimentos consumidos e registrados no Recordatório de 24 horas foi realizado utilizando-se o programa Virtual Nutri (PHILIPPI e col. 1996) com banco de dados de alimentos modificado. O banco de dados de alimentos do programa foi adaptado com a introdução das informações da composição de alimentos de tabelas de composição química dos alimentos de United States Department of Agriculture - USDA (2003), PHILIPPI (2001) e SOUCI e colaboradores (1994). A composiçăo dos alimentos industrializados foi obtida a partir das informaçðes de valor nutritivo disponíveis nos rótulos dos alimentos industrializados e/ou serviços de atendimento ao consumidor.

Para a digitação de preparações caseiras, tais como pizza, lasanha, sanduíches, optou-se pelo desdobramento destas em seus respectivos ingredientes a fim de melhor classificar os alimentos segundo os grupos da pirâmide alimentar. Para 
tal, foram utilizadas as padronizações de receitas propostas por PINHEIRO e colaboradores (2000) e FISBERG e VILLAR (2002). É importante salientar que em todas as preparações foi calculada e digitada separadamente a quantidade de sal de adição, tornando bastante cuidadosa a estimativa da ingestão de sal refinado.

Posteriormente à digitação dos Recordatório de 24 horas de cada entrevistado, realizou-se a consistência dos dados de consumo alimentar para verificação de possíveis erros de digitação. A consistência dos dados de ingestão alimentar foi realizada nos nutrientes e componentes dietéticos de interesse no presente momento para a pesquisa, sendo estes: energia, colesterol, cálcio, ferro, fósforo, sódio, vitamina $\mathrm{A}$ e vitamina $\mathrm{C}$. Foram verificados valores de ingestão muito baixos e muito altos para cada um desses componentes, sendo que quando isto ocorria, averiguou-se se havia erro de digitação no tamanho da porção ou erro no valor nutritivo do alimento.

Foram excluídos os indivíduos com ingestão de energia abaixo de $500 \mathrm{kcal} \mathrm{ou}$ acima de $4000 \mathrm{kcal}$, pois poderia ter ocorrido uma sub ou superestimação do consumo alimentar desses casos (WILLETT 1998). Assim, foram excluídos 64 indivíduos, resultando em uma amostra de estudo final de 1840 adultos.

\subsubsection{O Índice de Qualidade da Dieta (IQD)}

Para avaliação da qualidade da dieta foi utilizado o Índice de Qualidade da Dieta adaptado do Healthy Eating Index de KENNEDY e colaboradores (1995) por FISBERG e colaboradores (2004a). Este índice é obtido por uma pontuação distribuída em dez componentes que caracterizam diferentes aspectos de uma dieta saudável. Cada componente é avaliado e pontuado de zero (0) a dez (10), sendo que os valores intermediários são calculados na proporção em que são consumidos. Indivíduos com uma ingestão igual ao nível recomendado atingem a pontuação máxima de dez pontos. A pontuação mínima de zero ponto é obtida quando nenhum alimento do grupo alimentar foi consumido. $O$ valor máximo que o IQD pode atingir é de 100 pontos. Escores altos significam que a ingestão está próxima aos intervalos ou quantidades recomendadas; baixos escores indicam menor conformidade com a recomendação. 
O Índice de Qualidade da Dieta proposto por FISBERG e colaboradores (2004a) foi alterado para utilização neste estudo. O componente "gordura saturada" foi substituído pelo "grupo das leguminosas" e considerou-se o tamanho da porção de cada alimento para o cálculo da variedade da dieta. Desta forma, os seis primeiros componentes deste índice são representados pelos grupos de alimentos, três componentes são representados pelos nutrientes gordura total, colesterol e sódio, e o último, pela variedade da dieta. A seguir, são descritos os componentes do IQD e os critérios para a pontuação máxima e mínima de cada um:

Componentes de 1 a 6: grupos de alimentos. Mede o grau de adequação da ingestão das porçð̃es de cada um dos seis principais grupos de alimentos, estipulados pelo guia alimentar: cereais, pães, tubérculos e raízes; verduras e legumes; frutas; leite e produtos lácteos; carnes e ovos; e leguminosas. $O$ Quadro 1 apresenta a quantidade de energia fornecida por uma porção de cada grupo de alimentos. A partir do total de energia fornecido pela soma de todos os alimentos de um mesmo grupo, calcula-se o número de porções consumido desse grupo com base na quantidade de energia de uma porção definida no Quadro 1. Consumindo o mínimo recomendado pelo guia o indivíduo recebe 10 pontos, quando não houver consumo do alimento nenhum ponto (zero) é computado e o consumo de um número intermediário de porções (entre o consumo zero e o mínimo recomendado) é pontuado proporcionalmente.

Quadro 1 - Valor energético por porção de cada grupo de alimentos da Pirâmide Alimentar.

\begin{tabular}{|l|c|}
\hline Grupos de alimentos & Valor energético por porção (kcal) \\
\hline 1. Cereais, pães, tubérculos e raízes & 150 \\
2. Verduras e legumes & 15 \\
3. Frutas & 35 \\
4. Leite e produtos lácteos & 120 \\
5. Carnes e ovos & 190 \\
6. Leguminosas & 55 \\
\hline
\end{tabular}

Fonte: PHILIPPI e col. (1999) 
Foi estabelecida uma relação entre o consumo diário de alimentos obtido e os grupos de alimentos da Pirâmide Alimentar (PHILIPPI e col. 1999), agrupando os alimentos de acordo com sua composição. Preparaçð̃es que envolvem mais de um grupo de alimentos, como sanduíches, pizzas, massas recheadas e sucos enriquecidos, foram desmembrados em cada um de seus ingredientes e então seus ingredientes foram classificados em cada grupo de alimentos correspondente.

Componente 7: gordura total. O valor mínimo (zero) corresponde à ingestão de lipídios totais igual ou superior a $45 \%$ do total de energia fornecida pela dieta, enquanto que 10 são atribuídos a $30 \%$ ou menos do total de energia fornecido pela dieta, uma vez que a faixa compreendida entre 30 a $45 \%$ seria aceitável, segundo as recomendações do Dietary Guidelines for Americans (UNITED STATES DEPARTMENT OF AGRICULTURE 1995).

Componente 8: colesterol. Segundo o Committee on Diet and Health (NATIONAL RESEARCH COUNCIL 1989), a quantidade recomendada de colesterol na dieta é de 300 a $450 \mathrm{mg} /$ dia, sendo o primeiro valor equivalente à pontuação máxima, e o segundo, à pontuação mínima.

Componente 9: sódio. A ingestão de sódio é pontuada de zero $(4800 \mathrm{mg} / \mathrm{dia}$ ou mais) a 10 (2400 mg/dia ou menos), baseada também nas recomendações do Committee on Diet and Health (NATIONAL RESEARCH COUNCIL 1989).

Componente 10: variedade da dieta. É medida pelo número total de diferentes alimentos consumidos durante o dia, sendo que para ser considerado, o alimento deve ter sido consumido em quantidade suficiente para contribuir com pelo menos metade de uma porção no correspondente grupo alimentar. A pontuação máxima de 10 pontos é computada quando o indivíduo consumiu pelo menos metade da porção de 8 ou mais tipos diferentes de alimentos em um dia. O consumo de 3 ou menos tipos diferentes de alimentos corresponde à pontuação mínima (zero ponto) (BOWMAN e col. 1998). 
O Quadro 2 resume os componentes do IQD e os critérios definidos para a atribuição das pontuaçðes máxima e mínima.

Quadro 2 - Descrição, variação da pontuação e critérios para pontuação máxima e minima de cada componente do IQD.

\begin{tabular}{|c|c|c|}
\hline Componente & $\begin{array}{c}\text { Critério para a } \\
\text { Pontuação Mínima } \\
\text { (0 ponto) }\end{array}$ & $\begin{array}{c}\text { Critério para a Pontuação } \\
\text { Máxima } \\
\text { (10 pontos) }\end{array}$ \\
\hline $\begin{array}{l}\text { 1. Grupo dos cereais, pães, } \\
\text { tubérculos e raizes }\end{array}$ & 0 porção & 5 a 9 porções \\
\hline $\begin{array}{l}\text { 2. Grupo das verduras e } \\
\text { legumes }\end{array}$ & 0 porção & 4 a 5 porções \\
\hline 3. Grupo das frutas & 0 porção & 3 a 5 porções \\
\hline $\begin{array}{l}\text { 4. Grupo do leite e produtos } \\
\text { lácteos }\end{array}$ & 0 porção & 3 porçס̃es \\
\hline 5. Grupo das carnes e ovos & 0 porção & 1 a 2 porções \\
\hline 6. Grupos das leguminosas & 0 porção & 1 porção \\
\hline 7. Gordura total & $\begin{array}{l}45 \% \text { ou mais do total de } \\
\text { energia proveniente de } \\
\text { gordura }\end{array}$ & $\begin{array}{c}30 \% \text { ou menos do total de } \\
\text { energia proveniente de } \\
\text { gordura }\end{array}$ \\
\hline 8. Colesterol & $450 \mathrm{mg}$ ou mais & $300 \mathrm{mg}$ ou menos \\
\hline 9. Sódio & $4800 \mathrm{mg}$ ou mais & $2400 \mathrm{mg}$ ou menos \\
\hline 10. Variedade da dieta & $\begin{array}{l}3 \text { ou menos tipos } \\
\text { diferentes de alimentos } \\
\text { que contribuam com } \\
\text { pelo menos metade da } \\
\text { porção do grupo } \\
\text { alimentar } \\
\text { correspondente }\end{array}$ & $\begin{array}{l}8 \text { ou mais tipos diferentes } \\
\text { de alimentos que } \\
\text { contribuam com pelo } \\
\text { menos metade da porção } \\
\text { do grupo alimentar } \\
\text { correspondente }\end{array}$ \\
\hline
\end{tabular}

O processamento de dados para o cálculo do Índice de Qualidade da Dieta foi realizado através de um programa desenvolvido no software Statistical Package for the Social Sciences (SPSS, versão 10, 1999, SPSS Inc., Chicago, Illinois, EUA), 
específico para este estudo, o qual calcula e atribui a pontuação para cada componente do IQD e para cada indivíduo.

\subsection{Variáveis de Estudo}

\subsubsection{Variável Dependente}

* Qualidade da dieta: Índice de Qualidade da Dieta (IQD), em pontos, calculado a partir dos dados de consumo alimentar.

\subsubsection{Variáveis Independentes}

\section{Variáveis demográficas:}

Idade: em anos completos, calculada a partir da data de entrevista e da data de nascimento.

* Sexo: masculino ou feminino. Quando transformada em variável indicadora, o sexo masculino foi considerado de referência.

Etnia: cor ou raça referida pelo entrevistado, podendo ser classificado como branca, negra, parda, amarela ou indígena. Quando transformada em variável indicadora, ter etnia parda foi considerada a categoria de referência.

\section{Variáveis de estilo de vida:}

* Altura: em metros, referida pelo entrevistado.

* Peso: em quilogramas, referido pelo entrevistado.

* Índice de Massa Corporal (IMC): calculado a partir das informações sobre peso (em quilogramas) e altura (em metros) referidos, conforme equação: $\mathrm{MMC}=$ peso/(altura $)^{2}, \mathrm{em} \mathrm{kg} / \mathrm{m}^{2}$. Para a apresentação do $\mathrm{MC}$ em categorias, foi utilizada a divisão proposta por World Health Organization (2000).

* Atividade física: classificação do indivíduo em praticante ou não de esporte ou exercício. Quando transformada em variável indicadora, a não prática de atividade física foi considerada como categoria de referência.

* Hábito de fumar: classificação do individuo em não fumante, ex-fumante ou fumante. Para a análise de regressão linear, os indivíduos que referiram ser não fumantes e ex-fumantes foram agrupados como não fumantes atuais. 
Quando transformada em variável indicadora, a categoria de não fumante foi considerada de referência.

* Consumo de bebida alcoólica: classificação do indivíduo em consumidor ou não de bebida alcoólica. A categoria "não consumidor de bebida alcoólica" foi considerada de referência para transformação em variável indicadora.

* Ingestão de energia: quantidade de calorias fornecida pela dieta, calculada a partir do Recordatório de 24 horas.

\section{Variáveis socioeconômicas:}

Naturalidade: local de nascimento do entrevistado, classificando-o em natural do município de residência, de outro município do estado de São Paulo ou de fora do estado de São Paulo. Ser natural do município de residência foi considerada a categoria de referência para a variável indicadora.

* Situação conjugal: classificação do indivíduo em solteiro, casado ou unido, separado ou divorciado ou desquitado, e viúvo. Quando transformada em variável indicadora, ser solteiro foi considerada a categoria de referência.

* Situação de trabalho: classifica o entrevistado segundo exercício de alguma atividade de trabalho: em atividade, desempregado, aposentado ou pensionista e outros (dona de casa, estudante e outros). Estar desempregado foi a categoria escolhida como de referência para a variável indicadora.

* Escolaridade do entrevistado: foi transformada em uma variável quantitativa contínua considerando: nunca freqüentou a escola e não sabe ler nem escrever com 0 ano de estudo; nunca freqüentou a escola mas sabe ler e escrever como 0,5 ano de estudo; $1^{\mathrm{a}}$ série do $1^{\circ}$ ciclo do ensino fundamental (antigo $1^{\circ} \mathrm{grau}$ ) como 1 ano de estudo; a cada ano de estudo completo somou-se mais um ano de estudo; curso técnico de nível médio incompleto com 10 anos de estudo; curso técnico de nível médio incompleto com 11 anos de estudo; curso superior incompleto com 12 anos de estudo; e curso superior completo com 13 anos de estudo.

Escolaridade do chefe da família: foi transformada em uma variável quantitativa contínua considerando: nunca freqüentou a escola e não sabe ler nem escrever com 0 ano de estudo; nunca freqüentou a escola mas sabe ler e 
escrever como 0,5 ano de estudo; $1^{a}$ série do $1^{\circ}$ ciclo do ensino fundamental (antigo $1^{\circ}$ grau) como 1 ano de estudo; a cada ano de estudo completo somouse mais um ano de estudo; curso técnico de nível médio incompleto com 10 anos de estudo; curso técnico de nível médio incompleto com 11 anos de estudo; curso superior incompleto com 12 anos de estudo; e curso superior completo com 13 anos de estudo.

Número de moradores: calculado a partir da contagem de todos os moradores no domicílio, com exclusão de pensionista, empregado doméstico e parente do empregado.

Renda per capita: foi calculada através da soma dos rendimentos informados por todos os componentes da família e dividindo-se pelo número de moradores do domicílio. Foram considerados os rendimentos declarados.

* Número de bens de consumo duráveis: foi verificada a disponibilidade de alguns bens de consumo duráveis, os quais incluíam: geladeira, freezer, televisão, máquina de lavar roupa, aparelho de som, aparelho de vídeo, aspirador de pó, máquina de lavar louça, condicionador de ar, telefone fixo, telefone celular, computador, forno de microondas, veículo automotor e outro imóvel além do utilizado como residência.

\section{Variáveis de caracterização do domicílio:}

* Área de residência: Grande São Paulo e Distrito do Butantã. Morar na Grande São Paulo foi considerada a categoria de referência para a variável indicadora.

* Tipo de habitação: caracterização do domicílio em casa, apartamento, barraco e cortiço. Para a análise de regressão linear, as categorias referentes ao tipo de habitação barraco e cortiço foram agrupadas em uma só categoria. Casa e apartamento também foram agrupadas em uma só categoria. Viver em barraco ou cortiço foi considerada a categoria de referência para a variável indicadora.

Condiçðes da habitação: classificação do domicílio em adequado e inadequado, sendo que habitação foi considerada adequada quando as moradias são constituidas por casas ou apartamentos, dispondo de rede 
interna de água ligada à rede pública, instalação sanitária interna ligada ao sistema público de esgoto e com iluminação artificial elétrica; já habitação é considerada inadequada quando há ausência de uma ou mais das condições de adequação. Quando transformada em variável indicadora, a condição inadequada foi considerada a categoria de referência.

* Condiçð̃es do entorno da habitação: classificação no entorno do domicílio em adequado em inadequado sendo que o entorno foi considerado adequado quando há rua pavimentada, guias e sarjetas, iluminação pública, rede pública de esgoto e coleta pública regular de lixo; já o entorno foi considerado inadequado na ausência de uma ou mais das condições de adequação. Quando transformada em variável indicadora, a condição inadequada foi considerada a categoria de referência.

\subsection{Análise dos dados}

O módulo Validate do software EPI INFO (versão 6.04d, 2001, Center for Disease Control and Prevention, Atlanta, Geórgia, EUA) foi utilizado para comparação dos códigos de identificação dos entrevistados do banco de dados de consumo alimentar com o banco de dados do restante das informações do questionário, com a conseqüente correção de erros para a junção correta dos dois bancos de dados.

Para a estruturação do banco de dados foi utilizado o Statistical Package for the Social Sciences (SPSS, versão 10, 1999, SPSS Inc., Chicago, Illinois, EUA) e para a análise de dados foi utilizado o STATA (versão 7, 2000, Stata Corporation, EUA).

Inicialmente, foi necessário que o programa de análise de dados incorporasse os fatores de ponderação da amostra baseados nas frações amostrais dos setores censitários (segundo características socioeconômicas) e dos indivíduos entrevistados (segundo idade e sexo). Desta forma, todas as medidas de tendência central e de dispersão e os resultados da modelagem foram obtidos com as correçð̃es necessárias conforme o desenho amostral e através de análises realizadas no módulo Survey do software STATA (versão 7, 2000, Stata Corporation, EUA). 
Para descrever a amostra estudada foram utilizadas freqüências, medidas de tendência central e de dispersão das variáveis demográficas, socioeconômicas, de estilo de vida e de caracterização do domicílio.

Para avaliar a qualidade da dieta, foram utilizadas frequêencias, medidas de tendência central e de dispersão do Índice de Qualidade da Dieta (IQD). Os indivíduos também foram classificados em três categorias definidas pela distribuição dos escores de qualidade da dieta encontrados na população alvo: abaixo de 51 pontos - dieta "inadequada"; entre 51 e 80 pontos - dieta que "necessita de modificação"; e superior a 80 pontos - dieta "saudável" (BOWMAN e col. 1998).

Também foram avaliados os componentes do Índice de Qualidade da Dieta (IQD) separadamente através de freqüências, medidas de tendência central e de dispersão. Calculou-se o percentual de indivíduos com pontuação mínima (zero) e máxima (dez) em cada um dos componentes do Índice de Qualidade da Dieta (IQD).

Foram calculados os coeficientes de correlação de Pearson entre o Índice de Qualidade da Dieta IQD e os nutrientes para observar a capacidade do IQD em ordenar os indivíduos ao longo da distribuição dos níveis de ingestão de nutrientes e verificar a correlação do IQD com outros nutrientes que não fazem parte diretamente de sua constituição. A correlação entre o IQD e a ingestão de nutrientes foi calculada de duas formas: primeiro com o nutriente bruto; depois com o nutriente ajustado para o total de energia ingerido usando o método residual proposto por WILLETT e STAMPFER (1986).

$O$ IQD foi dividido em tercis e posteriormente foi calculada a média de ingestão de nutrientes em cada tercil, a fim de verificar a existência de um gradiente de ingestão de nutrientes de acordo com a variação do IQD. Foi utilizado o teste de Wald para verificar se havia diferenças nas médias de ingestão de nutrientes entre os tercis de IQD, considerando o tercil inferior como a categoria de referência. $O$ teste de Bonferroni foi realizado para determinar qual a média de ingestão de nutriente seria maior ou menor em relação à média no tercil inferior do IQD.

O percentual de macronutrientes em relação ao total de energia da dieta de cada tercil do IQD foi comparado com as recomendações nutricionais das Dietary Reference Intakes (INSTITUTE OF MEDICINE 2002) para adultos que são as 
seguintes: carboidratos de 45 a $65 \%$, proteínas de 10 a $35 \%$ e gorduras de 20 a $35 \%$ do total de energia da dieta.

Para avaliar o efeito das variáveis socioeconômicas, demográficas, de estilo de vida e do domicílio sobre o IQD foi utilizada análise de regressão linear múltipla. O IQD foi considerado a variável dependente (uma variável quantitativa contínua) e as outras variáveis (demográficas, socioeconômicas, de estilo de vida e do domićlio) foram consideradas as independentes. Inicialmente, as variáveis de estudo foram verificadas quanto ao cumprimento das suposições básicas para realização de análise de regressão linear. Utilizou-se o teste de Kolmogorov-Smimov para verificar o grau de aderência da distribuição das variáveis quantitativas com a distribuição Normal. Apenas o IQD obteve aderência à distribuição Normal $(\mathrm{p}=0,067)$ (Anexo 3). As demais variáveis (ingestão de energia, idade, altura, $\mathrm{IMC}$, peso e renda per capita) não obtiveram aderência a distribuição Normal $(p<0,05)$. Houve a tentativa de transformar estas variáveis em seu logaritmo natural, porém não houve melhora de sua distribuição, como pode ser observado nos gráficos apresentados no Anexo 4. Portanto, analisando os gráficos de QQPLOTs dessas variáveis (Anexo 5), decidiu-se trabalhar com estas variáveis em suas unidades originais. As variáveis escolaridade do indivíduo, escolaridade do chefe da família, número de bens de consumo duráveis e número de moradores foram mantidas em sua unidade original pois são variáveis quantitativas discretas.

A análise de regressão linear simples foi realizada de duas formas, devido a existência de variáveis independentes qualitativas e quantitativas. Primeiramente, as variáveis qualitativas foram transformadas em variáveis indicadoras, permitindo a comparação das médias do Índice de Qualidade da Dieta entre as categorias de cada variável independente qualitativa através do teste de Wald (método de estimação da variância). Posteriormente, foi calculado o coeficiente de correlação de Pearson e realizada análise de regressão linear simples entre o IQD e as variáveis independentes quantitativas.

As variáveis que obtiveram valor $\mathrm{p}$ menor que 0,20 na análise de regressão linear simples foram selecionadas para inclusão no modelo de regressão linear múltiplo. Para a elaboração do modelo foi utilizada a estratégia de modelagem stepwise forward, ou seja, do modelo mais simples para o mais complexo. As 
variáveis que se mantiveram significativas foram mantidas no modelo de regressão linear múltiplo final.

A partir do modelo final de regressão elaborado para a população total, estratificou-se a população por sexo - masculino e feminino e foram estimados modelos para estas duas categorias.

A análise dos resíduos, através de gráfico do erro versus valores estimados e o gráfico QQPLOT do erro, foi realizada para verificar a presença de viés nos modelos e a presença de valores aberrantes. Qualquer variável que alterasse o coeficiente de regressão $(\beta)$ em $10 \%$ ou mais quando comparado ao modelo anterior foi considerada de controle. Ao final da modelagem foram avaliadas possíveis interações entre variáveis e feita a análise de resíduos.

Em todas as análises utilizou-se o nível de significância de $5 \%$. 
O projeto de pesquisa principal - Inquérito de Saúde do Estado de São Paulo: Inquérito Domiciliar de Saúde, de Base Populacional, em Municípios do Estado de São Paulo - e este projeto de pesquisa foram aprovados pelo Comitê de Ética em Pesquisa da Faculdade de Saúde Pública/USP, conforme documentos apresentados nos Anexos 6 e 7, respectivamente.

Os objetivos da pesquisa e o tipo de informação que seria solicitada foram apresentados aos indivíduos sorteados, sendo em seguida solicitada a assinatura do termo de consentimento livre e esclarecido de participação no estudo (Anexo 8). Foi assegurada a confidencialidade das informaçð̃es levantadas, sendo que apenas dados consolidados foram analisados e divulgados, impossibilitando a identificação dos indivíduos pesquisados.

Os procedimentos para o desenvolvimento deste estudo respeitaram as diretrizes e normas que regulamentam as pesquisas envolvendo humanos, aprovadas pela Resolução n 196, de 10 de outubro de 1996, do Conselho Nacional de Saúde. Desta forma, no banco de dados da pesquisa principal está mantido o anonimato e a confidencialidade dos dados. 


\section{RESULTADOS}


A amostra deste estudo foi composta por 1840 indivíduos adultos, que correspondem a uma população de 570013 indivíduos, com idade média de 39,72 anos (erro padrão $=0,55$ ), residentes nas áreas do Distrito do Butantã e Região Sudoeste da Grande São Paulo (municípios de Taboão da Serra, Embu e Itapecerica da Serra), com escolaridade média de 7,3 anos e renda per capita média de R\$ 490,44 (Tabela 1).

Tabela 1 - Estatística descritiva para as variáveis quantitativas. São Paulo, $2001 / 2002$

\begin{tabular}{|c|c|c|c|c|c|}
\hline Variável & $\begin{array}{l}\text { Valor } \\
\text { Mínimo }\end{array}$ & $\begin{array}{c}\text { Valor } \\
\text { Máximo }\end{array}$ & Mediana* & Média* & $\begin{array}{c}\text { Erro } \\
\text { Padrão* }\end{array}$ \\
\hline Ingestão de energia (kcal) & 502,16 & 3980,47 & 1690,43 & 1809,15 & 34,89 \\
\hline Idade (anos) & 20,00 & 97,00 & 37,00 & 39,72 & 0,55 \\
\hline Altura (m) ${ }^{a}$ & 1,30 & 1,96 & 1,65 & 1,66 & 0,003 \\
\hline Peso $(\mathrm{kg})^{\mathrm{b}}$ & 36,00 & 140,00 & 65,00 & 67,48 & 0,62 \\
\hline $\begin{array}{l}\text { Índice de massa corporal } \\
\left(\mathrm{kg} / \mathrm{m}^{2}\right)^{\mathrm{c}}\end{array}$ & 13,06 & 53,33 & 24,17 & 24,69 & 0,21 \\
\hline $\begin{array}{l}\text { Escolaridade do individuo } \\
\text { (anos) }\end{array}$ & 0 & 13,00 & 8,00 & 7,31 & 0,20 \\
\hline $\begin{array}{l}\text { Escolaridade do chefe da } \\
\text { família (anos) }\end{array}$ & 0 & 13,00 & 6,00 & 6,61 & 0,21 \\
\hline $\begin{array}{l}\text { Número de bens de consumo } \\
\text { duráveis }\end{array}$ & 0 & 15,00 & 8,00 & 7,70 & 0,21 \\
\hline Número de moradores & 1,00 & 12,00 & 4,00 & 4,21 & 0,15 \\
\hline Renda per capita (reais) & 0 & 14000,00 & 260,00 & 490,44 & 32,63 \\
\hline
\end{tabular}

Excluídos individuos com informação ignorada, dependendo da variável: ${ }^{2} 253,{ }^{\circ} 126,{ }^{c} 300,{ }^{d} 4,{ }^{\circ} 9,{ }^{\mathrm{T}} 6$.

* valores ponderados conforme desenho amostral.

A média de ingestão de energia entre homens foi significativamente maior do que entre mulheres $(2089,32 \mathrm{kcal}$ e $1568,64 \mathrm{kcal}$, respectivamente; $\mathrm{p}<0,001)$. Foram observados valores médios maiores na altura $(p<0,001)$, peso $(p<0,001)$ e índice de massa corporal $(p<0,05)$ de homens $\left(1,71 \mathrm{~m}, 73,34 \mathrm{~kg}\right.$ e $\left.25,047 \mathrm{~kg} / \mathrm{m}^{2}\right)$ em relação às mulheres $\left(1,60 \mathrm{~m}, 62,36 \mathrm{~kg}, 24,33 \mathrm{~kg} / \mathrm{m}^{2}\right)$.

A Tabela 2 apresenta as principais características demográficas e de estilo de vida. A maioria da população de estudo é da etnia branca, sendo a proporção de homens e mulheres muito semelhante. Cerca de $40 \%$ dos individuos foram 
classificados segundo o IMC com excesso de peso (sobrepeso e obesidade) e $70 \%$ referiram não praticar atividade física.

Tabela 2 - Distribuição do número e porcentagem de indivíduos, segundo variáveis demográficas e de estilo de vida qualitativas. São Paulo, 2001/2002.

\begin{tabular}{|c|c|c|c|}
\hline Variável & Categorias & $\mathbf{N}$ & $\% *$ \\
\hline \multirow[t]{2}{*}{ Sexo } & Masculino & 893 & 46,19 \\
\hline & Feminino & 947 & 53,81 \\
\hline \multirow[t]{5}{*}{ Etnia $^{a}$} & Parda & 425 & 30,88 \\
\hline & Negra & 124 & 7,17 \\
\hline & Branca & 1209 & 59,21 \\
\hline & Amarela & 57 & 2,28 \\
\hline & Indigena & 10 & 0,46 \\
\hline \multirow[t]{2}{*}{ Faixa etária } & 20 a 59 anos & 813 & 89,32 \\
\hline & 60 anos e mais & 1027 & 10,68 \\
\hline Índice de Massa & Menor que $18,5 \mathrm{~kg} / \mathrm{m}^{2}$ & 50 & 4,45 \\
\hline \multirow[t]{2}{*}{ Corporal $^{b}$} & 18,5 a $24,9 \mathrm{~kg} / \mathrm{m}^{2}$ & 772 & 55,14 \\
\hline & Maior ou igual $25,0 \mathrm{~kg} / \mathrm{m}^{2}$ & 718 & 40,41 \\
\hline \multirow[t]{2}{*}{ Atividade física $^{\mathfrak{c}}$} & Não pratica & 1247 & 68,09 \\
\hline & Pratica & 583 & 31,91 \\
\hline \multirow[t]{3}{*}{ Hábito de fumar $^{d}$} & Fumante & 371 & 25,00 \\
\hline & Nunca fumou & 987 & 54,09 \\
\hline & Ex-fumante & 478 & 20,91 \\
\hline Consumo de bebida & Não consome & 380 & 17,54 \\
\hline alcoólica $^{e}$ & Consome & 1388 & 82,46 \\
\hline
\end{tabular}

Excluídos indivíduos com informação ignorada, dependendo da variável: ${ }^{a} 15,{ }^{b} 300,{ }^{c} 10,{ }^{d} 4,{ }^{c} 72$.

*valores ponderados conforme desenho amostral.

A maioria da casuística está empregada, é unida ou casada (65\%), natural de fora do Estado de São Paulo (52\%), residente em casa (86\%) com condições de habitação e entorno adequadas (68\% e 64\%, respectivamente) (Tabela 3). 
Tabela 3 - Distribuição do número e porcentagem de indivíduos, segundo variáveis socioeconômicas e de do domicílio qualitativas. São Paulo, 2001/2002.

\begin{tabular}{|c|c|c|c|}
\hline Variável & Categorias & $\mathbf{N}$ & $\% *$ \\
\hline \multirow[t]{2}{*}{ Área de residência } & Grande São Paulo & 1024 & 53,25 \\
\hline & Distrito do Butantã & 816 & 46,75 \\
\hline \multirow[t]{3}{*}{ Naturalidade $^{\mathrm{a}}$} & Município de residência & 273 & 19,97 \\
\hline & Outro município do Estado de São Paulo & 617 & 28,29 \\
\hline & Fora do Estado de São Paulo & 941 & 51,75 \\
\hline \multirow[t]{4}{*}{ Situação de trabalho ${ }^{b}$} & Desempregado & 102 & 8,15 \\
\hline & Em atividade & 891 & 67,15 \\
\hline & Aposentado ou pensionista & 448 & 6,31 \\
\hline & Outros (dona de casa, estudante, outros) & 397 & 18,39 \\
\hline \multirow[t]{4}{*}{ Situação conjugal $^{\mathfrak{c}}$} & Solteiro & 279 & 23,94 \\
\hline & Unido/ casado & 1101 & 64,69 \\
\hline & Separado/ divorciado/ desquitado & 129 & 6,29 \\
\hline & Viúvo & 325 & 5,08 \\
\hline \multirow[t]{4}{*}{ Tipo de habitação ${ }^{a}$} & Casa & 1515 & 86,08 \\
\hline & Apartamento & 257 & 10,17 \\
\hline & Barraco & 46 & 2,79 \\
\hline & Cortiço & 13 & 0,96 \\
\hline \multirow[t]{2}{*}{ Condições da habitação $^{d}$} & Inadequada & 435 & 31,62 \\
\hline & Adequada & 1366 & 68,38 \\
\hline Condições do entorno da & Inadequada & 509 & 36,21 \\
\hline habitação ${ }^{e}$ & Adequada & 1326 & 63,79 \\
\hline Total & & 1840 & 100 \\
\hline
\end{tabular}

Excluídos indivíduos com informação ignorada, dependendo da variável: ${ }^{a} 9,{ }^{b} 2,{ }^{c} 6,{ }^{d} 39,{ }^{e} 5$.

* valores ponderados conforme desenho amostral.

A média do Índice de Qualidade da Dieta foi de 60,42 pontos (erro padrão = 0,54; $\left.\mathrm{IC}_{95 \%}[59,33 ; 61,50]\right)$, com variação de 13,89 a 92,32 pontos. Na Figura 2 
destaca-se que $75 \%$ da população estudada apresentaram dieta que necessita de melhora.

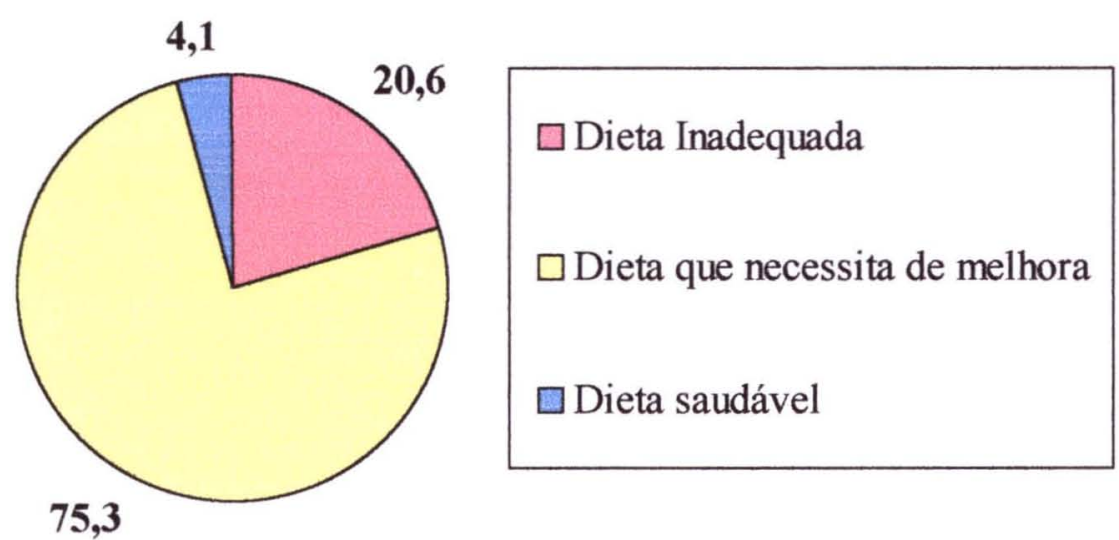

Figura 2 - Percentual de indivíduos segundo categorias do Índice de Qualidade da Dieta. São Paulo, 2001/2002.

Os valores médios de pontos dos diferentes componentes do IQD apresentaram-se baixos (abaixo de 5 pontos) para os grupos frutas, verduras e legumes, leite e produtos lácteos; valores intermediários (entre 5 e 8 pontos) para cereais, leguminosas, gordura, sódio e variedade de alimentos; e valores altos (superior a 8 pontos) para o grupo de carnes e ovos. O maior percentual de pontuações zero foi atribuído ao componente frutas (46\%). Entretanto, $81 \%$ e $73 \%$ da população estudada apresentaram pontuação máxima para os componentes carnes e ovos e colesterol, respectivamente (Tabela 4). 
Tabela 4 - Estatística descritiva para os escores de cada componente do Índice de Qualidade da Dieta (IQD) e percentual de indivíduos que obtiveram pontuação mínima (zero) ou máxima (dez). São Paulo 2001/2002.

\begin{tabular}{|c|c|c|c|c|c|}
\hline Componente do IQD & $\begin{array}{c}\text { Mediana* } \\
\text { (pontos) }\end{array}$ & $\begin{array}{l}\text { Média* } \\
\text { (pontos) }\end{array}$ & $\mathrm{IC}_{95 \%}{ }^{1 *}$ & $\begin{array}{l}\text { Escore } \\
0(\%)\end{array}$ & $\begin{array}{l}\text { Escore } \\
10(\%)\end{array}$ \\
\hline Cereais, pães, tubérculos e raízes & 7,00 & 6,84 & {$[6,60 ; 7,08]$} & 0,21 & 25,11 \\
\hline Verduras e legumes & 4,47 & 4,77 & {$[4,52 ; 5,02]$} & 3,96 & 13,43 \\
\hline Frutas & 0,21 & 3,71 & {$[3,37 ; 4,05]$} & 45,90 & 22,55 \\
\hline Leite e derivados & 2,22 & 2,90 & {$[2,67 ; 3,12]$} & 25,33 & 4,69 \\
\hline Carnes e ovos & 10,00 & 8,94 & {$[8,76 ; 9,12]$} & 4,70 & 81,15 \\
\hline Leguminosas & 9,07 & 6,38 & {$[5,98 ; 6,79]$} & 27,64 & 43,72 \\
\hline Gordura total & 5,70 & 5,51 & {$[5,17 ; 5,84]$} & 17,03 & 27,22 \\
\hline Colesterol & 10,00 & 8,17 & {$[7,93 ; 8,41]$} & 11,49 & 72,85 \\
\hline Sódio & 7,86 & 6,39 & {$[6,11 ; 6,68]$} & 14,82 & 34,81 \\
\hline Variedade de alimentos & 8,00 & 6,82 & {$[6,55 ; 7,09]$} & 5,96 & 39,07 \\
\hline
\end{tabular}

Tntervalo de confiança de $95 \%$.

* valores ponderados conforme desenho amostral.

Correlações positivas entre o IQD e os nutrientes são importantes pois indicam que o índice reflete a ingestão de nutrientes, mesmo que os componentes do índice que representam as características de uma dieta saudável não sejam definidos diretamente em termos da ingestão de micronutrientes (KENNEDY e col. 1995). Na Tabela 5 pode-se observar que o Índice de Qualidade da Dieta associou-se positivamente com a ingestão de energia, carboidrato, proteína, fibra alimentar, vitaminas $C, B 1, B 2, B 6$ e $B 12$, folato, ferro, cálcio e fósforo $(p<0,05)$. Foram observadas associaçð̃es negativas estatisticamente significativas para a ingestão de gordura e colesterol. Porém, após a remoção do efeito da ingestão de energia sobre a ingestão dos nutrientes, observou-se associação positiva entre o Índice de Qualidade da Dieta e a ingestão de carboidrato, fibra alimentar, vitaminas $\mathrm{C}, \mathrm{B} 1$ e B6, folato, ferro e cálcio $(p<0,05)$. Além das associações negativas com a ingestão de gordura e colesterol, sódio também passou a ter associação negativa estatisticamente significativa com o Índice de Qualidade da Dieta (Tabela 5). 
Tabela 5 - Correlação entre ingestão de nutrientes em valores brutos e ajustados e escores do Índice de Qualidade da Dieta. São Paulo, 2001/2002.

\begin{tabular}{|c|c|c|c|c|}
\hline \multirow{2}{*}{ Nutrientes da dieta } & \multicolumn{2}{|c|}{$\mathrm{IQD}^{1}$} & \multicolumn{2}{|c|}{ IQD $^{2}$} \\
\hline & $\mathbf{r}^{\mathbf{3} *}$ & $p^{4 *}$ & $\mathbf{r}^{3 *}$ & $p^{4 *}$ \\
\hline Energia (kcal) & 0,19 & $<0,001$ & -ב-- & $\ldots$ \\
\hline Carboidrato (g) & 0,40 & $<0,001$ & 0,44 & $<0,001$ \\
\hline Proteina (g) & 0,10 & 0,005 & $-0,05$ & 0,147 \\
\hline Gordura total (g) & $-0,08$ & 0,031 & $-0,43$ & $<0,001$ \\
\hline Colesterol (mg) & $-0,18$ & $<0,001$ & $-0,35$ & $<0,001$ \\
\hline Fibra alimentar (g) & 0,46 & $<0,001$ & 0,42 & $<0,001$ \\
\hline Retinol ( $\mu \mathrm{g})$ & 0,07 & 0,134 & 0,06 & 0,201 \\
\hline Vitamina $\mathrm{C}(\mathrm{mg})$ & 0,27 & 0,002 & 0,24 & 0,002 \\
\hline Vitamina B1 (mg) & 0,29 & $<0,001$ & 0,23 & $<0,001$ \\
\hline Vitamina B2 (mg) & 0,12 & 0,003 & 0,03 & 0,465 \\
\hline Vitamina B6 (mg) & 0,25 & $<0,001$ & 0,17 & $<0,001$ \\
\hline Vitamina B12 $(\mu \mathrm{g})$ & $-0,06$ & 0,112 & $-0,07$ & 0,062 \\
\hline Niacina (mg) & 0,05 & 0,143 & $-0,08$ & 0,091 \\
\hline Folato $(\mu \mathrm{g})$ & 0,32 & $<0,001$ & 0,26 & $<0,001$ \\
\hline Vitamina E (mg) & 0,11 & 0,010 & 0,00 & 0,964 \\
\hline Sódio (mg) & 0,06 & 0,153 & $-0,11$ & $<0,001$ \\
\hline Ferro (mg) & 0,22 & $<0,001$ & 0,12 & $<0,001$ \\
\hline Cálcio (mg) & 0,30 & $<0,001$ & 0,24 & $<0,001$ \\
\hline Fósforo (mg) & 0,14 & $<0,001$ & 0,01 & 0,900 \\
\hline
\end{tabular}

Ingestão do nutriente bruta

${ }^{2}$ Ingestão do nutriente ajustada pela ingestão total de energia.

${ }^{3}$ Coeficiente de correlação de Pearson.

${ }^{4}$ Valor de $\mathrm{p}$

*valores ponderados conforme desenho amostral.

Após partição dos escores do IQD em tercis, observa-se na Tabela 6 que há um gradiente de aumento da média de ingestão dos nutrientes conforme aumento do IQD, com exceção para colesterol, sódio e gordura.

$A$ ingestão de carboidrato, proteína, fibra alimentar, vitamina $C$, vitamina $B 1$, vitamina $\mathrm{B} 6$, folato, vitamina $\mathrm{E}$, cálcio, fósforo e ferro foi maior nos tercis intermediário e superior em relação ao tercil inferior do IQD. A diferença foi observada apenas no tercil superior para retinol, vitamina B2 e colesterol, sendo que 
para esse último a relação foi inversa, ou seja, o valor médio no tercil superior foi menor do que o inferior (Tabela 6).

Tabela 6 - Estatísticas descritivas da ingestão de nutrientes segundo tercis do Índice de Qualidade da Dieta (IQD) e teste estatístico em relação ao tercil inferior do IQD. São Paulo, 2001/2002.

\begin{tabular}{|c|c|c|c|c|}
\hline \multirow[t]{2}{*}{ Nutriente } & \multicolumn{3}{|c|}{ Tercis de IQD } & \multirow[t]{2}{*}{$\mathrm{p}^{1}$} \\
\hline & $\begin{array}{c}\text { Inferior } \\
\left.\text { Média }(\mathbf{E P})^{2}\right)\end{array}$ & $\begin{array}{l}\text { Intermediário } \\
\text { Média (EP }{ }^{2} \text { ) }\end{array}$ & $\begin{array}{c}\text { Superior } \\
\text { Média }\left(\mathbf{E P}^{2}\right)\end{array}$ & \\
\hline Energia (kcal) & $1578,53(50,83)$ & $1916,71(61,31)^{*}$ & $1934,58(52,17)^{*}$ & $<0,001$ \\
\hline Carboidratos (g) & $163,40(5,59)$ & $230,26(7,39)^{*}$ & $252,48(7,04)^{*}$ & $<0,001$ \\
\hline Proteína (g) & $61,72(2,50)$ & $72,95(3,19)^{*}$ & $73,38(3,07)^{*}$ & 0,001 \\
\hline Gordura total $(\mathrm{g})$ & $72,84(2,91)$ & $75,54(2,63)$ & $69,56(1,71)$ & 0,196 \\
\hline Fibra alimentar (g) & $7,65(0,35)$ & $11,73(0,45)^{*}$ & $16,89(0,74)^{*}$ & $<0,001$ \\
\hline Colesterol (mg) & $273,88(14,79)$ & $244,61(10,92)$ & $221,71(9,25)^{*}$ & 0,003 \\
\hline Retinol $(\mu \mathrm{g})$ & $632,37(100,43)$ & $684,46(55,47)$ & $999,44(109,46)^{*}$ & 0,031 \\
\hline Vitamina C (mg) & $40,20(3,57)$ & $89,55(19,38)^{*}$ & $167,08(17,24)^{*}$ & $<0,001$ \\
\hline Vitamina B1 (mg) & $0,86(0,04)$ & $1,19(0,05)^{*}$ & $1,31(0,04)^{*}$ & $<0,001$ \\
\hline Vitamina B2 (mg) & $1,07(0,05)$ & $1,20(0,05)$ & $1,32(0,04)^{*}$ & 0,001 \\
\hline Vitamina B6 (mg) & $0,93(0,05)$ & $1,27(0,06)^{*}$ & $1,41(0,05)^{*}$ & $<0,001$ \\
\hline Vitamina B12 $(\mu \mathrm{g})$ & $4,70(0,99)$ & $3,39(0,44)$ & $3,62(0,60)$ & 0,405 \\
\hline Niacina (mg) & $17,41(0,71)$ & $19,43(0,66)$ & $18,88(0,73)$ & 0,145 \\
\hline Folato $(\mu \mathrm{g})$ & $120,43(5,12)$ & $146,60(4,69)^{*}$ & $182,75(6,14)^{*}$ & $<0,001$ \\
\hline Vitamina $E(\mathrm{mg})$ & $10,50(0,51)$ & $12,34(0,43)^{*}$ & $12,32(0,41)^{*}$ & 0,003 \\
\hline Sódio (mg) & $2999,85(99,52)$ & $3487,79(121,56)^{*}$ & $3241,24(130,09)$ & 0,004 \\
\hline Cálcio (mg) & $345,39(17,32)$ & $456,99(19,85)^{*}$ & $542,31(18,06)^{*}$ & $<0,001$ \\
\hline Fósforo (mg) & $671,11(23,24)$ & $777,90(26,72)^{*}$ & $802,68(30,38)^{*}$ & 0,001 \\
\hline Ferro (mg) & $7,50(0,23)$ & $9,32(0,28)^{*}$ & $9,65(0,25)^{*}$ & $<0,001$ \\
\hline
\end{tabular}

\footnotetext{
'Significância estatística do teste de Wald em relação à média no tercil inferior ${ }^{2} \mathrm{EP}=$ erro padrăo

*Teste de Bonferroni em relação à média no tercil inferior.
} 
Observa-se na Figura 3 que o percentual de macronutrientes em relação ao total de energia está mais próximo da recomendação das Dietary Reference Intakes (Institute of Medicine 2002) no tercil superior do Índice de Qualidade da Dieta. O percentual de proteínas não se altera entre os tercis de IQD $(p>0,05)$. A ingestão de gordura diminui conforme aumenta o IQD, sendo que os tercis intermediário e superior obtiveram médias do percentual de gordura em relação à ingestão de energia menores do que o tercil inferior $(\mathrm{p}<0,001)$. Em relação à ingestão de carboidratos, seu percentual do total de energia é maior nos tercis intermediário e superior em relação ao tercil inferior $(\mathrm{p}<0,001)$.

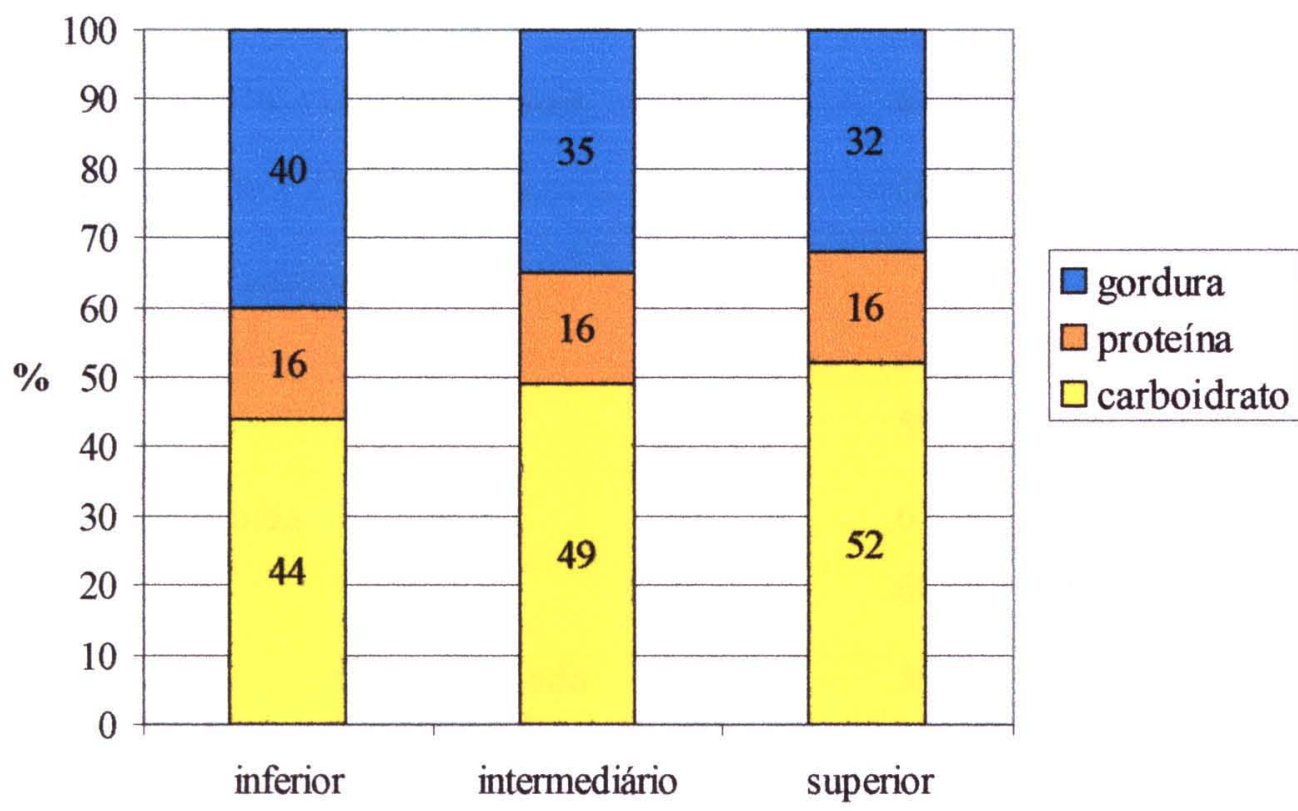

Tercil de IQD

Figura 3 - Valor médio do percentual de macronutrientes em relação à ingestão de energia segundo tercis do Índice de Qualidade da Dieta (IQD). São Paulo, 2001/2002.

Nas Tabelas 7 e 8 pode-se observar que houve diferença estatisticamente significativa na média do Índice de Qualidade da Dieta segundo sexo, faixa etária, situação de trabalho e tipo de habitação. Ou seja, os maiores escores do IQD foram obtidos por indivíduos do sexo masculino, com idade maior ou igual a 60 anos, aposentados ou pensionistas e moradores de casa ou apartamento. 
Tabela 7 - Estatística descritiva do Índice de Qualidade da Dieta (IQD) segundo variáveis demográficas e de estilo de vida. São Paulo, 2001/2002.

\begin{tabular}{|c|c|c|c|c|c|}
\hline Característica & Categorias & Média & $\mathbf{E P}^{1}$ & $\mathrm{IC}_{95 \%}{ }^{2}$ & $\mathbf{p}^{3}$ \\
\hline \multirow[t]{5}{*}{ Etnia* } & Parda & 59,74 & 0,88 & {$[57,98 ; 61,49]$} & 0,667 \\
\hline & Negra & 59,88 & 3,06 & {$[53,74 ; 66,01]$} & \\
\hline & Branca & 60,69 & 0,79 & {$[59,11 ; 62,28]$} & \\
\hline & Amarela & 62,78 & 2,52 & {$[57,74 ; 67,83]$} & \\
\hline & Indígena & 65,19 & 7,81 & {$[49,53 ; 80,86]$} & \\
\hline \multirow[t]{2}{*}{ Sexo } & Masculino & 61,34 & 0,66 & {$[60,01 ; 62,67]$} & 0,024 \\
\hline & Feminino & 59,63 & 0,65 & {$[58,33 ; 60,92]$} & \\
\hline \multirow[t]{2}{*}{ Faixa etária } & $20-59$ anos & 60,25 & 0,59 & {$[59,05 ; 61,44]$} & 0,020 \\
\hline & 60 anos e mais & 61,86 & 0,46 & {$[60,96 ; 62,76]$} & \\
\hline \multirow[t]{2}{*}{ Atividade fisica* } & Não pratica & 60,15 & 0,66 & {$[58,82 ; 61,47]$} & 0,333 \\
\hline & Pratica & 61,02 & 0,70 & {$[59,62 ; 62,42]$} & \\
\hline \multirow[t]{2}{*}{ Hábito de fumar* } & Não fumante & 60,76 & 0,62 & {$[59,51 ; 62,00]$} & 0,144 \\
\hline & Fumante & 59,27 & 0,85 & {$[57,56 ; 60,98]$} & \\
\hline Consumo de bebida & Não bebe & 61,05 & 1,02 & {$[59,01 ; 63,08]$} & 0,455 \\
\hline alcoólica* & Bebe & 60,19 & 0,59 & {$[58,99 ; 61,38]$} & \\
\hline Situação de & Desempregado & 59,41 & 1,22 & {$[56,97 ; 61,85]$} & $\mathbf{0 , 0 2 8}$ \\
\hline \multirow[t]{3}{*}{ trabalho* } & Em atividade & 60,67 & 0,67 & {$[59,32 ; 62,02]$} & \\
\hline & Aposentado ou pensionista & 63,24 & 0,79 & {$[61,65 ; 64,82]$} & \\
\hline & Outros** & 58,98 & 1,14 & {$[56,69 ; 61,26]$} & \\
\hline Situação conjugal & Solteiro & 59,50 & 1,34 & {$[56,82 ; 62,18]$} & 0,813 \\
\hline \multirow[t]{3}{*}{ do indivíduo* } & Unido/ casado & 60,77 & 0,72 & {$[59,32 ; 62,22]$} & \\
\hline & Separado/ divorciado & 60,52 & 2,08 & {$[56,35 ; 64,70]$} & \\
\hline & Viúvo & 60,90 & 0,84 & {$[59,21 ; 62,60]$} & \\
\hline
\end{tabular}

${ }^{1} \mathrm{EP}=$ erro padrăo.

${ }^{2}$ Intervalo de confiança de $95 \%$.

${ }^{3}$ Valor de $p$.

*Excluídos os indivíduos com informação ignorada.

**Inclui estudantes, dona de casa e outras informações. 
Tabela 8 - Estatística descritiva do Índice de Qualidade da Dieta (IQD) segundo variáveis socioeconômicas e do domicílio. São Paulo, 2001/2002.

\begin{tabular}{llllll}
\hline Característica & Categorias & Média & $\mathbf{E P}^{1}$ & IC $_{95 \%}{ }^{2}$ & $\mathbf{p}^{3}$ \\
\hline Naturalidade* & Município de residência & 60,28 & 0,95 & {$[58,38 ; 62,18]$} & 0,989 \\
& Outro município do Estado de SP & 60,47 & 1,06 & {$[58,34 ; 62,59]$} & \\
& Fora do Estado de SP & 60,45 & 0,58 & {$[59,28 ; 61,61]$} & \\
Área de & Grande São Paulo & 60,58 & 0,82 & {$[58,94 ; 62,21]$} & 0,749 \\
residência & Distrito do Butantã & 60,24 & 0,68 & {$[58,87 ; 61,61]$} & \\
Tipo de & Barraco/cortiço & 57,08 & 1,58 & {$[53,93 ; 60,24]$} & $\mathbf{0 , 0 3 6}$ \\
habitação* & Casa/apartamento & 60,53 & 0,56 & {$[59,41 ; 61,65]$} & \\
Condiçð̃es da & Inadequada & 59,90 & 1,07 & {$[57,75 ; 62,06]$} & 0,552 \\
habitação* & Adequada & 60,78 & 0,76 & {$[59,26 ; 62,29]$} & \\
Condiçơes do & Inadequada & 59,83 & 0,85 & {$[58,13 ; 61,53]$} & 0,415 \\
entorno da & Adequada & 60,75 & 0,72 & {$[59,30 ; 62,19]$} & \\
habitação* & & & & & \\
\hline
\end{tabular}

TEP = erro padrão.

${ }^{2}$ Intervalo de confiança de $95 \%$.

${ }^{3}$ Valor de p.

*Excluídos os indivíduos com informação ignorada.

$\mathrm{Na}$ análise de regressão linear simples entre o Índice de Qualidade da Dieta e as variáveis quantitativas, houve correlação estatisticamente significativa para ingestão de energia da dieta, altura, escolaridade do indivíduo, escolaridade do chefe da família, número de bens de consumo duráveis e renda per capita (Tabela 9). 
Tabela 9 - Análise de regressão linear simples: coeficiente de correlação de Pearson, beta e intervalo de confiança de $95 \%$ (IC 95\%) da análise de regressão simples entre o Índice de Qualidade da Dieta e cada variável independente quantitativa. São Paulo, 2001/2002.

\begin{tabular}{lcccc}
\hline Variável independente & $\mathbf{r}^{1}$ & $\boldsymbol{\beta}^{\mathbf{2}}$ & $\mathbf{I} \mathbf{C}_{95 \%}{ }^{\mathbf{3}}$ & $\mathbf{p}^{\mathbf{4}}$ \\
\hline Ingeståo de energia (kcal) & 0,192 & 0,003 & {$[0,002 ; 0,004]$} & $<\mathbf{0 , 0 0 1}$ \\
Altura $(\mathrm{m})^{*}$ & 0,062 & 8,035 & {$[0,865 ; 15,205]$} & 0,029 \\
Peso $(\mathrm{kg})^{*}$ & 0,001 & 0,001 & {$[-0,066 ; 0,067]$} & 0,980 \\
IMC $(\mathrm{kg} / \mathrm{m} 2)^{*}$ & $-0,057$ & $-0,149$ & {$[-0,330 ; 0,032]$} & 0,104 \\
Escolaridade do individuo (anos) & 0,108 & 0,316 & {$[0,136 ; 0,497]$} & $\mathbf{0 , 0 0 1}$ \\
Escolaridade do chefe da família & 0,132 & 0,385 & {$[0,153 ; 0,616]$} & $\mathbf{0 , 0 0 2}$ \\
Número de bens de consumo & 0,158 & 0,561 & {$[0,292 ; 0,830]$} & $<\mathbf{0 , 0 0 1}$ \\
Número de moradores & $-0,032$ & $-0,201$ & {$[-0,747 ; 0,345]$} & 0,464 \\
Renda per capita (reais) & 0,094 & 0,001 & {$[0,001 ; 0,002]$} & $\mathbf{0 , 0 0 1}$ \\
\hline
\end{tabular}

${ }^{T}$ Coeficiente de correlação de Pearson.

${ }^{2}$ Coeficiente de regressäo.

${ }^{3}$ Intervalo de confiança de $95 \%$.

${ }^{4}$ Valor de p.

*Excluídos os individuos com informação ignorada.

A análise de regressão múltipla foi realizada para investigar se as diferenças observadas no IQD durante a análise univariada se manteriam quando as variáveis fossem examinadas em conjunto. Para tanto, foram selecionadas as variáveis que obtiveram nível descritivo menor do que 0,20 na análise univariada. Estas foram ordenadas conforme o valor do $\mathrm{p}$, da maior significância para a menor (Quadro 3). 
Quadro 3 - Seleção e ordenação das variáveis para entrada no modelo múltiplo.

\begin{tabular}{|cc|}
\hline Ordem de entrada no modelo & Variável \\
\hline 1 & Ingestão de energia \\
2 & Número de bens de consumo duráveis \\
3 & Escolaridade do indivíduo \\
4 & Renda per capita \\
5 & Escolaridade do chefe da família \\
6 & Faixa etária \\
7 & Sexo \\
8 & Situação de trabalho \\
9 & Altura \\
10 & Tipo de domicílio \\
11 & Índice de massa corporal \\
12 & Hábito de fumar \\
\hline
\end{tabular}

A Tabela 10 apresenta os detalhes da elaboração do modelo de regressão linear múltiplo e o modelo final escolhido foi o $\mathrm{n}^{\circ} 6 . \mathrm{Na}$ análise múltipla, observouse que as variáveis ingestão de energia, número de bens de consumo duráveis existentes no domicílio, escolaridade do chefe da família e ter idade maior ou igual a 60 anos tiveram efeitos independentes sobre o Índice de Qualidade da Dieta. Este modelo foi estatisticamente significativo $(F(4,51)=14,39 ; p<0,001)$ e as variáveis que compôem o modelo final explicaram a maior proporção da variância do IQD. Todas as outras variáveis quando inseridas no modelo de regressão linear múltiplo não foram estatisticamente significativas. Assim, observa-se que quanto maior a ingestão de energia ou maior o número de bens de consumo duráveis ou maior a escolaridade do chefe da família, maior é o IQD. Estar na faixa etária de 60 anos ou mais ocasiona um aumento médio de mais 3 pontos no IQD, independente da ingestão de energia, da escolaridade do chefe da família e do número de bens de consumo duráveis.

Foram testadas interaçóes entre as variáveis que permaneceram no modelo final, mas não foi constatada nenhuma interação significativa. Nenhuma variável foi considerada de controle ou confusão. Também foi realizada análise de resíduos e constatou-se que os modelos não apresentavam viés, embora houvesse presença de valores aberrantes, como pode ser observado no Anexo 9. 
Tabela 10 - Resultado da análise de regressão múltipla do Índice de Qualidade da Dieta (pontos) e as características demográficas, de estilo de vida e socioeconômicas da população estudada. São Paulo, 2001/2002.

\begin{tabular}{|c|c|c|c|c|c|}
\hline Modelo & Variáveis independentes & $\beta_{0}$ & $\beta$ & $\mathbf{p}$ & $\mathbf{R}^{2}$ \\
\hline 1 & Ingestão de energia & 54,98 & 0,003 & $<0,001$ & 0,037 \\
\hline \multirow[t]{2}{*}{2} & Ingestão de energia & 51,32 & 0,003 & $<0,001$ & 0,057 \\
\hline & $\mathrm{N}^{\circ}$ de bens de consumo duráveis & & 0,515 & 0,001 & \\
\hline \multirow[t]{3}{*}{3} & Ingestão de energia & 51,27 & 0,003 & $<0,001$ & 0,058 \\
\hline & $\mathrm{N}^{o}$ de bens de consumo duráveis & & 0,507 & 0,006 & \\
\hline & Escolaridade do indivíduo & & 0,018 & 0,885 & \\
\hline \multirow[t]{3}{*}{4} & Ingestão de energia & 51,46 & 0,003 & $<0,001$ & 0,058 \\
\hline & $\mathrm{N}^{0}$ de bens de consumo duráveis & & 0,471 & 0,007 & \\
\hline & Renda per capita & & 0,0004 & 0,395 & \\
\hline \multirow[t]{3}{*}{5} & Ingestão de energia & 50,78 & 0,003 & $<0,001$ & 0,062 \\
\hline & $\mathrm{N}^{\circ}$ de bens de consumo duráveis & & 0,393 & 0,011 & \\
\hline & Escolaridade do chefe da família & & 0,221 & 0,074 & \\
\hline \multirow[t]{4}{*}{6} & Ingestão de energia & 50,12 & 0,003 & $<0,001$ & 0,068 \\
\hline & $\mathrm{N}^{\circ}$ de bens de consumo duráveis & & 0,365 & 0,018 & \\
\hline & Escolaridade do chefe da família & & 0,258 & 0,044 & \\
\hline & Faixa etária de 60 anos ou mais* & & 2,990 & $<0,001$ & \\
\hline \multirow[t]{5}{*}{7} & Ingestão de energia & 50,52 & 0,003 & $<0,001$ & 0,068 \\
\hline & $\mathrm{N}^{\circ}$ de bens de consumo duráveis & & 0,363 & 0,018 & \\
\hline & Escolaridade do chefe da família & & 0,266 & 0,045 & \\
\hline & Faixa etária de 60 anos ou mais* & & 2,981 & $<0,001$ & \\
\hline & Sexo feminino & & $-0,453$ & 0,594 & \\
\hline \multirow[t]{7}{*}{8} & Ingestão de energia & 50,37 & 0,003 & $<0,001$ & 0,071 \\
\hline & $\mathrm{N}^{0}$ de bens de consumo duráveis & & 0,373 & 0,014 & \\
\hline & Escolaridade do chefe da família & & 0,245 & 0,056 & \\
\hline & Faixa etária de 60 anos ou mais $*$ & & 2,298 & 0,006 & \\
\hline & Situação de trabalho: em atividade** & & 0,0003 & 1,000 & \\
\hline & Situação de trabalho: aposentado** & & 1,910 & 0,210 & \\
\hline & Outras situações de trabalho** & & $-0,999$ & 0,530 & \\
\hline
\end{tabular}


(Continuação)

\begin{tabular}{|c|c|c|c|c|c|}
\hline Modelo & Variáveis independentes & $\beta_{0}$ & $\boldsymbol{\beta}$ & $\mathbf{p}$ & $\mathbf{R}^{2}$ \\
\hline \multirow[t]{5}{*}{9} & Ingestão de energia & 49,00 & 0,003 & $<0,001$ & 0,059 \\
\hline & $N^{0}$ de bens de consumo duráveis & & 0,253 & 0,081 & \\
\hline & Escolaridade do chefe da família & & 0,301 & 0,022 & \\
\hline & Faixa etária de 60 anos ou mais * & & 2,770 & $<0,001$ & \\
\hline & Altura referida & & 1,421 & 0,688 & \\
\hline \multirow[t]{5}{*}{10} & Ingestão de energia & 49,94 & 0,003 & $<0,001$ & 0,066 \\
\hline & $\mathrm{N}^{\circ}$ de bens de consumo duráveis & & 0,355 & 0,031 & \\
\hline & Escolaridade do chefe da família & & 0,265 & 0,041 & \\
\hline & Faixa etária de 60 anos ou mais * & & 2,972 & $<0,001$ & \\
\hline & Habitação do tipo casa/apartamento*** & & 0,437 & 0,823 & \\
\hline \multirow[t]{5}{*}{11} & Ingestão de energia & 54,46 & 0,003 & $<0,001$ & 0,060 \\
\hline & $\mathrm{N}^{\circ}$ de bens de consumo duráveis & & 0,302 & 0,039 & \\
\hline & Escolaridade do chefe da família & & 0,263 & 0,040 & \\
\hline & Faixa etária de 60 anos ou mais * & & 2,807 & $<0,001$ & \\
\hline & Índice de massa corporal & & $-0,127$ & 0,171 & \\
\hline \multirow[t]{5}{*}{12} & Ingestão de energia & 50,41 & 0,003 & $<0,001$ & 0,069 \\
\hline & $\mathrm{N}^{\circ}$ de bens de consumo duráveis & & 0,359 & 0,027 & \\
\hline & Escolaridade do chefe da família & & 0,271 & 0,040 & \\
\hline & Faixa etária de 60 anos ou mais * & & 2,890 & $<0,001$ & \\
\hline & Fumante**** & & $-0,751$ & 0,469 & \\
\hline
\end{tabular}

*em relação a faixa etária de 20 a 59 anos.

**em relação a situação desempregado.

***em relação a habitação do tipo barraco/ cortiço.

**** em relação ao hábito de não fumar.

A partir das variáveis que permaneceram no modelo final de regressão, foram elaborados dois outros modelos de regressão múltipla estratificados por sexo pois observou-se diferença na média do IQD entre homens e mulheres mas a variável não se manteve no modelo final. Verifica-se que para o sexo masculino, todas as variáveis inseridas se mantiveram estatisticamente significativas. Porém, para o sexo feminino, a ingestão de energia da dieta e ter idade de 60 anos ou mais foram as variáveis que se mantiveram estatisticamente significativas. Além disso, pode-se observar que para cada 1 quilocaloria ingerida o efeito no Índice de Qualidade da Dieta da mulheres é 2 vezes maior do que nos homens e ter 60 anos ou mais impõe um efeito 0,5 a mais nas mulheres do que nos homens. 
Tabela 11 - Resultado da análise de regressão múltipla final estratificada por sexo.

São Paulo, 2001/2002.

\begin{tabular}{|c|c|c|c|c|c|c|}
\hline \multirow{2}{*}{$\begin{array}{l}\text { Variáveis } \\
\text { Independentes }\end{array}$} & \multicolumn{2}{|c|}{$\begin{array}{c}\text { Sexo Masculino } \\
(n=888)\end{array}$} & \multicolumn{2}{|c|}{$\begin{array}{c}\text { Sexo Feminino } \\
(n=939)\end{array}$} & \multicolumn{2}{|c|}{$\begin{array}{c}\text { Total } \\
(n=1827)\end{array}$} \\
\hline & & $\mathbf{p}^{2}$ & & $\mathbf{p}^{2}$ & & \\
\hline Ingestão de energia & 0,002 & 0,018 & 0,004 & $<0,001$ & 0,003 & $<0,001$ \\
\hline $\mathrm{N}^{\circ}$ de bens de consumo duráveis & 0,276 & 0,032 & 0,449 & 0,092 & 0,365 & 0,018 \\
\hline Escolaridade do chefe em anos & 0,465 & 0,007 & 0,057 & 0,760 & 0,258 & 0,044 \\
\hline Faixa etária de 60 anos ou mais* & 2,564 & 0,005 & 3,077 & 0,003 & 2,990 & $<0,001$ \\
\hline$r^{2}$ & & & & & & $\overline{068}$ \\
\hline $\mathrm{p}$ do modelo & & & $<0$ & & & 001 \\
\hline
\end{tabular}

${ }^{T}$ Coeficiente de regressão.

${ }^{2}$ Valor de $p$.

*em relação à faixa etária de 20 a 59 anos. 
7. DISCUSSÃO 
Este estudo foi realizado com o objetivo de avaliar os fatores demográficos, socioeconômicos e de estilo de vida associados à qualidade da dieta de adultos residentes no Distrito do Butantã e nos municípios de Taboão da Serra, Embu e Itapecerica da Serra, áreas que compõem a região metropolitana de São Paulo.

Foi utilizado um processo de amostragem que obtivesse amostra representativa de base populacional dos residentes dessas áreas. A representatividade da amostra deste estudo pode ser confirmada através da comparação dos resultados de caracterização demográfica e socioeconômica com os dados do último levantamento da Pesquisa Nacional por Amostra de Domicílios (PNAD), para o ano de 2002, da região metropolitana de São Paulo (IBGE 2004). Observou-se que a amostra de estudo obteve uma média de 7,3 anos de estudo, corroborando com a média de 7,6 anos de estudo da população com 10 anos ou mais de idade da região metropolitana de São Paulo. Esta região possuía, em 2002, uma população com 8,5\% de pessoas que haviam estudado, $9,4 \%$ com 1 a 3 anos de estudo, $30,2 \%$ com 4 a 7 anos de estudo, $35 \%$ com 8 a 11 anos de estudo e 16,9\% com 12 anos ou mais de estudo. Resultados semelhantes foram observados na amostra estudada: 6,4\%, 12,1\% $29,5 \%, 36,6 \%$ e $15,4 \%$, respectivamente (IBGE 2004).

A proporção de homens foi de $46 \%$ e de mulheres foi de $54 \%$, sendo porcentagens semelhantes às da PNAD (de $48 \%$ e $52 \%$, respectivamente). $O$ levantamento da PNAD demonstrou que 63,8\% eram brancos, 28,3\% pardos, 6,3\% negros e 1,6\% amarelos e indígenas na região metropolitana de São Paulo. A amostra estudada tinha uma distribuição étnica semelhante $(59,2 \%, 30,9 \%, 7,2 \%$ e $2,7 \%$, respectivamente). Em relação à caracterização por faixa etária, 10,7\% da amostra estudada era composta por indivíduos com 60 anos ou mais, proporção semelhante à observada na PNAD (13,5\%) na região metropolitana de São Paulo. Quanto à situação de trabalho, $67 \%$ da amostra estudada referiu estar em atividade no momento da pesquisa, resultado semelhante ao descrito pela PNAD $(63,8 \%)$. Já a taxa de desocupação observada na PNAD é um pouco superior à encontrada neste estudo (13,5\% e $8,2 \%$, respectivamente). Os dados da PNAD demonstraram que $80,1 \%$ dos domicílios eram casas, caracterização semelhante à observada neste estudo (86\%) (IBGE 2004). 
A prevalência de excesso de peso (Índice de Massa Corporal igual ou superior a $25 \mathrm{~kg} / \mathrm{m}^{2}$ ) observada neste estudo (40\%) foi semelhante à observada pelo INSTITUTO NACIONAL DE CÂNCER (2003) no "Inquérito Domiciliar sobre Comportamentos de Risco e Morbidade Referida de Doenças e Agravos Não Transmissíveis" para o município de São Paulo, de 41\%, e para o Brasil, de $40 \%$.

A média do Índice de Qualidade da Dieta (IQD) foi de 60,42 pontos no presente estudo, indicando uma qualidade da dieta moderada. RAFFERTY e colaboradores (2002), utilizando o Michigan Healthy Diet Indicator (MI-HDI), que é um índice de qualidade da dieta baseado no Healthy Eating Index - HEI, obtiveram média inferior ao observado no presente estudo (55,7 pontos) entre indivíduos de 18 anos e mais. Entretanto, outros estudos encontrados na literatura e que utilizaram o HEI obtiveram resultados superiores. KENNEDY e colaboradores (1995), que pela primeira vez aplicavam o HEI em amostra representativa da população norteamericana, observaram média de 63,9 pontos. Resultado semelhante foi encontrado por BOWMAN e colaboradores (1998) ao utilizarem dados do Continuing Survey of Food Intakes by Individuals de 1994 a 1996 (média = 63,6 pontos). Essa média permaneceu praticamente inalterada (63,8 pontos) quando o HEI foi novamente aplicado em dados norte-americanos mais recentes do National Health and Nutrition Examination Survey de 1999 a 2000 (BASIOTIS e col. 2002). Ao aplicar o HEI nos dados do Third National Health and Nutrition Examination Survey (NHANES III), GUO e colaboradores (2004) encontraram média de 63,2 pontos entre adultos de 20 a 75 anos. McCULLOUGH e colaboradores (2000a, 2000b) observaram valores médios do HEI de 64,4 pontos em mulheres e 68,3 pontos em homens, também pontuações superiores ao encontrado neste estudo. Os valores médios dos índices de qualidade da dieta dos estudos citados anteriormente se encontram entre 50 e 70 pontos, o que pode significar que em média as pessoas têm uma qualidade da dieta que necessita de modificações.

Estudos utilizando outros índices de qualidade da dieta também obtiveram resultados semelhantes aos citados anteriormente. KIM e colaboradores (2003), utilizando o Diet Quality Index-International (DQI-I), observaram que a qualidade da dieta na China e nos Estados Unidos alcançou cerca de $60 \%$ do escore máximo, 
corroborando com os resultados dos estudos citados anteriormente e que utilizaram o HEI.

O percentual de indivíduos com dieta saudável observado no presente estudo (4\%) foi inferior ao observado na literatura. Utilizando dados populacionais norteamericanos, BOWMAN e colaboradores (1998) encontraram um percentual de indivíduos com dieta saudável 3 vezes superior (12\%) e BASIOTIS e colaboradores (2002) e GUO e colaboradores (2004) obtiveram resultados cerca de 2 vezes maior $(10 \%)$ do que o obtido neste estudo.

Ao comparar as pontuações médias dos componentes do IQD obtidas nesse estudo com os dados da literatura, observou-se que houve semelhança com os escores dos componentes frutas, colesterol e variedade de alimentos (BOWMAN e col. 1998; BASIOTIS e col. 2002; RAFFERTY e col. 2002). BOWMAN e col. (1998) e BASIOTIS e col. (2002) obtiveram médias superiores para os componentes verduras e legumes (6,0 pontos em ambos), leite e produtos lácteos (5,4 e 5,9 pontos, respectivamente) e gordura total (6,9 pontos em ambos). Os resultados de RAFFERTY e colaboradores (2002) foram superiores para o componente leite e produtos lácteos (6,7 pontos) e gordura total ( 7,3 pontos) e inferiores para cereais (2,5 pontos) e verduras e legumes (3,8 pontos). As médias de pontos do componente carnes e ovos não pode ser comparado aos dados da literatura pois, neste estudo, as leguminosas fizeram parte de um componente em separado, diferentemente do HEI original.

A média de pontos do componente fruta foi semelhante aos resultados de estudos encontrados na literatura (KENNEDY e col. 1995; BOWMAN e col. 1998; BASIOTIS e col. 2002; RAFFERTY e col. 2002). Além da pontuação média para o consumo de frutas ter sido baixa (3,7 pontos), observa-se que $50 \%$ dos indivíduos deste estudo obtiveram pontuação próxima de zero, o que significa um consumo de praticamente nenhuma porção de fruta, em um dia, por metade da população de estudo. Deve-se destacar a importância do consumo adequado de frutas na prevenção de doenças. SLATTERY e colaboradores (1998) observaram que o padrão dietético caracterizado pela alta ingestão de carne vermelha, carne processada, fast food, grãos refinados e alimentos com açúcar e baixo consumo de hortaliças e frutas, denominado de dieta ocidental, aumentava o risco de câncer de cólon em homens e 
mulheres; enquanto que uma dieta considerada prudente, rica em hortaliças, grãos, frutas, pescados e aves, poderia auxiliar na prevenção do câncer de cólon. Estudo realizado por MARCHIONI (2003), a partir de dados do Município de São Paulo obtidos em estudo multicêntrico tipo caso-controle de base hospitalar, verificou que o padrão alimentar tradicional, composto por arroz, massas, feijão e carne, associouse inversamente ao câncer oral, enquanto que o padrão considerado monótono, caracterizado por pão, manteiga, embutidos, queijos, doces e sobremesas, associouse positivamente com a mesma doença. Estes dados sugerem que a dieta tradicional do brasileiro composta por arroz e feijåo, além do consumo de frutas, vegetais e quantidades moderadas de carnes, poderia proteger contra $o$ câncer oral, independente de fatores de risco conhecidos, como o fumo e o consumo alcoólico. A Organização Mundial da Saúde recomenda o consumo de pelo menos $400 \mathrm{~g}$ de frutas e hortaliças por dia para redução do risco de desenvolvimento de câncer pois evidências baseadas em estudos epidemiológicos sugerem que o risco de câncer de cavidade oral, esôfago e estômago pode ser diminuído através de uma alta ingestão de frutas e hortaliças (WHO 2003).

Em relação à doença coronariana, HU e WILLETT (2002) fizeram revisão de estudos metabólicos, epidemiológicos e ensaios clínicos sobre a relação entre dieta e doença coronariana e concluíram que as estratégias eficazes na prevenção da doença coronariana são: substituição da gordura saturada e ácidos graxos trans pela insaturada (principalmente polinsaturada); aumento do consumo de ácidos graxos ômega-3 provenientes de óleo de peixe e vegetais e consumo de uma dieta rica em frutas, hortaliças, nozes e grãos integrais e pobre em grãos refinados. Além da alimentação, atividade física regular, hábito de não fumar e manutenção de um peso corporal saudável são atitudes que podem prevenir esta doença. NESS e POWLES (1997), em revisão da literatura, verificaram forte efeito protetor do consumo de frutas e hortaliças sobre a ocorrência de acidente vascular cerebral.

No presente estudo, nota-se também consumo muito baixo de leite e produtos lácteos, já que a pontuação média alcançada equivale ao consumo de menos de uma porção deste grupo alimentar por dia, resultado bem inferior ao observado em outros estudos. A importância do consumo adequado de alimentos desse grupo deve-se ao fato de se constituírem alimentos fontes de cálcio. Esse micronutriente é um dos 
principais minerais para formação óssea e o suprimento adequado para o osso é essencial em todos os estágios da vida. Estudos em populações sobre a ingestão de cálcio sugerem que há aumento do risco de fratura do quadril com a diminuição da ingestão do nutriente. Esse risco parece estar aumentado também entre indivíduos com baixo consumo de leite e queijo, indicativo de baixa ingestão de cálcio. Assim, a ingestão adequada de cálcio a partir do consumo de leite e seus derivados, ou ainda de outras fontes como peixe com espinha comestivel, hortaliças verdes e leguminosas, é necessária para redução do risco de desenvolvimento de osteoporose e de suas complicações (WHO 2003; PRENTICE 2004).

É interessante destacar que a recomendação de consumo de leite e produtos lácteos é de 3 porçð̃es por dia, o que equivale a aproximadamente 3 copos de requeijåo de leite integral que fornecem cerca de $800 \mathrm{mg}$ de cálcio. Essa quantidade é inferior à recomendação de Ingestão Adequada (Adequate Intake - AI) estabelecida para cálcio, que varia de 1.000 - 19 a 50 anos - a $1.200 \mathrm{mg}$ - 51 anos e mais (INSTITUTE OF MEDICINE 2000). No Estudo Multicêntrico sobre Consumo Alimentar realizado em cinco municípios brasileiros (Campinas, Goiânia, Ouro Preto, Curitiba e Rio de Janeiro) já havia sido observada uma inadequação da disponibilidade de cálcio para todas as faixas de renda e idade, com exceção do Rio de Janeiro que apresentou adequação de $100 \%$ para a disponibilidade de cálcio na faixa de maior renda (GALEAZZI e col. 1997).

$\mathrm{O} I Q D$ avalia o consumo de alimentos e de alguns nutrientes. Essa abordagem pode facilitar o entendimento da população sobre onde o consumo alimentar está inadequado e onde há necessidade de melhora, já que o ser humano consome alimentos e não nutrientes. Outro ponto positivo no IQD é que ele avalia indiretamente a ingestão de outros nutrientes. Por exemplo, ao avaliar o consumo de frutas e hortaliças, a ingestão de vitaminas e minerais também está sendo avaliada; ao avaliar o consumo de leite e produtos lácteos, a ingestão de cálcio também está sendo verificada.

Assim, observou-se a correlação estatisticamente significativa do Índice de Qualidade da Dieta com outros nutrientes que não fazem parte diretamente de seu cálculo. As correlaçð̃es entre o IQD e os nutrientes, em seus valores brutos, foram semelhantes às observadas por KENNEDY e colaboradores (1995) para energia 
$(r=0,21)$, vitamina $E(r=0,15)$, fósforo $(r=0,14)$ e ferro $(r=0,21)$. Os resultados encontrados por HANN e colaboradores (2001) foram semelhantes apenas para fibra alimentar $(r=0,42)$, sendo que para folato $(r=0,46)$ e vitamina $C(r=0,53)$ as associações deste estudo foram mais fortes (respectivamente, coeficiente de correlação de 0,32 e 0,27). Já os resultados de WEINSTEIN e colaboradores (2004) foram semelhantes para colesterol $(r=0,29)$, ácido fólico $(r=0,29)$, vitamina $\mathrm{E}$ $(r=0,08)$ e vitamina $B 12(r=-0,03)$ nas correlações entre o IQD e a ingestão de nutrientes quando ajustadas pela ingestão total de energia. Apesar de KANT e colaboradores (2000) terem utilizado um índice baseado no número de alimentos consumidos de cada grupo alimentar, as correlaç̃es entre o Recommended Foods Score (RFS) e os nutrientes foram semelhantes ao encontrado no presente estudo para fibra alimentar $(r=0,45)$, vitamina $C(r=0,28)$ e vitamina $E(r=0,11)$.

Os resultados de ingestão de nutrientes segundo tercis do Índice de Qualidade da Dieta foram semelhantes aos encontrados por DREWNOWSKI e colaboradores (1997), com exceção dos achados de menor ingestão de sódio e de energia entre os indivíduos com altos escores (dieta saudável) do Diet Quality Index (DQI) em relação aos com pontuação zero (dieta ruim). Como esperado, é interessante observar que a ingestão de gordura (em percentual do total de energia da dieta) e de colesterol foi menor no tercil superior do que no inferior, já que podem ser considerados componentes da dieta promotores de doenças.

O Índice de Qualidade da Dieta não inclui em seus componentes a avaliação da ingestão de energia, porém é uma associação positiva esperada: uma pessoa que consome mais alimentos, conseqüentemente, ingere maior quantidade de energia $e$ tem maior chance de alcançar os valores recomendados de nutrientes, principalmente vitaminas e minerais. Por outro lado, a maior ingestão de energia pode acarretar uma tendência de ingestão excessiva de gordura total, gordura saturada, colesterol, açúcar, álcool e sódio, componentes da dieta que podem ser prejudiciais à saúde se consumidos em excesso. Por isso decidiu-se incluir a ingestão de energia como variável independente na análise de regressão linear. Os resultados desse estudo demonstraram que a ingestão de energia apresentou correlação positiva com o IQD, independente de idade, escolaridade do chefe da família e do número de bens de consumo duráveis, resultado semelhante ao encontrado por THIELE e colaboradores 
(2004). KENNEDY e colaboradores (2001) avaliaram associaçðes entre indicadores de saúde e nutrição e dietas populares e encontraram que a ingestão de energia foi maior entre os indivíduos que consumiam uma dieta baseada nas recomendações da Pirâmide Alimentar Americana do que entre os que tinham uma dieta que não seguia o recomendado. O grupo com dieta baseada na Pirâmide Alimentar relatou nível de atividade física maior do que o outro e, por isso, deve ter sido capaz de equilibrar o consumo alimentar com o gasto energético (KENNEDY e col. 2001). Apesar desses fatos, o efeito independente que a ingestão de energia impôs ao IQD no presente estudo foi pequeno $(\beta=0,003)$. Portanto, provavelmente nesse estudo a ingestão de energia não estaria relacionada com a promoção de doença.

Os resultados do presente estudo demonstraram que a qualidade da dieta variou significativamente de acordo com as características demográficas de sexo e faixa etária. Estes resultados são semelhantes aos relatados por BOWMAN e colaboradores (1998) e BASIOTIS e colaboradores (2002), os quais verificaram média superior do Healthy Eating Index entre mulheres do que entre homens e nos indivíduos com idade superior a 50 anos do que nos adultos com idade inferior. GUO e colaboradores (2004), analisando os dados do Third National Health and Nutrition Examination Survey (NHANES III), encontraram que indivíduos do sexo feminino e com mais de 60 anos têm media do HEI maior do que os adultos do sexo masculino e com idade inferior a 60 anos, respectivamente. Estudo que aplicou o Michigan Healthy Diet Indicator - MI-HDI (índice de qualidade da dieta baseado no HEI) em dados do Michigan "Behavioral Risk Factor Surveillance System" observou que a média do MI-HDI foi estatisticamente maior entre mulheres $(58,8$ pontos) do que entre homens (52,3 pontos) e aumentou de acordo com a idade (RAFFERTY e col. 2002). A influência da idade sobre a qualidade da dieta pode refletir uma mudança de consciência sobre a saúde com o aumento da idade, influenciando diretamente nas escolhas alimentares por este grupo etário, ou a manutenção dos hábitos devido à menor exposição ao ambiente. Deste modo, pode ser que as políticas de promoção de um estilo de vida saudável possam ser direcionadas mais para a população jovem do que para a idosa.

Quanto à etnia, relatou-se na literatura que negros tiveram menor média dos índices de qualidade da dieta utilizados do que brancos (BOWMAN e col. 1998, 
BASIOTIS e col. 2002, RAFFERTY e col. 2002, GUO e col. 2004), resultado não observado no presente estudo, provavelmente devido à dificuldade do brasileiro em se autoclassificar etnicamente.

GUO e colaboradores (2004) encontraram diferenças nas médias de HEI segundo características de estilo de vida. Indivíduos que relataram praticar exercício 3 ou mais vezes por semana tiveram média maior do que os que não praticavam nada ou que o faziam até 3 vezes por semana. Observou-se também que fumantes tiveram média do índice menor que não fumantes (58,6 e 65,2 pontos, respectivamente). Ao contrário do observado na literatura, as associações entre o Índice de Qualidade da Dieta e atividade física e hábito de fumar não foram observadas neste estudo.

Em relação às características socioeconômicas, os resultados do presente estudo demonstraram que a qualidade da dieta melhora de acordo com o aumento do nível de escolaridade, tanto do individuo quanto do chefe da família, e melhora das condiçð̃es socioeconômicas (número de bens de consumo e renda per capita). Resultados semelhantes foram relatados por BOWMAN e colaboradores (1998), BASIOTIS e colaboradores (2002) e GUO e colaboradores (2004), que observaram o aumento do HEI de acordo com os níveis de escolaridade e renda. RAFFERTY e colaboradores (2002) encontraram que o índice de qualidade da dieta MI-HDI obteve média maior entre os indivíduos com nível superior completo do que entre os com menor escolaridade, mas não observou diferenças estatisticamente significativas entre as categorias de renda familiar. THIELE e colaboradores (2004) também verificaram que mulheres com alto nível de escolaridade e homens com escolaridade intermediária possuem altos escores do índice de qualidade da dieta. Utilizando dados do 1994-1996 Continuing Survey of Food Intake by Individuals e Diet and Health Knowledge Survey de indivíduos adultos, PÉREZ-ESCAMILLA e HALDEMAN (2002) também observaram que a educaçăo formal estava positivamente associada à qualidade da dieta, medida pelo $\mathrm{HEI}$.

Segundo POPKIN e colaboradores (2003), o mecanismo pelo qual o maior nível de escolaridade promove dietas saudáveis não foi completamente elucidado, mas pode ser causado pela difusão de conhecimento, experiências, atitudes e crenças que ocorre enquanto as pessoas estão no sistema educacional. Assim, indivíduos com escolaridade mais elevada tendem a possuir maior conhecimento para aquisição de 
alimentos, aumentando a variedade da dieta através do consumo de, principalmente, mais frutas e hortaliças e, conseqüentemente, aumentando a pontuação do Índice de Qualidade da Dieta. O impacto da escolaridade do chefe da família sobre a capacidade de escolha dos alimentos foi encontrado por FISBERG e colaboradores (2004b) em estudo que utilizou os dados de consumo alimentar do "Inquérito de Saúde do Estado de São Paulo - ISA-SP”, o que incluía parte da região da Grande São Paulo, distrito do Butantã e os municípios de Campinas e Botucatu. Observou-se o aumento das médias de escores de verduras e legumes, frutas, leite e produtos lácteos e variedade de alimentos conforme aumento da escolaridade do chefe da família. Para o grupo das leguminosas foi encontrada situação inversa: a categoria de maior escolaridade do chefe da família possuía a menor média de pontos para esse componente. Provavelmente, na população de menor renda, o hábito alimentar tradicional brasileiro composto por arroz e feijão, esteja mantido devido ao fácil acesso a estes alimentos (boa disponibilidade e baixo custo). A combinação de arroz e feijão é benéfica ao organismo principalmente quanto ao fornecimento dos aminoácidos essenciais.

Durante a modelagem múltipla, observou-se que a variável escolaridade do chefe da família teve um efeito importante sobre o IQD, podendo assim ser considerada uma variável indicadora da condição socioeconômica do indivíduo ou da família. $O$ uso deste indicador tem se destacado devido à facilidade de coleta e relativa precisão, o que permite uma classificação satisfatória das condições de vida de populações. CESAR (2004), ao analisar as condições de vida do estudo "Inquérito de Saúde do Estado de São Paulo - ISA-SP" verificou que o grau de escolaridade do chefe de família mostrou-se um bom indicador da condição de vida descrita em suas diferentes dimensões. Os chefes de família de baixa escolaridade caracterizaram-se por serem indivíduos mais velhos, do sexo feminino, sendo que estas duas condições, na realidade brasileira, significam, em geral, menor disponibilidade financeira decorrentes de proventos de aposentadorias ou pensões e de menores salários. Os chefes de família de menor escolaridade em grande parte eram migrantes de regiões mais pobres do país, com grande proporção excluída da população economicamente ativa, moradores de habitaçð̃es e entornos inadequados e com menor consumo de bens duráveis. Assim, a maior facilidade de obtenção da escolaridade do chefe de 
família, a boa precisão da informação e a sua associação com aspectos importantes das condições de vida, indicam o seu uso em inquéritos de saúde.

Os resultados encontrados por RAFFERTY e colaboradores (2002) na análise univariada foram confirmados na análise de regressão múltipla. $\mathrm{O}$ índice MI-HDI tendeu a aumentar com idade e educação, ser maior entre mulheres do que entre homens e maior entre brancos do que negros. Estudo de THIELE e colaboradores (2004) observou, através de análise múltipla, que uma dieta saudável estava positivamente associada à renda, escolaridade, idade, ingestão de energia, variedade de alimentos, atividade física e vegetarianismo. Neste estudo foram criados dois índices de qualidade da dieta opostos: um deles combinou nutrientes considerados "protetores", ou seja, que podem ser consumidos em quantidades acima da recomendação (vitaminas, minerais, proteína, carboidrato, dois ácidos graxos essenciais e fibra alimentar) e o outro combinou nutrientes considerados "promotores" de doenças, ou seja, que devem ser consumidos em quantidades moderadas (gordura, colesterol, razão entre gordura saturada e insaturada, açúcar, álcool, sódio).

Após estratificação do modelo final de regressão por sexo, apenas a ingestão de energia da dieta e ter idade de 60 anos ou mais foram as variáveis que se mantiveram estatisticamente significativas paras as mulheres. Para os homens, todas as variáveis do modelo múltiplo final mantiveram sua significância estatística. A escolaridade do chefe da família manteve efeito significativo sobre o IQD de homens porque aproximadamente $70 \%$ dos chefes de família da população de estudo eram do sexo masculino. Esta proporção é consistente com a PNAD, na qual $67 \%$ da população de referência da região metropolitana de São Paulo era do sexo masculino (IBGE 2004).

É interessante observar que o efeito da ingestão de energia e da idade são maiores em mulheres do que em homens. Para cada 1 quilocaloria ingerida o efeito no Índice de Qualidade da Dieta de mulheres é 2 vezes maior do que nos homens e ter 60 anos ou mais impre um efeito 0,5 ponto a mais nas mulheres do que nos homens.

As variáveis ingestão de energia, escolaridade do chefe da família, quantidade de bens de consumo duráveis e faixa etária explicaram pouco da variabilidade do 
Índice de Qualidade da Dieta. Durante a modelagem a adição de outras variáveis não melhorou o coeficiente de determinação do modelo. Outros estudos encontrados na literatura obtiveram percentual de explicação da qualidade da dieta semelhante ao desse estudo. Isto pode estar ocorrendo devido à dieta ser influenciada por muitos fatores, desde biológicos até psicológicos.

Salienta-se que os resultados deste estudo são baseados em um estudo transversal. Porém, os padrões de escolha dos alimentos pela população podem sofrer alteraçð̃es com o passar dos anos. Entretanto, a amostra desse estudo foi representativa da população adulta do distrito do Butantã e de parte da região sudoeste da Grande São Paulo, refletindo tendências gerais na região metropolitana de São Paulo. Estas análises podem ser uma etapa inicial para determinar os grupos da população com qualidade da dieta inadequada.

A avaliação do consumo alimentar de populações tem sido realizada tradicionalmente com foco sob a ingestão de energia e a composição de nutrientes da dieta. Entretanto, análises baseadas em alimentos estão se tornando mais freqüentes e assumindo lugar de destaque na pesquisa em nutrição através do surgimento de vários índices que unem diversos aspectos dietéticos em uma só medida, como o Healthy Eating Index (KENNEDY e col. 1995), o Diet Quality Index (PATTERSON e col. 1994) e o Índice de Qualidade da Dieta (FISBERG e col. 2004a).

Para estudos epidemiológicos sobre a relação entre dieta e doença, a medida da qualidade da dieta deve ser considerada como uma boa alternativa que captura a natureza multidimensional de diversas variáveis dietéticas (KANT 1996). HANN e col. (2001) consideram que a utilização desse tipo de índice melhor do que o a avaliação da ingestão de um único nutriente ajustada pelo total de energia da dieta. Assim, a utilização de medidas que resumem vários aspectos da dieta, como o Índice de Qualidade da Dieta, parece ser útil em estudos populacionais. Estudos de correlação do HEI com marcadores bioquímicos têm sido conduzidos e têm obtido resultados positivos, mostrando que as escolhas alimentares baseadas em um guia alimentar levam a uma dieta saudável (HANN e col. 2001; WEINSTEIN e col. 2004).

O Índice de Qualidade da Dieta é uma medida resumo da qualidade da dieta baseada em alimentos e nutrientes. Entretanto as escolhas alimentares são 
freqüentemente influenciadas por diversas variáveis, como idade, sexo, etnia, escolaridade e renda. Por exemplo, embora o consumo de pães seja amplamente distribuído através de todos os grupos de renda, consumo de frutas não é (FISBERG e col. 2004b). Como resultado disso, alguns componentes do IQD podem ser mais sensíveis do que outros a fatores socioeconômicos da escolha de alimentos. Desta forma, um próximo passo seria verificar quais são os fatores associados a cada um dos componentes do Índice de Qualidade da Dieta.

Os resultados deste estudo sugerem que condição socioeconômica (representada pela escolaridade do chefe da família e pelo número de bens de consumo duráveis) e faixa etária são fatores que podem ser utilizados para direcionar os esforços em atividades de promoção da saúde e de uma alimentação saudável. São necessárias Políticas Públicas em Alimentação e Nutrição para atingir toda a população, mas principalmente direcionadas para adultos jovens, de menor renda e residentes em famílias com chefes de baixa escolaridade. Deve se ter atenção especial na orientação sobre o aumento do consumo de frutas, hortaliças, leite e produtos lácteos. Campanhas educativas de incentivo para a elaboração de hortas comunitárias e aumento do consumo de alimentos da estação, que geralmente têm custo mais baixo, são algumas ações que podem ser realizadas para melhorar a disponibilidade de alimentos para toda a população, permitindo que as pessoas coloquem as orientaç̃̃es obtidas sobre uma dieta saudável em prática. 


\section{CONCLUSÕES}


* A média do Índice de Qualidade da Dieta foi de 60 pontos, indicando uma dieta que necessita de melhora.

* As médias para a pontuação dos componentes do Índice de Qualidade da Dieta apresentaram-se baixas para verduras e legumes, leite e produtos lácteos e frutas e elevadas para os componentes carnes e ovos e colesterol.

* Quanto maior a ingestão de energia ou maior o número de bens de consumo duráveis ou maior a escolaridade do chefe da familia, maior é o Índice de Qualidade da Dieta. Indivíduos na faixa etária de 60 anos ou mais têm um Índice de Qualidade da Dieta maior do que os adultos com menos de 60 anos, independente da ingestão de energia, da escolaridade do chefe da família e do número de bens de consumo duráveis.

* A estratificação do modelo final de regressão segundo sexo resultou em diferenças entre homens e mulheres. Para os indivíduos do sexo masculino todas as variáveis do modelo final se mantiveram significativas, enquanto que para os do sexo feminino apenas a ingestão de energia e a faixa etária mantêm efeito significativo sobre a sua qualidade da dieta. 


\section{REFERÊNCIAS}


1. Alves MCGP. Técnicas de replicação em análise de dados de inquéritos domiciliares. São Paulo; 2002 [Tese de Doutorado - Faculdade de Saúde Pública da USP].

2. Basiotis PP, Carlson A, Gerrior SA, Juan WY, Lino M. The Healthy Eating Index: 1999-2000. U.S. Department of Agriculture, Center for Nutrition Policy and Promotion. 2002.

3. Bowman SA, Lino M. Gerrior SA, Basiotis PP. The Healthy Eating Index: 1994-96. U.S. Department of Agriculture, Center for Nutrition Policy and Promotion. 1998.

4. Caballero B, Rubinstein S. Environmental factors affecting nutritional status in urban areas of developing countries. Arch Latinoamer Nutr 1997; 47 (2 supl 1): $3-8$.

5. Cesar CLG, Figueiredo GM, Westphal MF, Cardoso MRA, Costa MZA, Gattás VL. Morbidade referida e utilização de serviços de saúde em localidades urbanas brasileiras: metodologia. Rev Saúde Pública 1996; 30 (2): 153-160.

6. Cesar CLG. Condição de vida da população estudada. In: Saúde e condição de vida em São Paulo: Inquérito Multicêntrico no Estado de São Paulo (ISASP). 2004 (no prelo).

7. Drewnowski A, Henderson SA, Driscoll A, Rolls BJ. The Dietary Variety Score: assessing diet quality in healthy young and older adults. J Am Diet Assoc 1997; 97:266-271.

8. Drewnowski A, Popkin BM. The nutrition transition: new trends in the global diet. Nutr Rev 1997; 55 (2): 31-43.

9. Fisberg RM, Slater B, Barros RR, Lima FD, Carandina L, Barros MBA, Goldbaum M, César CLG. Índice de qualidade da dieta IQD: avaliação e aplicabilidade. Rev Nutr 2004a; 17(4): 301-308.

10. Fisberg RM, Slater B, Morimoto JM, Bueno MB. Índice de Qualidade da Dieta. In: Saúde e condição de vida em São Paulo: Inquérito Multicêntrico no Estado de São Paulo (ISA-SP). 2004b (no prelo). 
11. Fisberg RM, Villar BS. Manual de Receitas e Medidas Caseiras para Cálculo de Inquéritos Alimentares: manual elaborado para auxiliar o processamento de inquéritos alimentares. São Paulo: Signus Ed.; 2002.

12. Fundação SEADE (Sistema Estadual de Análise de Dados). Informações dos municípios paulistas [online]. 2004. Disponível em URL: http://www.seade.gov.br [2004 set 29].

13. Galeazzi MAM, Domene SMA, Sichieri R (org.). Estudo Multicêntrico sobre consumo alimentar. Cadernos de Debate 1997; volume especial. 62p.

14. Guenther PM, Kott PS, Carriquiry AL. Development of an approach for estimating usual nutrient intake distributions at the population level. J Nutr 1997; 127: 1106-1112.

15. Guo X, Warden BA, Paeratakul S, Bray GA. Healthy Eating Index and obesity. Eur J Clin Nutr advance online publication, 19 may 2004; 1-7.

16. Haines PS, Siega-Riz AM, Popkin BM. The Diet Quality Index Revised: a measurement instrument for populations. J Am Diet Assoc 1999; 99: 697-704.

17. Hann CS, Rock CL, King I, Drewnowski A. Validation of the Healthy Eating Index with use of plasma biomarkers in a clinical sample of women. Am J Clin Nutr 2001; 74: 479-486.

18. Hu FB, Willett WC. Optimal diets for prevention of coronary heart disease. JAMA 2002; 288 (20): 2569-2578.

19. Institute of Medicine. Dietary Reference Intakes. Applications in Dietary Assessment. Washington, DC: National Academy Press; 2000.

20. Institute of Medicine. Dietary Reference Intakes for Energy, Carbohydrates, Fiber, Fat, Protein, and Amino Acids (macronutrients). Washington, DC: National Academy Press; 2002.

21. Instituto Brasileiro de Geografia e Estatística (IBGE). Síntese de Indicadores Sociais 2003. Estudos \& Pesquisas. Informação Demográfica e Socioeconômica, número 12. Rio de Janeiro; 2004. 
22. Instituto Nacional de Câncer (INCA). Secretaria de Vigilância em Saúde (SVS), Ministério da Saúde (MS). Inquérito Domiciliar sobre Comportamentos de Risco e Morbidade Referida de Doenças e Agravos Não Transmissíveis. Rio de Janeiro; 2003.

23. Kant AK, Schatzkin A, Graubard BI, Schairer C. A prospective study of diet quality and mortality in women. JAMA 2000, 283 (16): 2109-2115.

24. Kant AK. Indexes of overall diet quality: a review. J Am Diet Assoc 1996; 96 : 785-791.

25. Kennedy ET, Bowman SA, Spence JT, Freedman M, King J. Popular diets: correlation to health, nutrition, and obesity. J Am Diet Assoc 2001; 101: 411420.

26. Kennedy ET, Ohls J, Carlson S, Fleming K. The Healthy Eating Index: design and applications. J Am Diet Assoc 1995; 95:1103-1108.

27. Kim S, Haines PS, Siega-Riz AM, Popkin BM. The Diet Quality IndexInternational (DQI-I) provides an effective tool for cross-national comparison of diet quality as illustrated by China and the United States. J Nutr 2003; 133 : 3476-3484.

28. Lee RD, Nieman DC. Standards for nutrient intake. In: Nutritional Assessment. $3^{\text {rd }}$ ed. Mc Graw Hill. 2003. p. 12-72

29. Lustosa TQ de O. Para que servem os dados sobre consumo alimentar? In: Consumo alimentar: as grandes bases de informação: simpósio. São Paulo: Instituto Danone, 2000. 53-61.

30. Majem LIS, Bartrina JA. Introducción a la epidemiología nutricional. In: Majem LIS, Bartrina JA, Verdú MJ. Nutrición y Salud Publica: métodos, bases científicas y aplicaciones. España: Masson S.A. 1995. p.59-65.

31. Marchioni DML. Fatores dietéticos e câncer oral: um estudo caso-controle na regiåo metropolitana de São Paulo. São Paulo; 2003 [Tese de Doutorado Faculdade de Saúde Pública da USP]. 
32. McCullough ML, Feskanich D, Rimm EB, Giovannucci EL, Ascherio A, Variyam JN, Spiegelman D, Stampfer MJ, Willett WC. Adherence to the Dietary Guidelines for Americans and risk of major chronic disease in men. Am J Clin Nutr 2000a; 72: 1223-1231.

33. McCullough ML, Feskanich D, Stampfer MJ, Rosner BA, Hu FB, Hunter DJ, Variyam JN, Colditz GA, Willett WC. Adherence to the Dietary Guidelines for Americans and risk of major chronic disease in women. Am J Clin Nutr 2000b; 72: 1214-1222.

34. Mertz W. Foods and nutrients. J Am Diet Assoc 1984; 84: 769-770.

35. Mondini L, Monteiro CA. Mudanças no padrão de alimentação. In: Monteiro CA (organizador). Velhos e novos males da saúde no Brasil. São Paulo: Editora HUCITEC NUPENS/USP. 1995. p.79-89.

36. Monteiro CA, Mondini L, Costa RBL. Mudanças na composição e adequação nutricional da dieta familiar nas áreas metropolitanas do Brasil (1988-1996). Rev Saúde Pública 2000; 34(3): 251-258.

37. Murphy SP, Rose D, Hudes M, Viteri FE. Demographic and economic factors associated with dietary quality for adults in the 1987-88 Natiowide Food Consumption Survey. J Am Diet Assoc 1992; 92: 1352-1357.

38. National Research Council (NRC). Committee on Diet and Health, Food And Nutrition Board, Commission on Life Sciences. Diet and Health: Implications for Reducing Chronic Disease Risk. Washington, DC: National Academy Press. 1989.

39. Ness AR, Powles JW. Fruit and vegetables, and cardiovascular disease: a review. Int J Epidemiol 1997; 26(1): 1-13.

40. Patterson RE, Haines PS, Popkin BM. Diet Quality Index: capturing a multidimensional behavior. J Am Diet Assoc 1994; 94:57-64.

41. Pereira MG. Epidemiologia: Teoria e Prática. Rio de Janeiro: Guanabara Koogan; 2002. 
42. Pérez-Escamilla R, Haldeman L. Food label use modifies association of income with dietary quality. J Nutr 2002; 132: 768-772.

43. Philippi ST, Latterza AR, Cruz ATR, Ribeiro LC. Pirâmide alimentar adaptada: guia para escolha dos alimentos. Rev Nutr 1999; 12(1): 65-80.

44. Philippi ST, Szarfarc SC, Latterza AR. Virtual Nutri [software]. Versão 1.0 for Windows. São Paulo: Departamento de Nutrição, Faculdade de Saúde Pública, Universidade de São Paulo; 1996.

45. Philippi ST. Tabela de Composição Química de Alimentos: suporte para decisão nutricional. Brasília: ANVISA, FINATEC/NUT - UnB; 2001

46. Pinheiro ABV, Lacerda EM de A, Benzecry EH, Gomes MC da S, Costa, VM da. Tabela para Avaliação de Consumo Alimentar em Medidas Caseiras. $4^{a}$ ed. São Paulo: Ed. Atheneu; 2000.

47. Popkin BM, Zizza C, Siega-Riz AM. Who is leading the change? U.S. dietary quality comparison between 1965 and 1996. Am J Prev Med 2003; 25(1): 1-8.

48. Popkin BM. Nutritional patterns and transitions. Population and Development Review 1993; 19(1): 138-157.

49. Prentice A. Diet Nutrition and the prevention of osteoporosis. Public Health Nutr 2004; 7(1A): 227-243.

50. Rafferty AP, Anderson JV, McGee HB, Miller CE. A Healthy Diet Indicator: quantifying compliance with the dietary guidelines using the BRFSS. Prev Med 2002; 35: 9-15.

51. Roos E, Prättălå R, Lahelma E, Kleemola P, Pietinen. Modern and healthy?: Socioeconomic differences in the quality of diet. Eur J Clin Nutr 1996; 50: 753760 .

52. Silva EN. Pesquisa de orçamentos familiares. Características gerais. In: Consumo alimentar: as grandes bases de informação: simpósio. São Paulo: Instituto Danone, 2000. 39-45.

53. Slattery ML, Boucher KM, Caan BJ, Potter JD, Ma KN. Eating patterns and risk of colon cancer. Am J Epidemiol 1998; 148:4-16. 
54. Souci SW, Farchman W, Kraut. Food composition and nutrition tables. 5a ed. Stutgard: Medpharm Scientific Publishers - Boca Raton, Ann Arbor, London, Tokio: CRC Press; 1994.

55. Stookey JD, Wang Y, Ge K, Lin H, Popkin BM. Measuring diet quality in China: the INFH-UNC-CH Diet Quality Index. Eur J Clin Nutr 2000; 54: 811-821.

56. Thiele S, Mensink GBM, Beitz R. Determinants of diet quality. Public Health Nutr $2004 ; 7(1): 29-37$.

57. Thompson FE, Byers T. Dietary assessment resource manual. J Nutr 1994; 124 (Suppl): 2245-2317.

58. United States Department of Agriculture (USDA). Agricultural Research Service. Report of the Dietary Guidelines Advisory Committee on the Dietary Guidelines for Americans. Washington: USDA/ Agricultural Research Service. 1995.

59. United States Department of Agriculture (USDA). Agricultural Research Service. USDA National Nutrient Database for Standard Reference, Release 16. [tabela de composição de alimentos] 2003; Disponível em <URL: http://www.nal.usda.gov/fnic/foodcomp> [2004 jan 28].

60. Variyam JN, Blaylock J, Smallwood D, Basiostis PP. USDA's Healthy Eating Index and Nutrition Information. Washington: United States Department of Agriculture/ Economic Research Service; 1998. (Technical Bulletin $n^{\circ} 1866$ ).

61. Vasconcellos $M$ de. Caracterização geral e principais aspectos metodológicos do Estudo Nacional da Despesa Familiar - ENDEF. In: Consumo alimentar: as grandes bases de informação: simpósio. São Paulo: Instituto Danone, 2000. 1930.

62. Weinstein SJ, Vogt TM, Gerrior SA. Healthy Eating Index scores are associated with blood nutrient concentrations in the Third National Health and Nutrition Examination Survey. J Am Diet Assoc 2004; 104: 576-584.

63. Willett WC, Stampfer MJ. Total energy intake: implications for epidemiologic analyses. Am J Epidemiol 1986; 124: 17-27. 
64. Willett WC. Nutritional Epidemiology. $2^{\mathrm{a}}$ ed. New York: Oxford University Press. 1998.

65. World Health Organization (WHO). Joint WHO/FAO Expert Concultation on Diet, Nutrition and the Prevention of Chronic Diseases. Diet, nutrition and the prevention of chronic diseases. Geneva; 2003. (WHO Technical Report Series, 916).

66. World Health Organization (WHO). Report of a WHO Consultation on Obesity. Obesity: preventing and managing the global epidemic. Geneva; 2000. (WHO Technical Report Series, 894).

67. Yates AA, Schlicker SA, Siutor CW. Dietary reference intakes: the new basis for recommendations for calcium and related nutrients, B vitamins, and choline. $\mathbf{J}$ Am Diet Assoc 1998; 98: 699-706. 
ANEXOS 
ANEXO 1 - QUESTIONÁRIO DA PESQUISA "INQUÉRITO DE SAÚDE DO ESTADO DE SATO PAULO". 


\section{Inquérito de Saúde no Estado de São Paulo}

USP, UNICAMP, UNESP E SES-SP

\section{RELAÇÄO DOS MORADORES DOS DOMICÍLIOS SORTEADOS}

BLOCO A

Telefone: $\begin{array}{lll}\text { visita data hora } & \begin{array}{l}\text { nome do } \\ \text { entrevistador }\end{array}\end{array}$

$\begin{array}{ll}1 & 1 \\ 2 & 1 \\ 3 & 1\end{array}$

A 08. Nümero de visitas realizadas:

A 09. Código do entrevistador: A 10. Data da realização da entrevista:

A 07 .

resultado da visita
1. realizada

2. não pertence à população em estudo 3. número inexistente

4. domicilio fechado

5. domicilio de uso ocasional

6. recusa

7. domicilio vago

8. outros, especificar

Obs 
A 11. Tipo de domicilio:

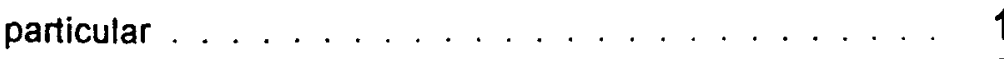

coletivo

A 12. Número de familias no domicílio:

\section{Quadro de moradores no domicilio:}

\begin{tabular}{|c|c|c|c|c|c|c|c|}
\hline & $n^{\circ}$. & nome & $\begin{array}{l}\text { relação com } \\
\text { o chefe da } \\
\text { familia }\end{array}$ & sexo & idade & sorteio & $\begin{array}{l}n^{0} \text { de } \\
\text { ordem }\end{array}$ \\
\hline A 13a. & 1 & & Chefe 1 & & & & \\
\hline A 13b. & 2 & & & & & & \\
\hline A 13c. & 3 & & & & & & \\
\hline A 13d. & 4 & & & & & & \\
\hline$A 13 e$. & 5 & 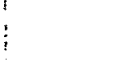 & & & & & \\
\hline A 13f. & 6 & & & & & & \\
\hline$A$ 13g. & 7 & & & & & & \\
\hline A 13h. & 8 & & & & 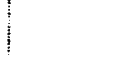 & & \\
\hline A 13i. & 9 & & & & & & \\
\hline$A$ 13j. & 10 & & & & & & \\
\hline$A 13 k$. & 11 & & & & & & \\
\hline A 131. & 12 & & & & & & \\
\hline A $13 \mathrm{~m}$. & 13 & & & & & & \\
\hline A 13n. & 14 & & & & & & \\
\hline A 13o. & 15 & & & & & & \\
\hline A 13p. & 16 & & & & & & \\
\hline A 13q. & 17 & & & & & & \\
\hline$A 13 r$. & 18 & & & & & & \\
\hline A $13 s$. & 19 & & & & & & \\
\hline
\end{tabular}

A 13t. $\quad 20$

2. cónjuge
3. filho ou enteado
4. outro parente
5. agregado
6. pensionista
7. empregado
doméstico
8. parente do
empregado
9. outro

1. masc anos

2. fem. completos anotar quando

forem meses para menores de 1 ano

\section{marque}

com

um X o moradorque foi sorteado 


\section{Inquérito de Saúde no Estado de São Paulo}

\section{FOLHA DE CONTROLE}

BLOCO B

B 01. Número do questionário: .

Municipio:

B 02. Setor:

End.:

$N^{\circ}:$ Compl:

Bairro:

Quarteirão:

Tel:

Nome completo do selecionado:

B 03. Número do domicilio:

B 05. Data de nascimento:

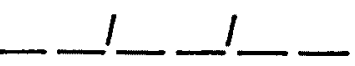

branca ... 1

preta .... 2

parda .... 3

amarela .. 4

indigena .. 5

NS/NR ... 9
B 04. Número de ordem do entrevistado:

B 06. Sexo: masculino $\ldots \ldots \ldots \ldots \ldots 1$

feminino

2

B 08. Qual é a sua religião ou culto?

\begin{tabular}{|c|c|}
\hline & $:$ \\
\hline $\begin{array}{l}\text { B 09. resultado } \\
\text { da visita }\end{array}$ & \multirow{4}{*}{$\begin{array}{l}\text { 1. realizada } \\
\text { 2. adiada } \\
3 \text { morador ausente } \\
4 \text { recusa total } \\
5 \text { recusa parcial } \\
6\end{array}$} \\
\hline & \\
\hline & \\
\hline & \\
\hline
\end{tabular}

B $10 . N^{\circ}$. de visitas realizadas:

B 11. Horário da entrevista: inicio: tèrmino:

B 12. Código do entrevistador:

B 13. Data da realização da entrevista:

o próprio / o responsável... 1

outro .............. 2

Observaçōes: 


\section{MORBIDADE DE 15 DIAS}

BLOCOI

C 01. O(a) sr.(a) teve algum problema de saúde, nos últimos quinze dias?

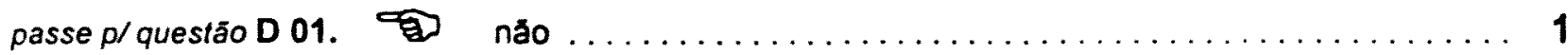

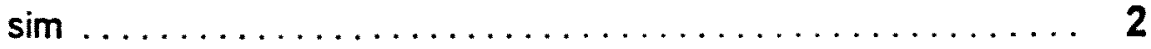

NS/NR

Qual(is) foi(ram)?

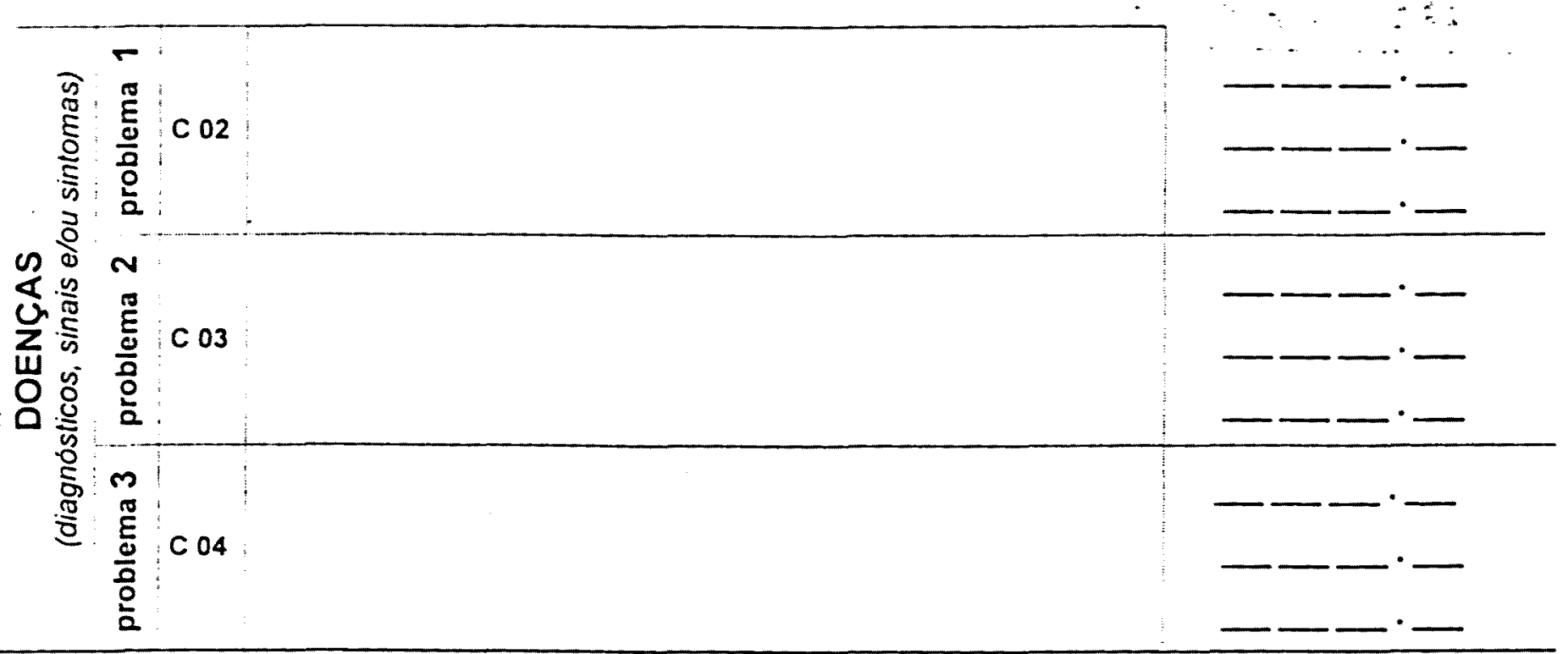

Que lesão o(a) sr.(a) teve?

C 05a

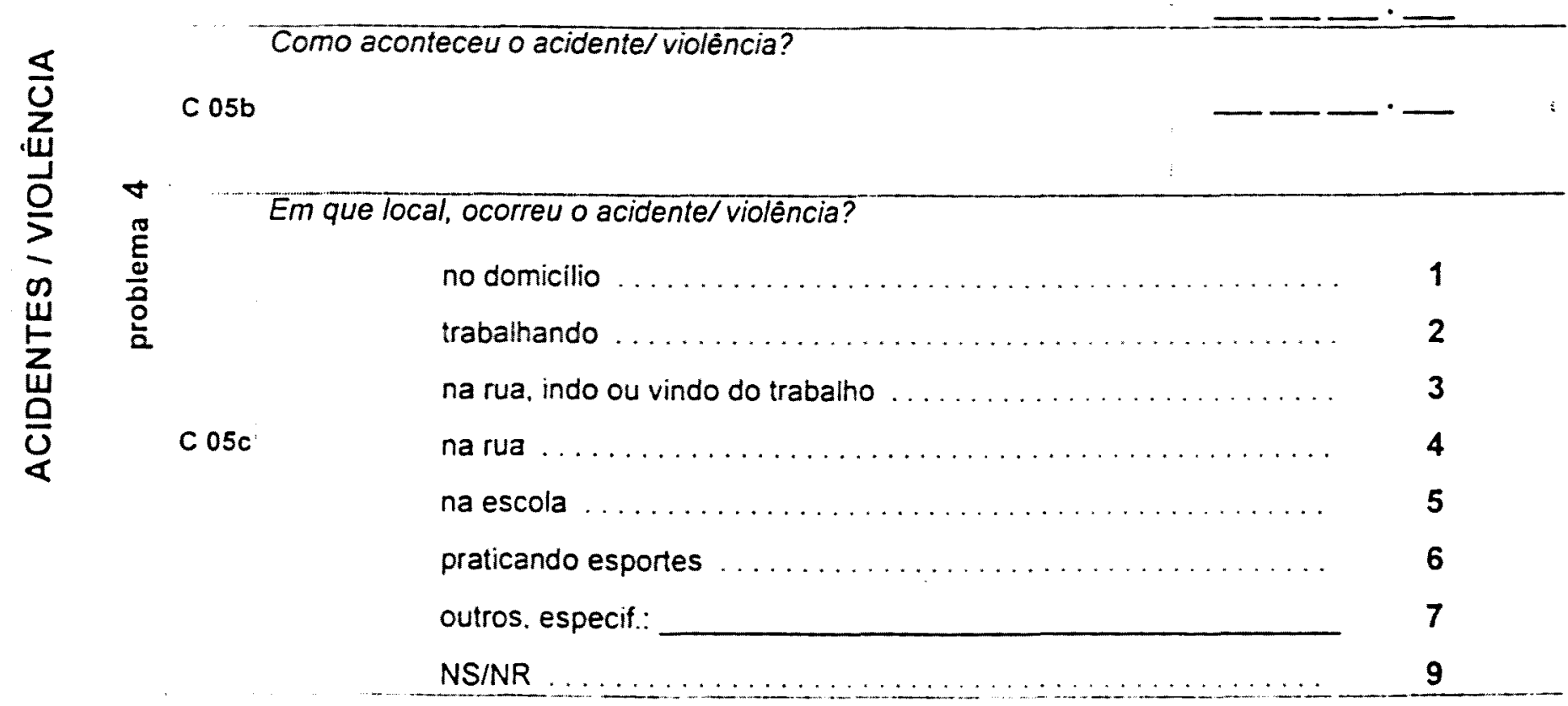

Se o entrevistado NĀO referiu nenhum problema de saúde nos últimos 15 dias, ENCERRE O BLOCO e passe para o BLOCO D.

Se o entrevistado referiu algum problema de saude nos últimos 15 dias, passe para o BLOCO C _ . Preencha um BLOCO C _. para cada problema referido. 
fo PARA TODAS AS PESSOAS COM 12 ANOS OU MAIS.

\section{HÁBITO ALIMENTAR}

L 02. Qual a sua altura?

m. e cm.

NS/NR $9 / 99$

L 03. Qual o seu peso?

Kg. e

NS/NR gr.

$999 / 999$

L 04. Gostaria que seu peso fosse diferente do atual?

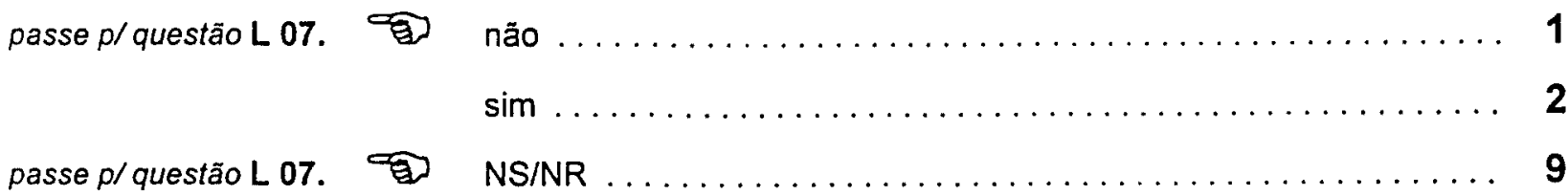

L 05. Quanto o(a) sr.(a) gostaria de pesar?

se desejar aumentar o peso - passe p/ questão L 07.

? Kg. e gr.

NS/NR

L 06. O(a) sr.(a) faz alguma coisa para emagrecer? Pode haver mais de uma resposta

não

tenho cuidado com o que vou comer 02

sigo uma dieta 03

pratico exercicios 04

pulo refeições 05

participo de programa de perda de peso 06

fumo 07

uso medicamento, especif: 08

outros, especif.: 09 


\title{
L 08. RECORDATÓRIO DE 24 HORAS
}

Nome:

\author{
Sexo masculino \\ feminino
}

Data de nasc:: Data da entrevista:

Dia da semana do recordatório:

Anote a refeição, o local onde foi realizada e os alimentos e ou preparaçōes (ingredientes) consumidos no dia anterior. Anote as marcas comerciais, medidas caseiras, utensilios (tipo de colher, copo, prato, etc.).

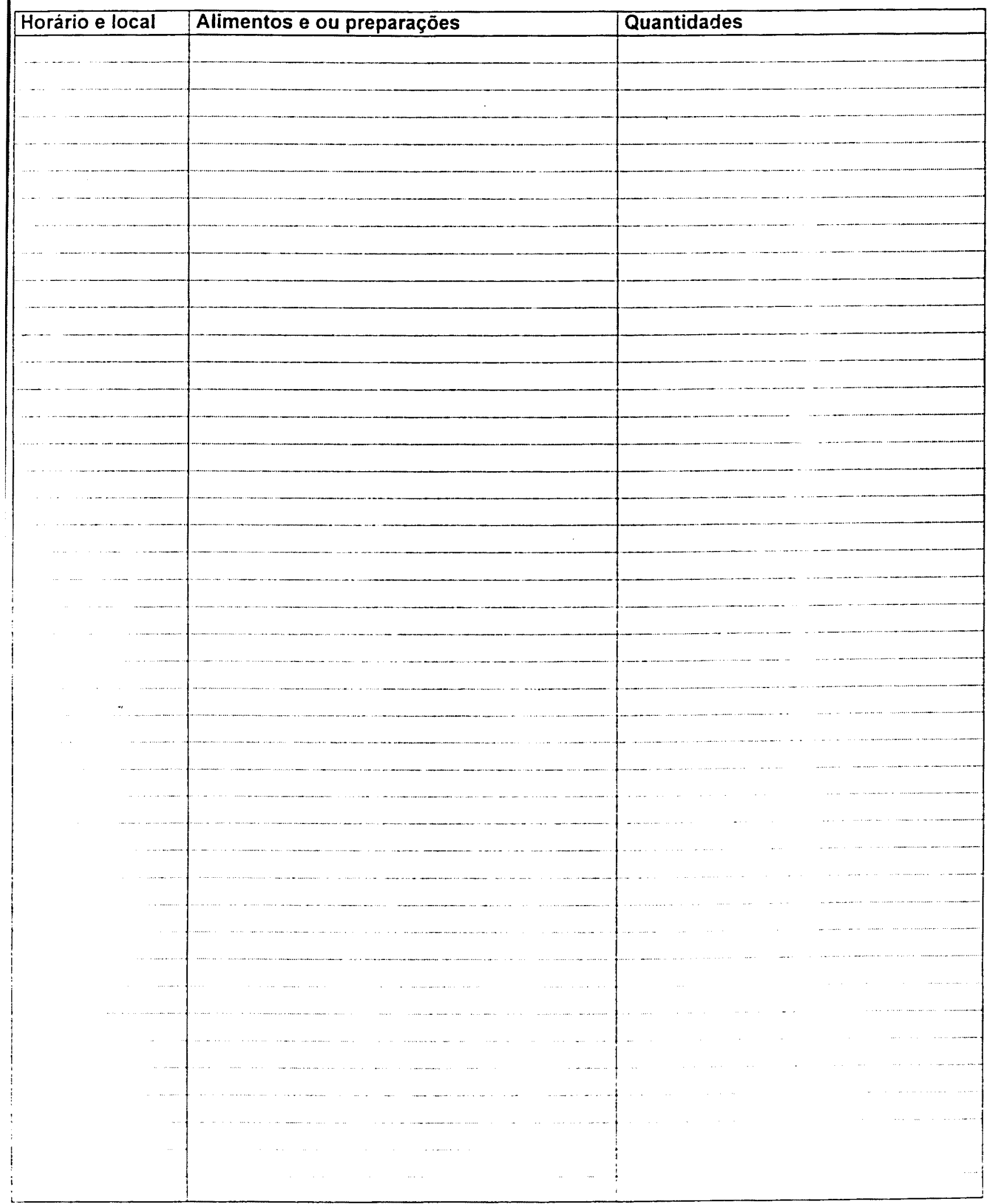




\section{ATIVIDADE FÍSICA}

As questões que se seguem estão relacionadas ao tempo que o(a) sr.(a) gasta fazendo atividade física em uma semana NORMAL USUAL ou HABITUAL.

L 10a. Existem atividades consideradas vigorosas como por exemplo: correr, fazer ginástica aeróbica, jogar futebol, pedalar rápido na bicicleta, jogar basquete, fazer serviços domésticos pesados como lavar roupa, fazer faxina, limpar o quintal, carregar pesos elevados ou outra atividade que faça o(a) sr.(a) suar bastante ou que aumente muito sua respiraçāo ou batimentos do coração. Em quantos dias de uma semana normal o(a) sr.(a) realiza estas atividades por pelo menos 10 minutos seguidos?

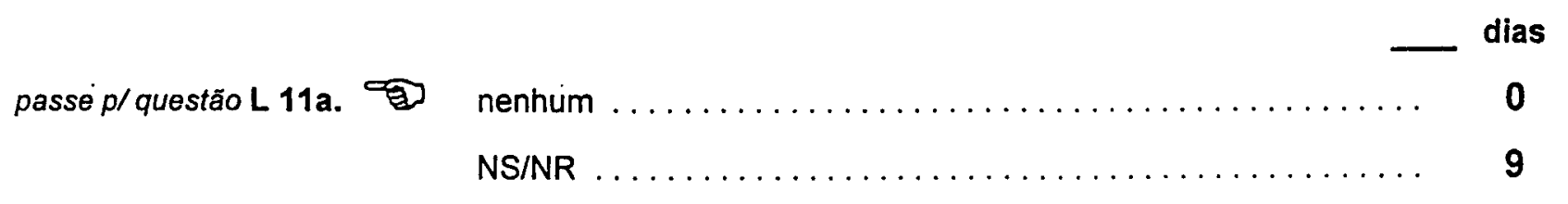

$L$ 10b. Nos dias em que o(a) sr.(a) faz essas atividades vigorosas por pelo menos 10 minutos seguidos, quanto tempo no total o(a) sr.(a) gasta fazendo estas atividades por dia?

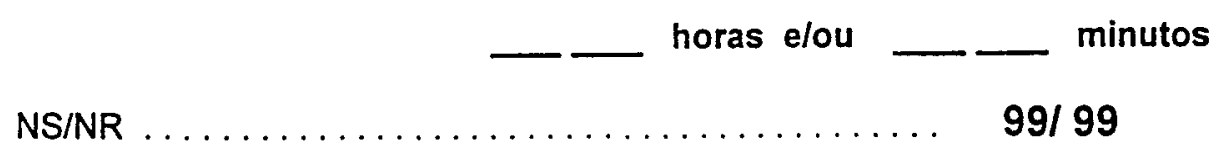

L 11a. Existem atividades consideradas moderadas como por exemplo: pedalar leve na bicicleta, nadar, dạçar, fazer ginástica aeróbica leve, carregar pesos leves, fazer serviços domésticos leves como varrer, aspirar, cuidar das plantas, ou qualquer atividade que faça o(a) sr.(a) suar leve ou aumentar moderadamente sua respiração ou batimentos do coração (nāo incluir caminhada) Em quantos dias de uma semana normal, o(a) sr.(a) realiza estas atividades por pelo menos 10 minutos seguidos?

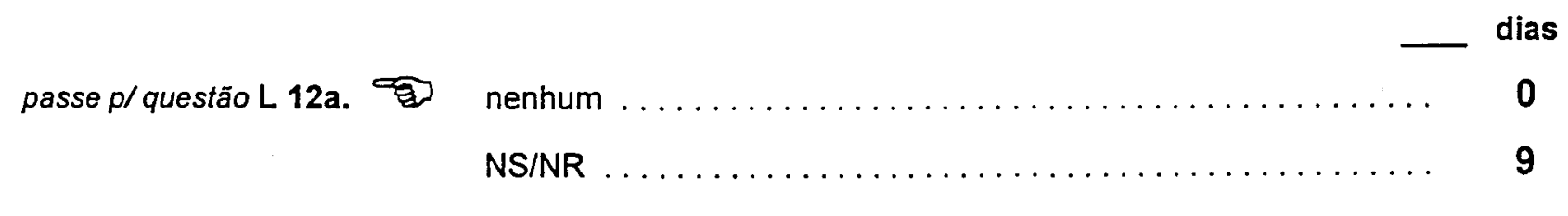

L 11b. Nos dias em que o(a) sr.(a) faz essas atividades moderadas por pelo menos 10 minutos seguidos, quanto tempo no total o(a) sr.(a) gasta fazendo estas atividades por dia?

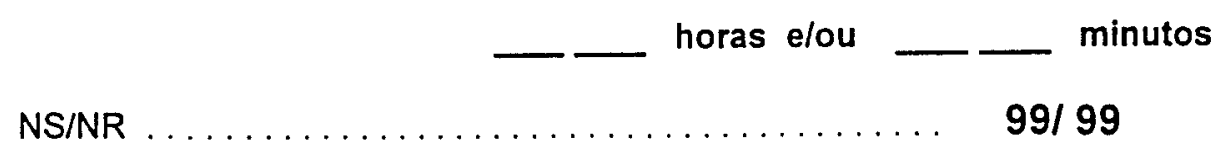

L'12a. Em quantos dias de uma semana normal, o(a) sr.(a) caminha por pelo menos 10 minutos seguidos em casa ou no trabalho, como forma de transporte, para ir de um lugar para outro, por lazer, por prazer ou como forma de exercicio?

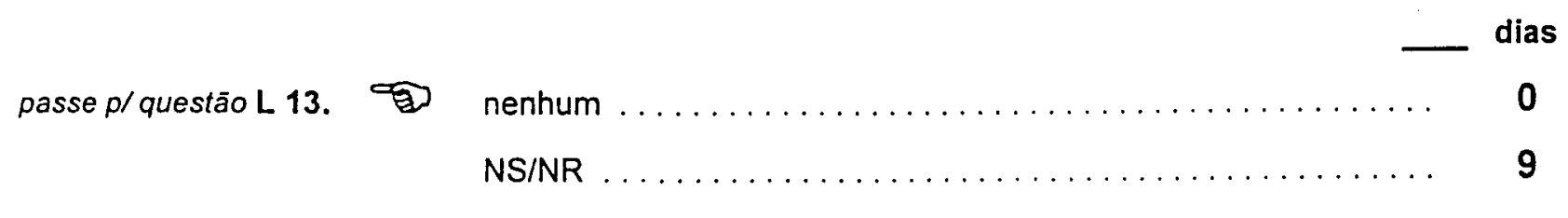

L 12b. Nos dias em que o(a) sr.(a) caminha por pelo menos 10 minutos seguidos, quanto tempo no total o(a) sr.(a) gasta caminhando por dia? 
passo vigoroso (respiraçăo muito mais forte que o normal) ...... 1

passo moderado (respiraçăo um pouco mais forte que o normal) ... 2

passo lento (sem alteraçăo da respiraçăo) $\ldots \ldots \ldots \ldots \ldots \ldots \ldots$

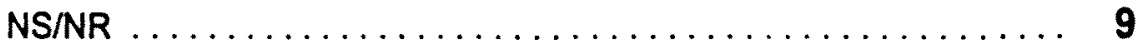

As questões que se seguem são em relação ao tempo que o(a) sr.(a) gasta sentado ao todo no trabalho, em casa, na escola e durante o tempo livre. Isto inclui o tempo que o(a) sr.(a) gasta sentado no escritório ou estudando, visitando amigos, lendo e sentado ou deitado assistindo televisāo.

L 13. Quanto tempo por dia o(a) sr.(a) fica sentado em um dia de semana?

NS/NR

L 14. Quanto tempo por dia o(a) sr.(a) fica sentado no final de semana?

NS/NR

L 15. O(a) sr.(a) já ouviu falar no programa "AGITA SÃO PAULO"?

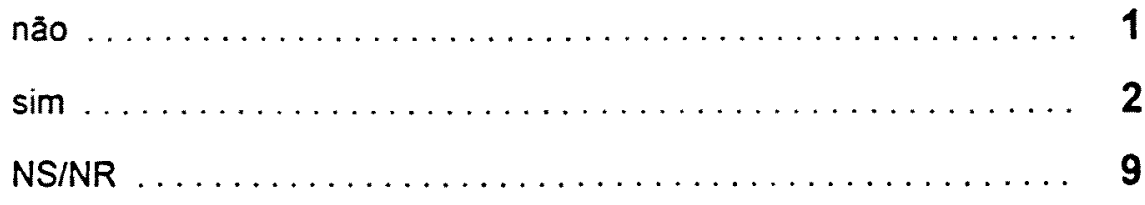

Quanto tempo em média o(a) sr.(a) passa nessas atividades em dia de semana e em dia de final de semana?

\begin{tabular}{|c|c|c|c|c|}
\hline-- & dia de semana & NS/NR & dia de final de semana & NS/NR \\
\hline L 16a. assistindo tv & $\min$. & $99 / 99$ & - - hs. & $99 / 99$ \\
\hline L 16b. no computador & $={ }^{\text {hs. }}==^{\min }$. & $99 / 99$ & 二 ${ }^{\text {hs. }}=$ min. & $99 / 99$ \\
\hline L 16c. trabalhando & _hs. __ $\min$. & $99 / 99$ & _—hs. __ $\min$. & $99 / 99$ \\
\hline L 16d. estudando & ${ }^{\text {hs. }}=\square_{\min }$ & $99 / 99$ & _ ns. & $99 / 99$ \\
\hline Li6e. no transporte & $\min$. & $99 / 99$ & _ & $99 / 99$ \\
\hline L 16f. fazendo serviço em casa & $=$ hs. & $99 / 99$ & $={ }^{h s}=\square^{\min }$. & $99 / 99$ \\
\hline L16g. em lazer & hs. & $99 / 99$ & $-\min$. & $99 / 99$ \\
\hline L 16h. dormindo & - & $99 / 99$ & hs. & $99 / 99$ \\
\hline
\end{tabular}


L 17. Pratica regularmente, pelo menos uma vez por semana, algum esporte ou exercício físico? Se sim, qual?

Pode haver mais de uma resposta

nâo pratica nenhum esporte ou exercício físico .......... 01

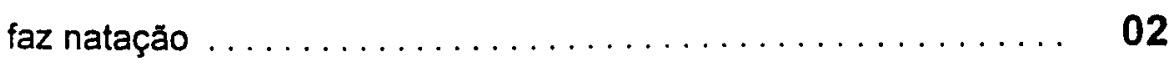

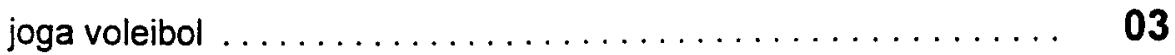

joga basquete $\ldots \ldots \ldots \ldots \ldots \ldots \ldots \ldots \ldots \ldots \ldots \ldots \ldots \ldots \ldots$

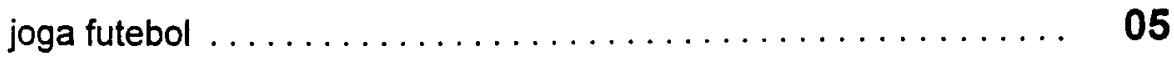

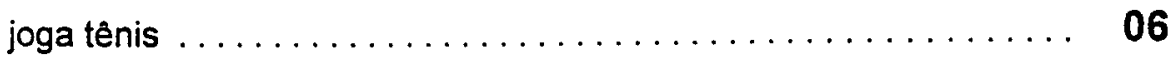

faz caminhadas $\ldots \ldots \ldots \ldots \ldots \ldots \ldots \ldots \ldots \ldots \ldots \ldots \ldots$

faz ginástical musculaçăo $\ldots \ldots \ldots \ldots \ldots \ldots \ldots \ldots \ldots, 08$

anda de bicicleta $\ldots \ldots \ldots \ldots \ldots \ldots \ldots \ldots \ldots \ldots \ldots . \ldots . \ldots$

outros, especif.:

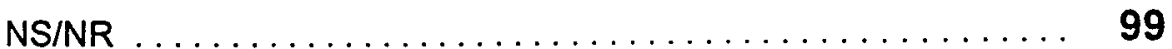

\section{FUMO}

L 18. O(a) sr.(a) já fumou alguma vez, ao menos algum cigarro por dia, todos os dias durante ao menos um mês?

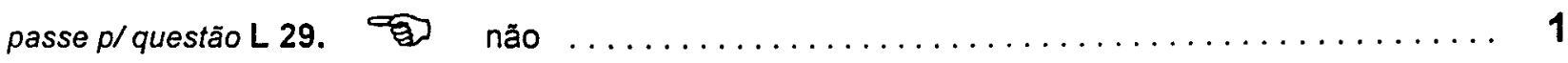

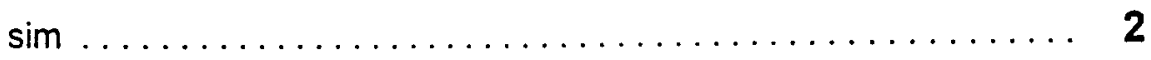

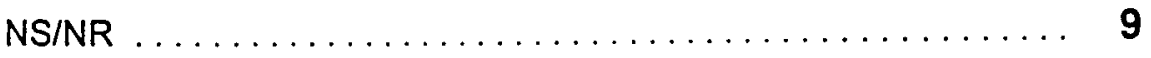

L 19. Que idade o(a) sr.(a) tinha quando começou a fumar regularmente?

NS/NR

$L 20.0$ (a) sr.(a) fuma atualmente?

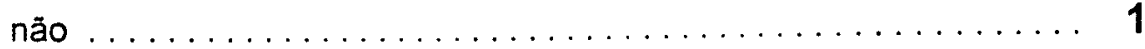

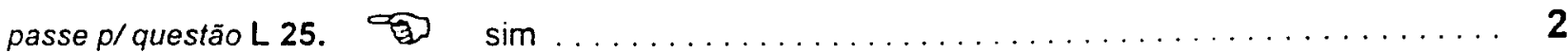

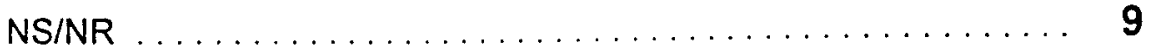

L 21. Há quantos meses ou anos o(a) sr.(a) deixou de fumar? 
L 22. Por que o(a) sr.(a) deixou de fumar?

Pode haver mais de uma resposta.

acha que faz mal para saúde $\ldots \ldots \ldots \ldots \ldots \ldots \ldots \ldots, 1$

teve algum problema de saúde $\ldots \ldots \ldots \ldots \ldots \ldots \ldots \ldots, \mathbf{2}$

restriçăo ao fumo no trabalho/locais públicos ............ 3

restriçăo em casa $\ldots \ldots \ldots \ldots \ldots \ldots \ldots \ldots \ldots \ldots \ldots, 4$

outro, especif.: _ـ 5

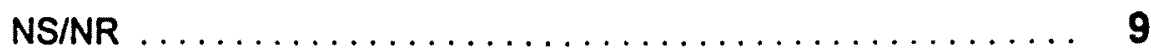

L 23. Contou com algum tipo de apoio quando deixou de fumar?

Pode haver mais de uma resposta

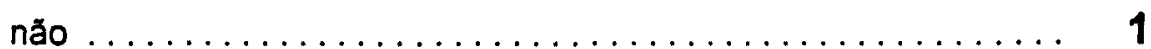

sim, grupo de apoio em serviço de saúde $\ldots \ldots \ldots \ldots \ldots \ldots \ldots \quad 2$

sim, local de trabalho $\ldots \ldots \ldots \ldots \ldots \ldots \ldots \ldots \ldots \ldots$

sim, parente e amigo $\ldots \ldots \ldots \ldots \ldots \ldots \ldots \ldots \ldots \ldots, 4$

sim, usou acupuntura $\ldots \ldots \ldots \ldots \ldots \ldots \ldots \ldots \ldots \ldots$

sim, algum tipo de tratamento (ex: adesivo), especif.:

6

outro, especif.: 7

NS/NR

L 24. Quantos cigarros o(a) sr.(a) fumava em média por dia?

passe $p$ / questão L 29. cigarros

NS/NR

L 25. Quanto tempo após acordar o(a) sr.(a) fuma o primeiro cigarro?

na primeira meia hora 25

na segunda meia hora

após: horas

NS/NR 99

L 26. Atualmente quantos cigarros o(a) sr.(a) fuma por dia? cigarros 
L 27. O(a) sr.(a) já tentou parar de fumar?

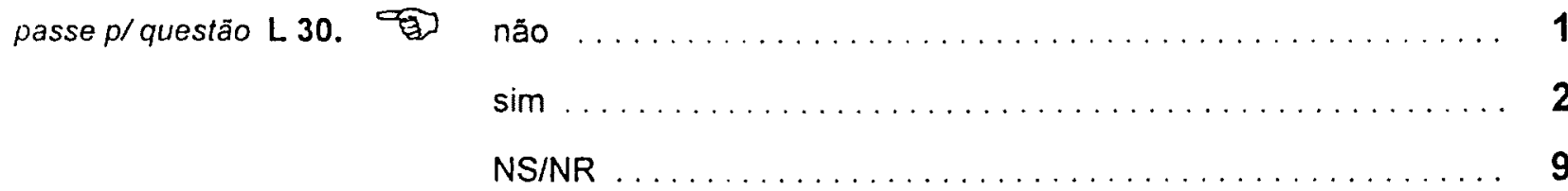

L 28. Por que?

Pode haver mais de uma resposta.

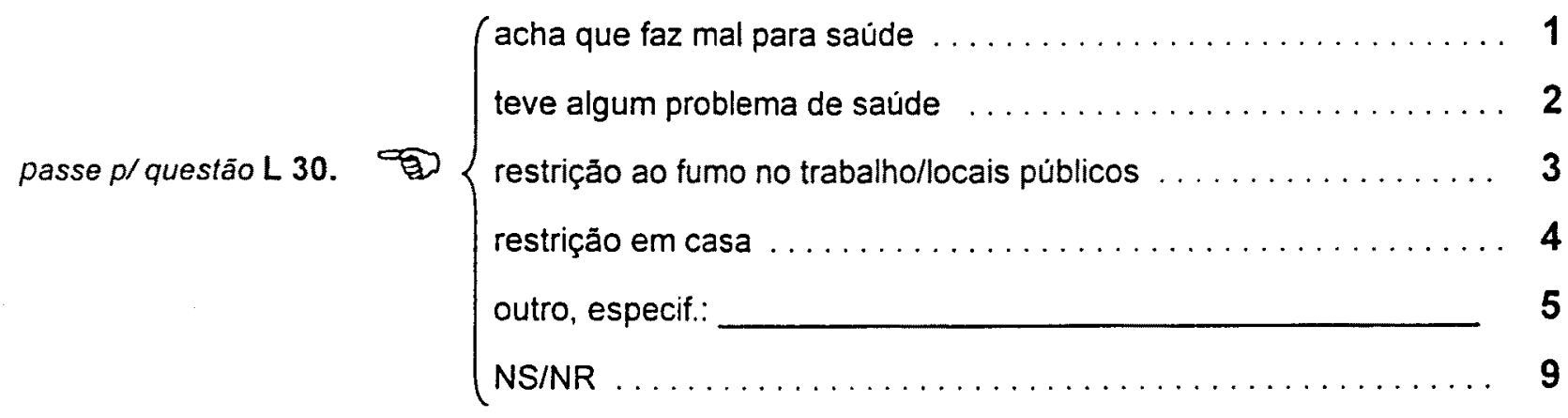

L 29. O(a) sr.(a) que não fuma, quantas horas por dia fica exposto/próximo de alguém fumando? horas/dia

NS/NR

\section{ÁLCOOL}

L 30. Qual é a bebida de sua preferência?

especif.:

L 31. Qual é a bebida alcoólica de sua preferência?

passe p/questão L 33 . especif.:

não bebe àlcool

L 32. Há quanto tempo o(a) sr.(a) não ingere bebida alcoólica?

passe $p /$ questão M 01. 일

năo bebe há mais de um ano 


\section{"PARA OS QUE BEBEM"}

L 33. Alguma vez o(a) sr.(a) sentiu que deveria diminuir a quantidade de bebida ou parar de beber?

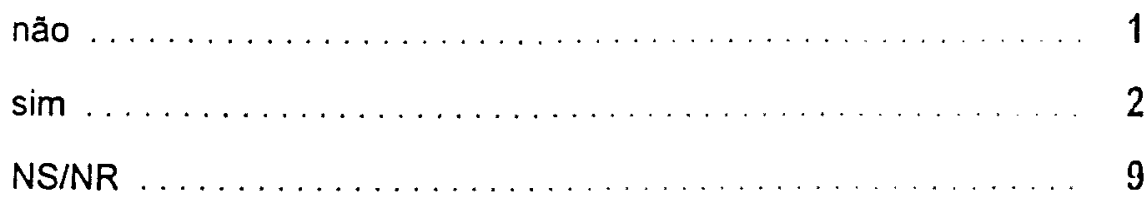

L 34. As pessoas o aborrecem porque criticam o seu modo de beber?

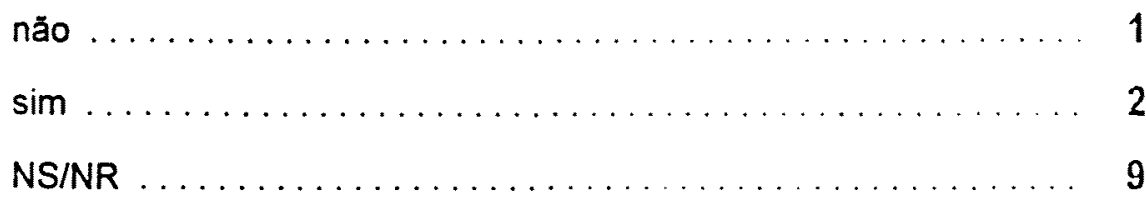

L 35. O(a) sr.(a) costuma beber pela manhã para diminuir o nervosismo ou a ressaca?

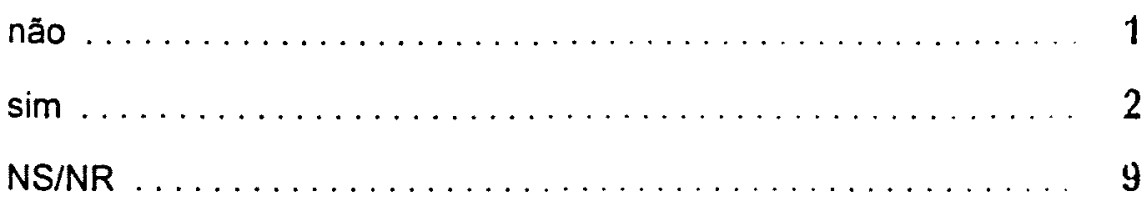

$L$ 36. $O(a)$ sr.(a) fica chateado ou se sente culpado pela maneira como costuma beber?

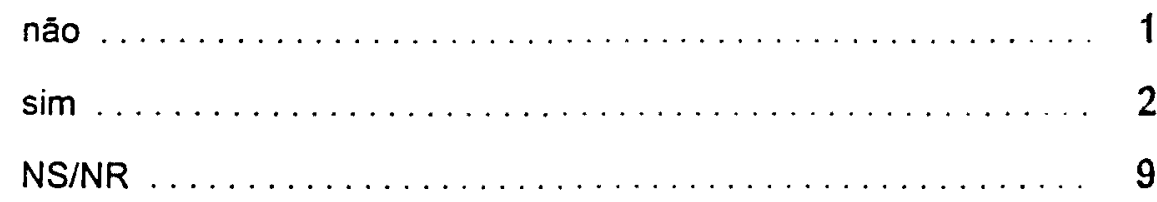

L 37. Com que freqüência o(a) sr.(a) toma bebida alcoólica?

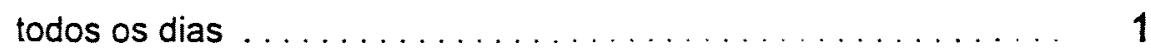

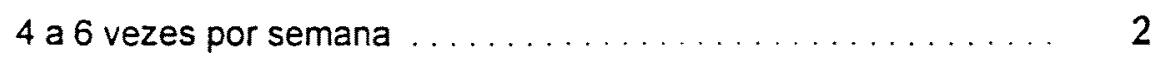

2 a 3 vezes por semana ...................... 3

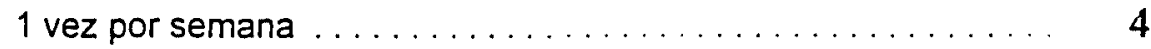

1 a 2 vezes por mês $\ldots \ldots \ldots \ldots \ldots \ldots \ldots \ldots \ldots \ldots$

menos de 1 vez por mês $\ldots \ldots \ldots \ldots \ldots \ldots \ldots \ldots \ldots$

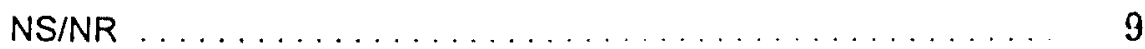

Qual bebida alcoólica e em que quantidade o(a) sr.(a) consome num dia tipico quando está bebendo?

L 38a. Bebida:

L 38b. Quantidade:

L 38c. Bebida:

L 38d. Quantidade:

L 38e. Bebida

L 38f. Quantidade: 


\section{CARACTERÍSTICAS SÓCIO-ECONÔMICAS}

(INFORMAÇŌES DO ENTREVISTADO)

BLOCO O

\section{PARA TODAS AS PESSOAS COM 12 ANOS OU MAIS.}

(SE FOR CHEFE DE FAMILIA PASSE PARA O BLOCO P)

O 02. Onde o(a) sr.(a) nasceu?

outro municipio, especifique o municipio e estado:

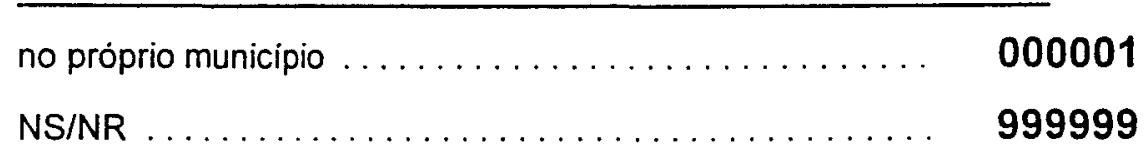

O 03. Há quanto tempo o(a) sr.(a) mora nesse municipio? anos

NS/NR

99/99

O 04. Há quanto tempo o(a) sr.(a) mora nesse domicilio? anos

NS/NR

$99 / 99$

O 05. Qual é a sua situação conjugal?

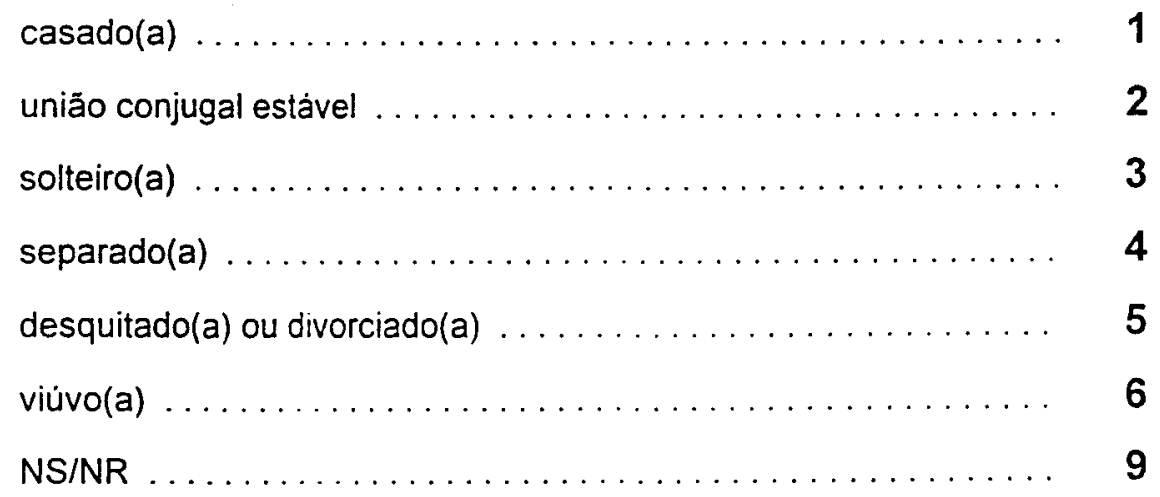

O 06. Até que ano da escola o(a) sr.(a) completou?

nunca freqüentou, não sabe ler e escrever ............. 01

nunca freqüentou. sabe ler e escrever . . . . . . . . . . . . . 02

$1^{\circ}$ grau ou primário ano/série

$(11-14)$

1

$1^{\circ}$ grau ou ginásio ano/série

$(15-18)$

$2^{\circ}$ grau ou colegial ano/série 1

cursos técnicos de nivel médio incompletos

cursos técnicos de nivel médio completos 
o 07. Atualmente o(a) sr.(a) exerce alguma atividade seja ela remunerada ou não remunerada de trabalho?

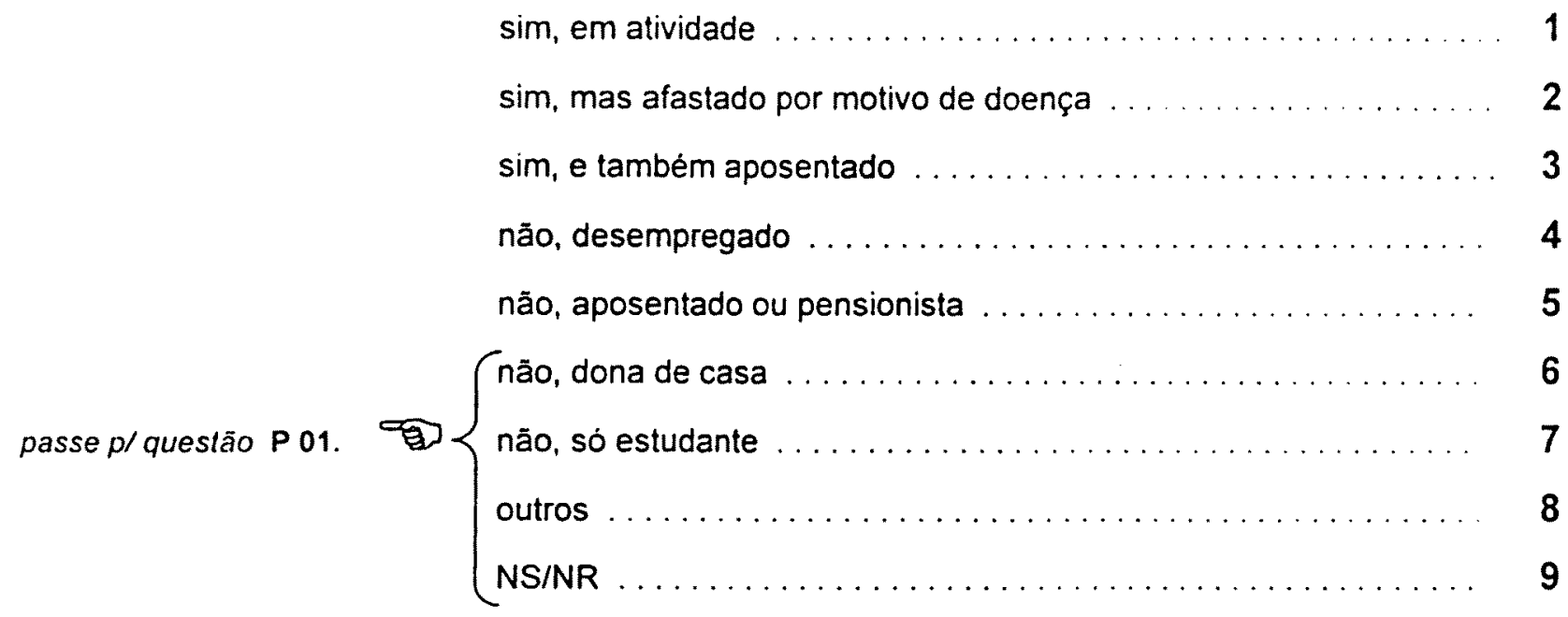

O 08. Qual élera a sua ocupação em seu trabalho principal?

(especificar se aposentado, qual era a sua ocupaçăo anterior)

NS/NR

O 09. No seu trabalho principal o(a) senhor(a) élera:

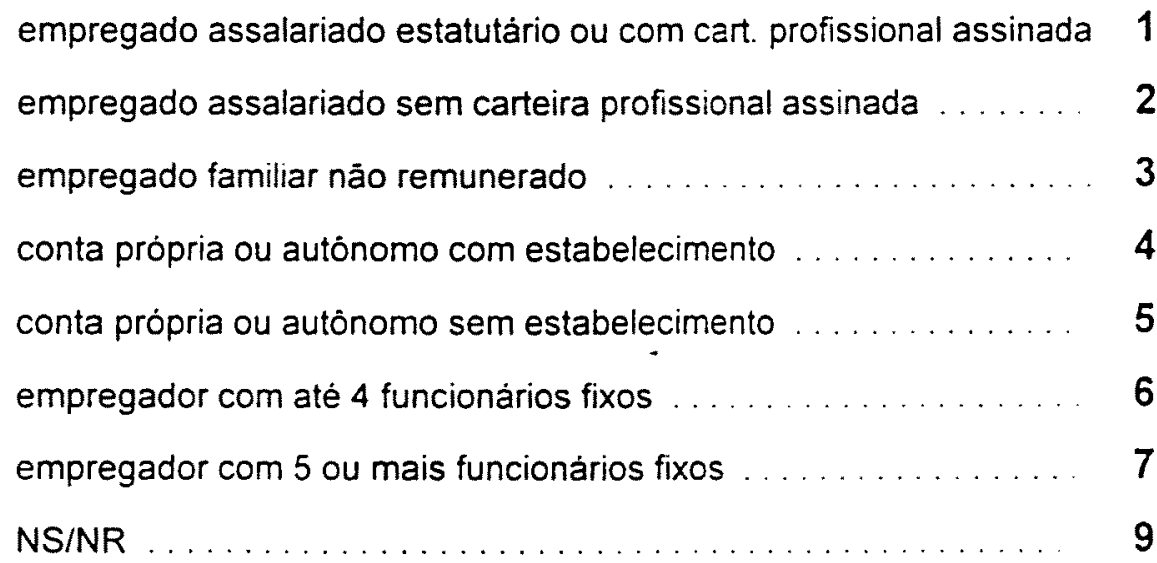

O 10. Especifique qual élera a atividade do estabelecimento, empresa, negócio ou instituição em que trabalha/trabalhou. 
J 11. Em que municipio fica o lugar que o(a) senhor(a) trabalha/trabalhou? ङ se estiver desempregado - passe p/ questão 015.

no próprio municipio

outro municipio, especif.:

NS/NR

O 12. Quanto o(a) senhor(a) ganhou com esse trabalho, aposentadoria ou pensão no mês passado?

salário liquido

R\$:

NSINR

99999

O 13. Além desse trabalho o(a) sr.(a) tem algum outro tipo de trabalho remunerado? (fixo ou eventual)

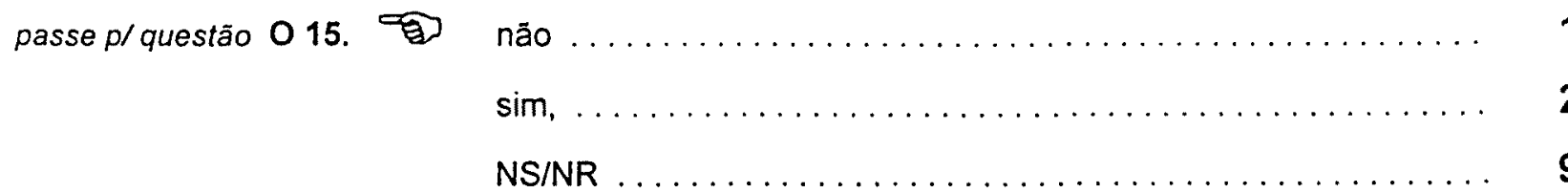

O 14. Quanto o(a) sr.(a) ganhou com este trabalho no mês passado?

salário liquido

R\$:

NS/NR

O 15. O(a) sr.(a) tem algum outro tipo de rendimento além do(s) declarado(s) anteriormente?

renda líquida

R\$:

não

00000

NS/NR

99999

Verifique o NÚMERO DE ORDEM do entrevistado: se for 1 passe para o BLOCO $P$, caso contrário, encerre o questionário. 


\section{(ङ PREENCHER UM BLOCO PARA CADA FAMILIA.}

P 02. Existem situaçōes em que pessoas idosas ou doentes ficam impossibilitadas de desenvolver sozinhas atividades como comer, caminhar, vestir-se, tomar banho e precisam de ajuda constante de outras pessoas. Em sua casa há alguém nesta situação?

passe $p /$ questão P 05. nāo $\ldots \ldots \ldots \ldots \ldots \ldots \ldots \ldots \ldots \ldots \ldots \ldots \ldots \ldots \ldots$

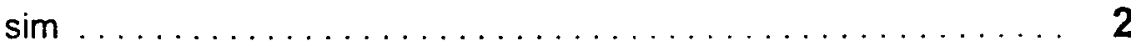

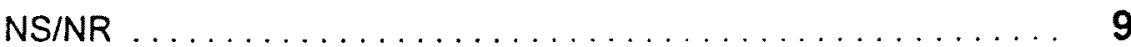

P 03. Que pessoa geralmente realiza estas atividades para ele(a) ou o(a) auxilia a realizá-las?

Pode haver mais de uma resposta

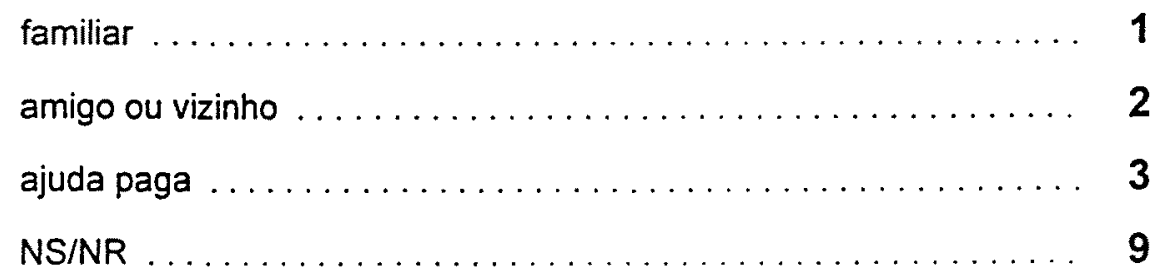

P 04. Qual o problema que levou esta pessoa a precisar de cuidados constantes?

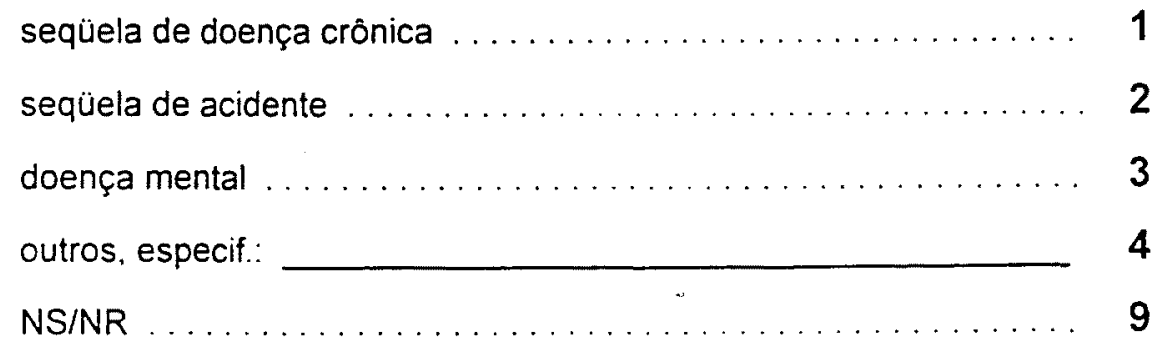

P 05. Existe algum membro da familia, internado em hospital, clinica, asilo, casa de repouso, clínica de recuperação para usuário de drogas, penitenciária, etc.?

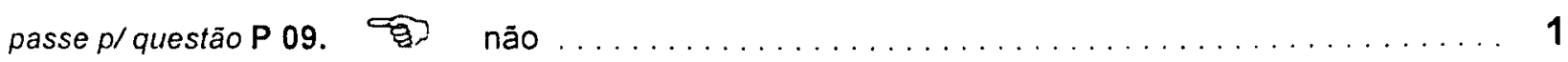

sim, especif.: _ 2

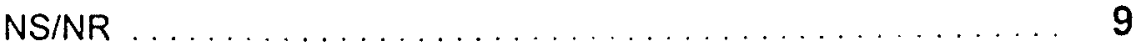

P 06. Há quantos anos ele(a) está institucionalizado? 
P 07. Qual o sexo dele?

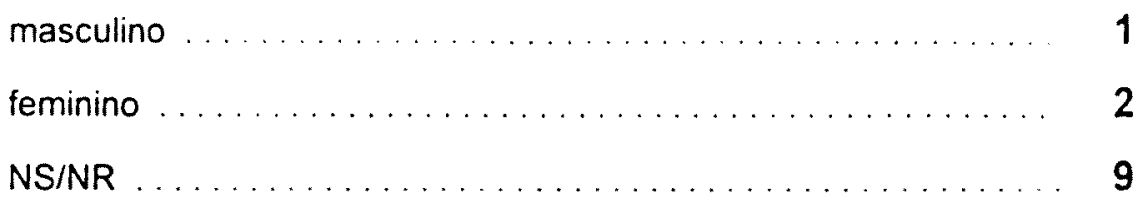

P 08. Qual a idade dele(a)?

NS/NR

P 09. Caracterizaçāo do domicilio:

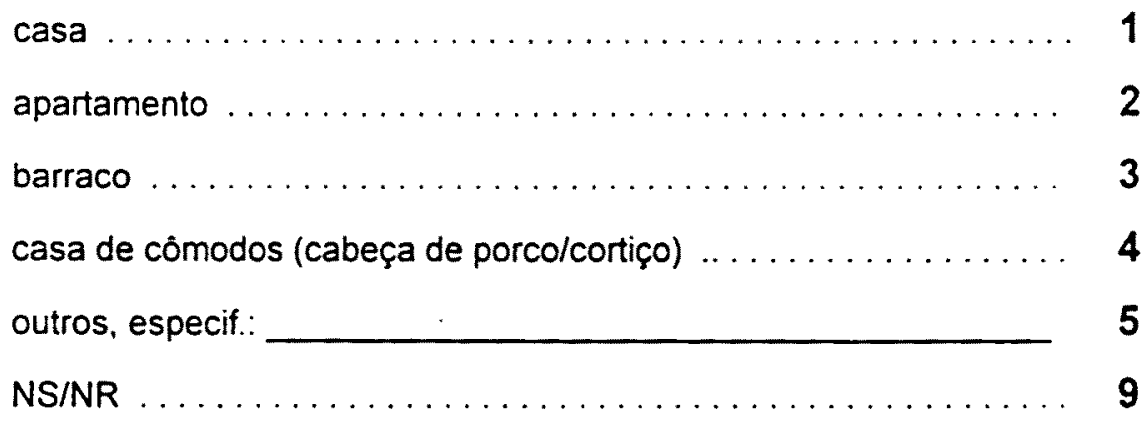

P 10. A sua casa é:

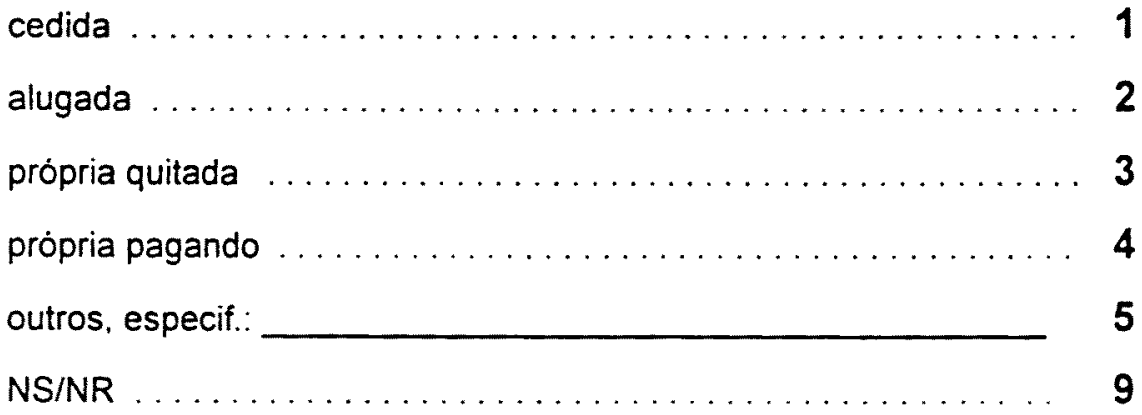

P 11. Quantos cômodos tem sua casa, tirando o banheiro?

NS/NR

P 12. As paredes externas do domicilio săo de alvenaria?

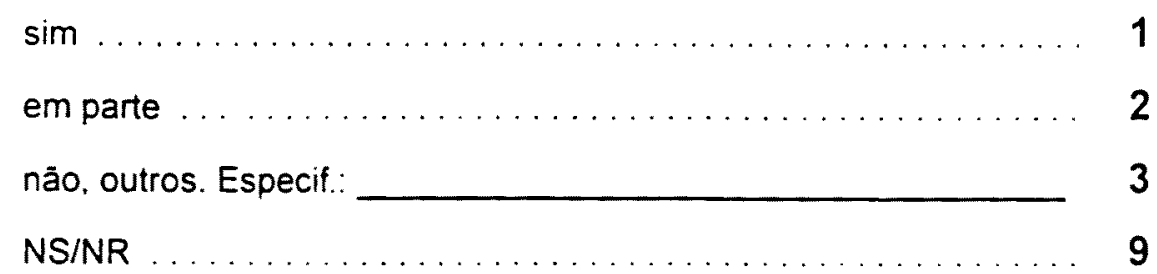

Na rua da sua casa existe:

P 13a. pavimentação 
P 13b. guias e sarjetas

não

sim

NS/NR

P 13c. iluminação pública

กão

$\operatorname{sim}$

NS/NR

P 14. O abastecimento de água de sua casa é

rede pública interna $\ldots \ldots \ldots \ldots \ldots \ldots \ldots \ldots$

rede pública externa $\ldots \ldots \ldots \ldots \ldots \ldots \ldots \ldots \ldots \ldots$

outros, especificar: _________ 3

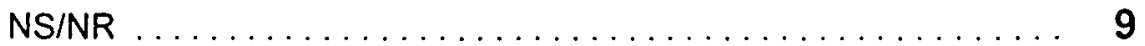

P 15. Qual o tipo de instalação sanitária do domicilio?

interna $\ldots \ldots \ldots \ldots \ldots \ldots \ldots \ldots \ldots \ldots \ldots \ldots \ldots \ldots \ldots \ldots$

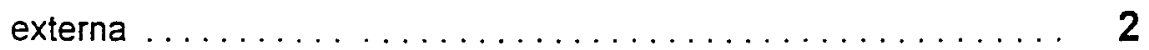

outros, especif:

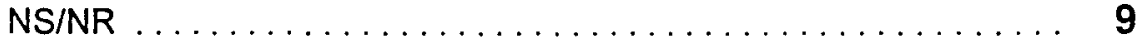

P 16. Qual o destino do esgoto?

sistema püblico de esgoto $\ldots \ldots \ldots \ldots \ldots \ldots \ldots$

outros, especif.:

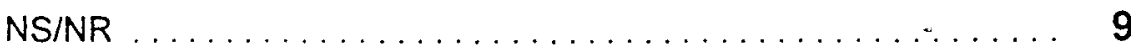

P 17. Qual o destino do lixo?

coleta pública regular $\ldots \ldots \ldots \ldots \ldots \ldots \ldots \ldots$

outros, especif: ___ 2

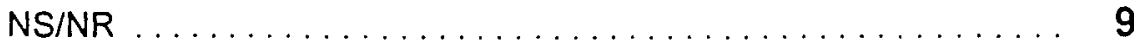

P 18. Que tipo é a iluminação artificial do domicilio?

elétrica $\ldots \ldots \ldots \ldots \ldots \ldots \ldots \ldots \ldots \ldots \ldots \ldots \ldots$

outros, especif:

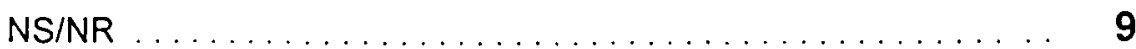


P 19. A familia possui:

geladeira $\ldots \ldots \ldots \ldots \ldots \ldots \ldots \ldots \ldots \ldots \ldots \ldots \ldots \ldots \ldots$

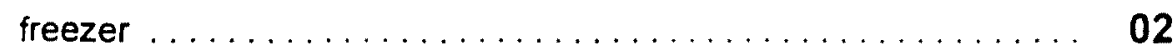

televisåo $\ldots \ldots \ldots \ldots \ldots \ldots \ldots \ldots \ldots \ldots \ldots \ldots . \ldots \ldots$

máquina de lavar roupa $\ldots \ldots \ldots \ldots \ldots \ldots \ldots \ldots \ldots \ldots$

aparelho de som $\ldots \ldots \ldots \ldots \ldots \ldots \ldots \ldots \ldots \ldots \ldots, 05$

aparelho de video $\ldots \ldots \ldots \ldots \ldots \ldots \ldots \ldots \ldots \ldots \ldots \ldots$

aspirador de pó $\ldots \ldots \ldots \ldots \ldots \ldots \ldots \ldots \ldots \ldots \ldots \ldots, 07$

máquina de lavar louça $\ldots \ldots \ldots \ldots \ldots \ldots \ldots \ldots \ldots . \ldots$

condicionador de ar .......................... 09

telefone fixo $\ldots \ldots \ldots \ldots \ldots \ldots \ldots \ldots \ldots \ldots \ldots \ldots \ldots$

telefone celular $\ldots \ldots \ldots \ldots \ldots \ldots \ldots \ldots \ldots \ldots \ldots \ldots \ldots$

computador ................................. 12

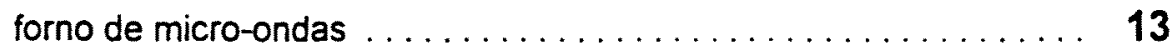

veiculo auto-motor $\ldots \ldots \ldots \ldots \ldots \ldots \ldots \ldots \ldots \ldots \ldots \ldots$

outro imóvel que não a residência atual $\ldots \ldots \ldots \ldots \ldots \ldots \ldots \quad 15$

\section{CARACTERÍSTICAS SÓCIO-ECONÔMICAS}

Q 01. Horário da entrevista: inicio: término:

Q 02. Código do entrevistador:

Q 03. Data da realizaçāo da entrevista: ___ _ _ _ _

Q 04. Quem respondeu esse questionário?

o próprio

outro

Q 05. Onde o(a) sr.(a) nasceu?

outro municipio, especifique municipio e estado:

Q 06. Há quanto tempo o(a) sr.(a) mora nesse município? 
Q 07. Há quanto tempo o(a) sr.(a) mora nesse domicilio?

anos

NS/NR

Q 08. Até que ano da escola o(a) sr.(a) completou?

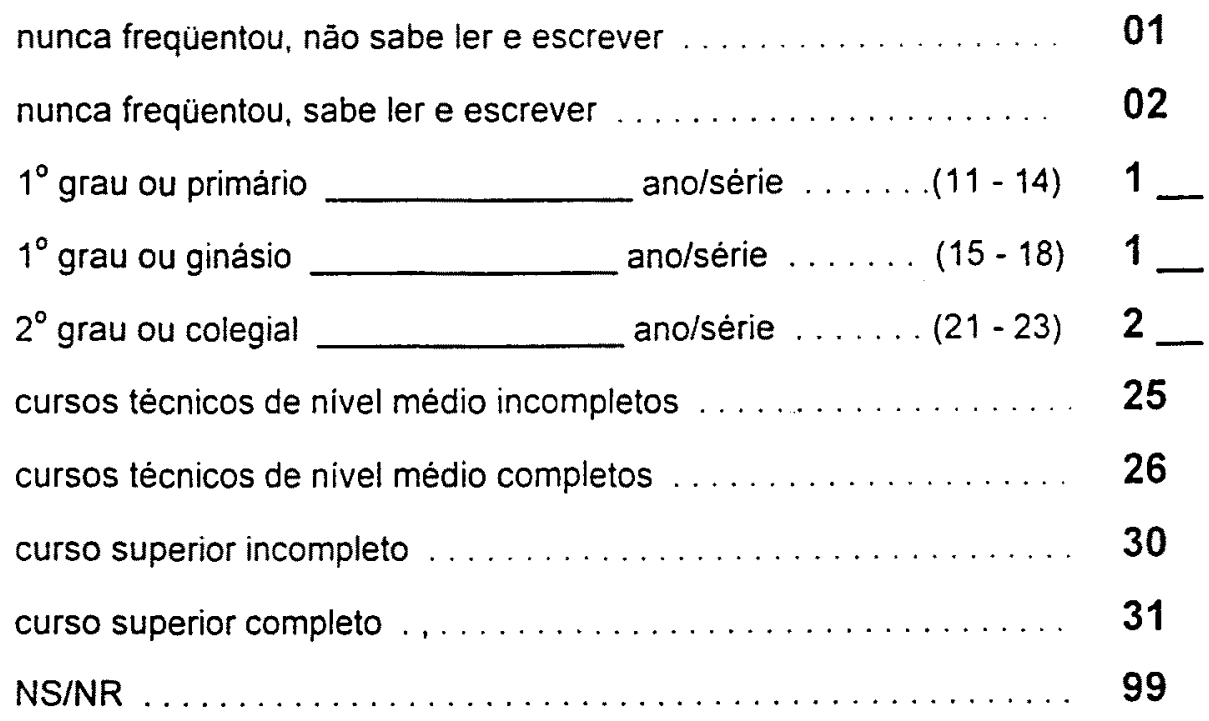

Q 09. Atualmente o(a) sr.(a) exerce alguma atividade seja ela remunerada ou não remunerada de trabalho?

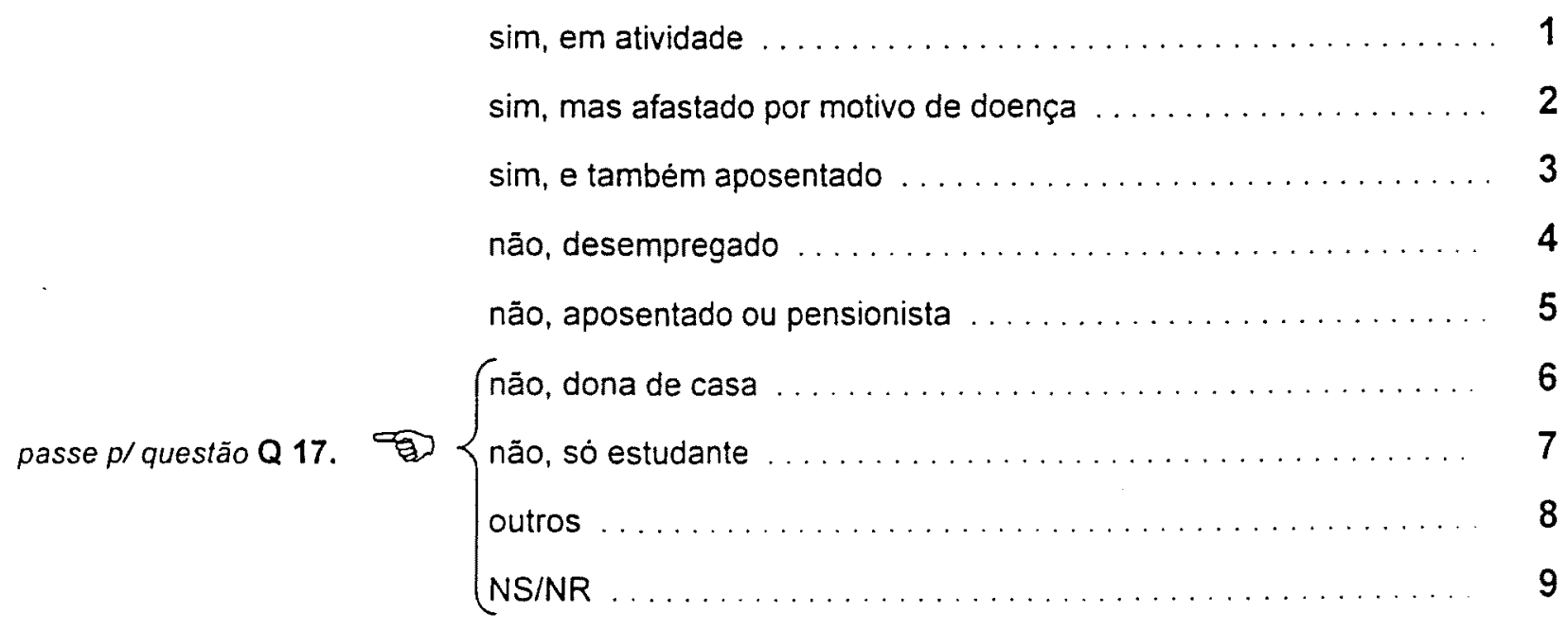

Q 10. Qual é/era sua ocupação em seu trabalho principal?

(especificar se aposentado, qual era a sua ocupação anterior) 
Q 11. No seu trabalho principal o(a) senhor(a) èlera:

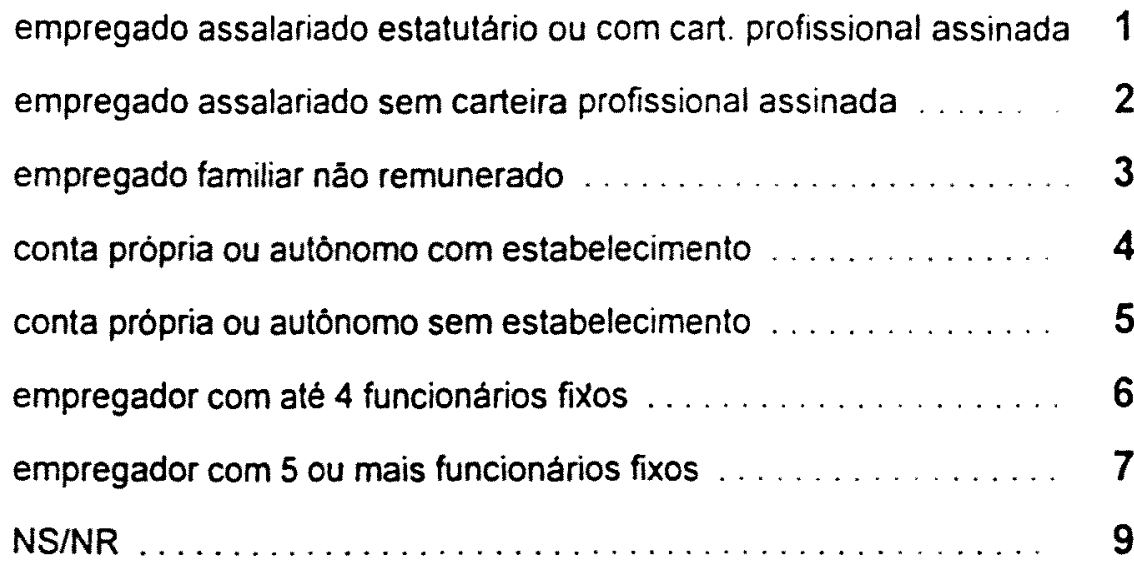

Q 12. Especifique qual élera a atividade do estabelecimento, empresa, negócio ou instituição em que trabalha/trabalhou.

NSINR

Q 13. Em que municipio fica o lugar o(a) senhor(a) trabalha/trabalhou?

se estiver desempregado - passe $p /$ questāo $Q 17$.

no próprio munici, $: 0$

outro municipio, especif.:

NS/NR

Q 14. Quanto o(a) senhor(a) ganhou com esse trabalho, aposentadoria ou pensão no mês passado?

salário liquido

RS:

NS/NR

Q 15. Além desse trabalho o(a) sr.(a) tem algum outro tipo de trabalho remunerado? (fixo ou eventual) passe p/ questão Q 17. ด्छ

não

$\operatorname{sim}$

NS/NR

Q 16. Quanto o(a) sr.(a) ganhou com este trabalho no mês passado?

salário liquido

NS/NR
RS: 
Q 17. O(a) sr.(a) tem algum outro tipo de rendimento além do(s) declarado(s) anteriormente?

renda liquida

não

RS:

NS/NR

Q 18. Qual é a sua situaçào conjugal?

se o(a) companheiro(a) foi sorteado(a), passe p/ questão Q 25. (2)

$\left\{\begin{array}{l}\text { casado(a) } \ldots \ldots \ldots \ldots \ldots \ldots \ldots \\ \text { uniāo conjugal estável } \ldots \ldots \ldots \ldots\end{array}\right.$

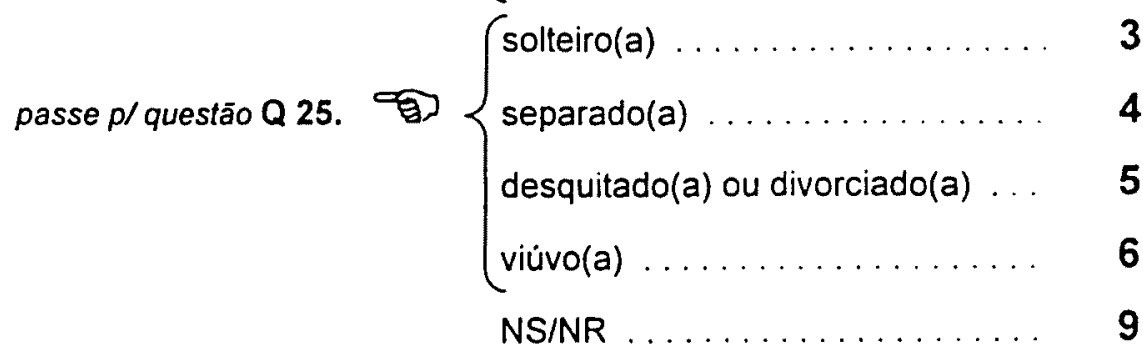

Q 19. Até que ano da escola seu(sua) companheiro(a) completou?

nunca freqüentou, năo sabe ler e escrever $\ldots \ldots \ldots \ldots \ldots \ldots .01$

nunca freqũentou, sabe ler e escrever ............... 02

$1^{\circ}$ grau ou primário ano/sèrie

1

$1^{\circ}$ grau ou ginásio ano/série

. (11-14)

$2^{\circ}$ grau ou colegial ano/série

$(15-18)$

1

cursos técnicos de nivel médio incompletos

$(21-23)$

2

cursos técnicos de nivel médio completos

curso superior incompleto

curso superior completo

NS/NR

Q 20. Atualmente seu(sua) companheiro(a) exerce alguma atividade seja ela remunerada ou nāo remunerada de trabalho?

sim, em atividade

sim, mas afastado por motivo de doença

sim, e também aposentado

năo, desempregado

não, aposentado ou pensionista

passe p/questão Q 25, छ)

não, dona de casa

não, só estudante 
Q 21 Qual èlera a ocupaçào de seu(sua) companheiro(a) em seu trabalho principal?

(especificar se aposentado, qual era a sua ocupação anterior)

NS/NR

Q 22. No trabalho principal seu(sua) companheiro(a) é/era:

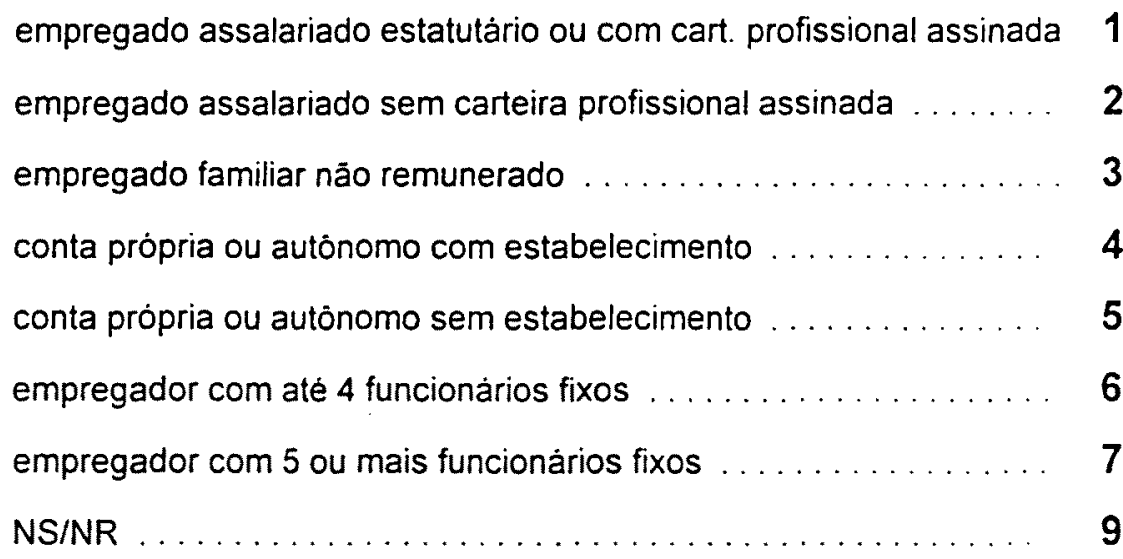

Q 23. Especifique qual élera a atividade do estabelecimento, empresa, negócio ou instituição em que seu(sua) companheiro(a) trabalha/trabalhou.

NSINR

Q 24. Quanto seu(sua) companheiro(a) ganhou com esse trabalho, aposentadoria ou pensão no mês passado?

salário liquido

NS/NR
RS:

Wuadro de composição e renda familiar:

nome

$25 a$.

25b.

$25 c$.

25d.

25 e.

$25 f$.

$25 \mathrm{~g}$.

$25 h$.

$25 i$.

$25 j$.

relação com o
chefe da familia
Chefe 1

renda

RS:

RS:

RS:

RS:

RS:

RS:

R\$:

RS:

RS:

RS: 2 3 4

5 6 7 
Q 26. No mês passado qual foi o valor da conta de luz?

RS:

NS/NR

\section{GASTOS COM SAÚDE}

BLOCOR

Quanto a familia gastou com saúde no último mês?

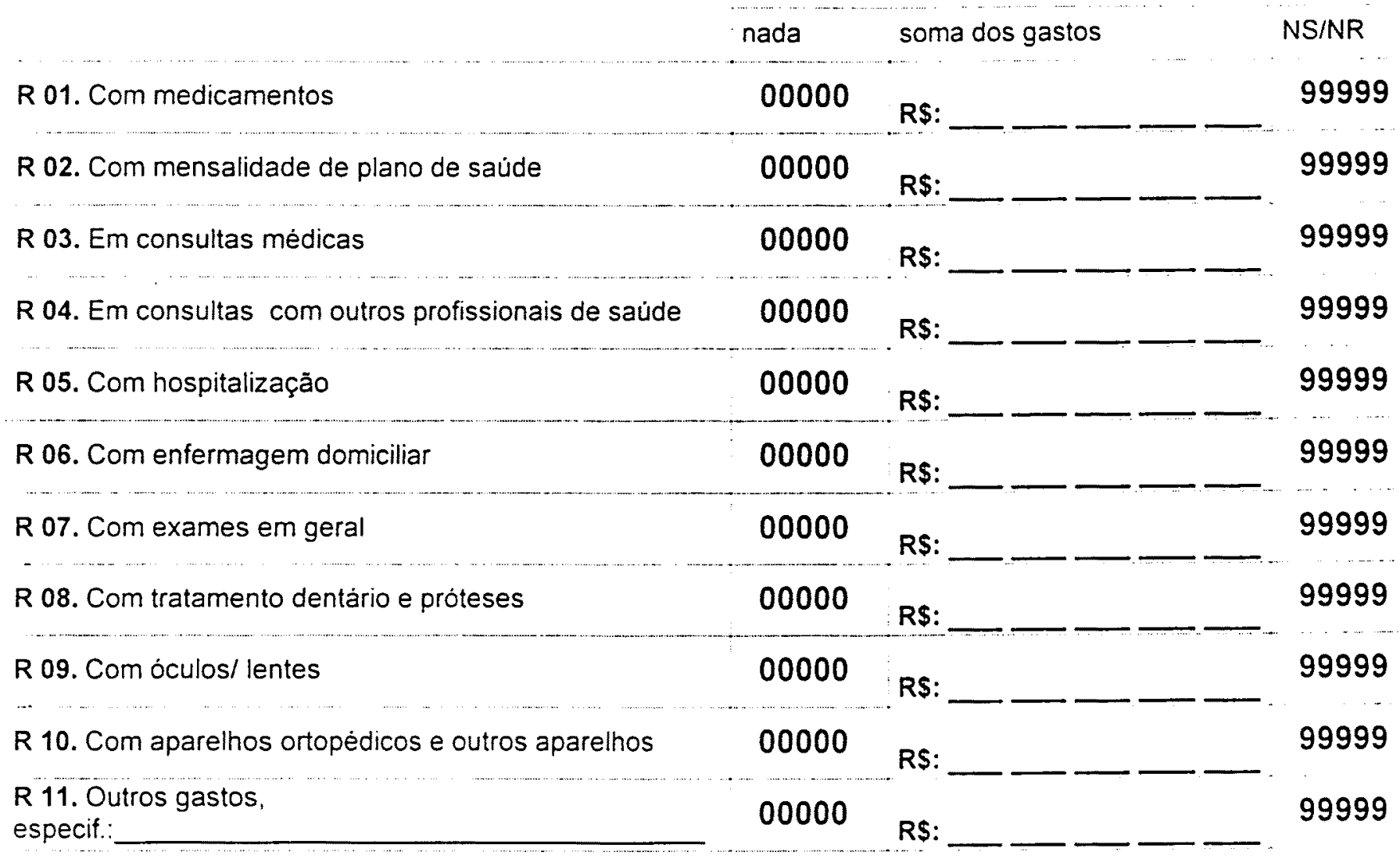


ANEXO 2-MANUAL DO ENTREVISTADOR PARA PREENCHIMENTO DO RECORDATÓRIO DE 24 HORAS. 


\section{MANUAL DO ENTREVISTADOR - RECORDATÓRIO DE 24 HORAS}

O método recordatório de 24 horas é realizado geralmente mediante uma entrevista pessoal no qual o indivíduo relata detalhadamente os alimentos consumidos no dia anterior à entrevista, começando pelo primeiro alimento consumido após acordar até a última refeição antes de dormir, incluindo os alimentos consumidos dentro e fora do domicilio.

O sucesso desde método dependerá da memória e da cooperação do entrevistado, assim como da habilidade do entrevistador em estabelecer um bom canal de comunicação com a pessoa entrevistada.

O seguimento da metodologia proposta proporcionará respostas precisas e não tendenciosas.

Passo 1: Perguntar para o individuo ou responsável (se for criança), seguindo textualmente a frase:

"A Sr. (Sra.) pode, por favor me dizer tudo o que (a criança) comeu ou bebeu ontem, o dia todo, começando pelo primeiro alimento ou bebida consumido"

Transcreva tudo o que for dito, sem preocupação com quantidades, por enquanto. Não diga nada nem interrompa o (a) informante.

Passo 2: O Sr. (Sra.) pode lembrar o horário (mais ou menos) e em que lugar?

Anote os horários e o lugar referido e com quem nos espaços indicados.

Passo 3: Volte à descrição dos alimentos e pergunte as quantidades em medidas caseiras consumidas, de cada alimento ou preparação.

"Quanto a Sr. (Sra.) (a criança) comeu deste alimento" 
a. No caso de alimentos como frutas, pães, biscoitos e ovos, perguntar quantas unidades foram consumidas. Exemplo: 1 fatia de pão de forma, 1 pão francês, 1 pão de queijo, 1 banana nanica, 1 biscoito recheado, etc.

b. Se for possível registre a marca comercial e variedade dos alimentos (banana nanica, prata, maçã).

c. No caso especifico de alimentos compostos, por exemplo: café com leite, mingaus, mamadeiras, vitaminas, sopas. Pergunte os ingredientes da preparação, as quantidades e medidas utilizadas na composição.

\section{Exemplo: mamadeira}

Leite integral tipo B $\quad 150 \mathrm{ml}$

Açúcar 1 colher de sopa rasa

Mucilon de arroz $\quad 1$ colher de sopa cheia.

d. Para alimentos como carnes (porco, frango, peixe, vaca) utilize unidades como: fatia (pequena, média, grande), pedaço (pequena, média, grande), posta (pequena, média, grande).

e. Registre se a preparação da carne foi frita, cozida, assada, a milanesa ou grelhada.

f. No caso de verduras e legumes. Perguntar os ingredientes da salada.

Exemplo: Salada de alface com tomate, pepino e cebola.

$\begin{array}{ll}\text { Alface } & 5 \text { folhas } \\ \text { Tomate } & 4 \text { rodelas } \\ \text { Pepino } & 5 \text { fatias } \\ \text { Cebola } & 2 \text { rodelas } \\ \text { Azeite } & 1 \text { fio }\end{array}$


Legumes (cenoura, abobrinha, beringela, milho, etc.) registre em colheres de sopa ou de servir e pergunte o tipo de preparação: cozidos ou refogados.

g. Preparações habituais como arroz, feijão e macarrão utilizar as medidas caseiras de referência (colher de sopa, colher de servir, concha, pegador de macarrão).

h. Não faça perguntas tendenciosas. Exemplo: Você tomou café da manhã? Você come pouco?

Estando o entrevistador dentro do domicílio, em caso de dúvidas em relação as medidas caseiras, poderá solicitar à apresentação do utensílio.

A equipe deverá ter pelo menos 3 horas de treinamento com profissional nutricionista. $O$ treinamento deverá incluir apresentação de kit básico de medidas caseiras para a padronização da informação coletada. 
ANEXO 3 - TESTE DE KOLMOGOROV-SMIRNOVE GRAFICO QQPLOT DO ÍNDICE DE QUALIDADE DA DIETA (IQD). 
Teste de Kolmogorov-Smirnov e gráfico QQPLOT do Índice de Qualidade da Dieta (IQD).

One-Sample Kolmogorov-Smirnov Test

\begin{tabular}{|ll|r|}
\hline & & \multicolumn{1}{|c|}{$I Q D$} \\
\hline Normal Parametersa,b & Mean & 1840 \\
& Std. Deviation & 60,9415 \\
Most Extreme & Absolute & 12,1557 \\
Differences & Positive &, 030 \\
& Negative &, 017 \\
Kolmogorov-Smirnov Z & &,- 030 \\
Asymp. Sig. (2-tailed) & & 1,302 \\
\hline
\end{tabular}

a. Test distribution is Normal.

b. Calculated from data.

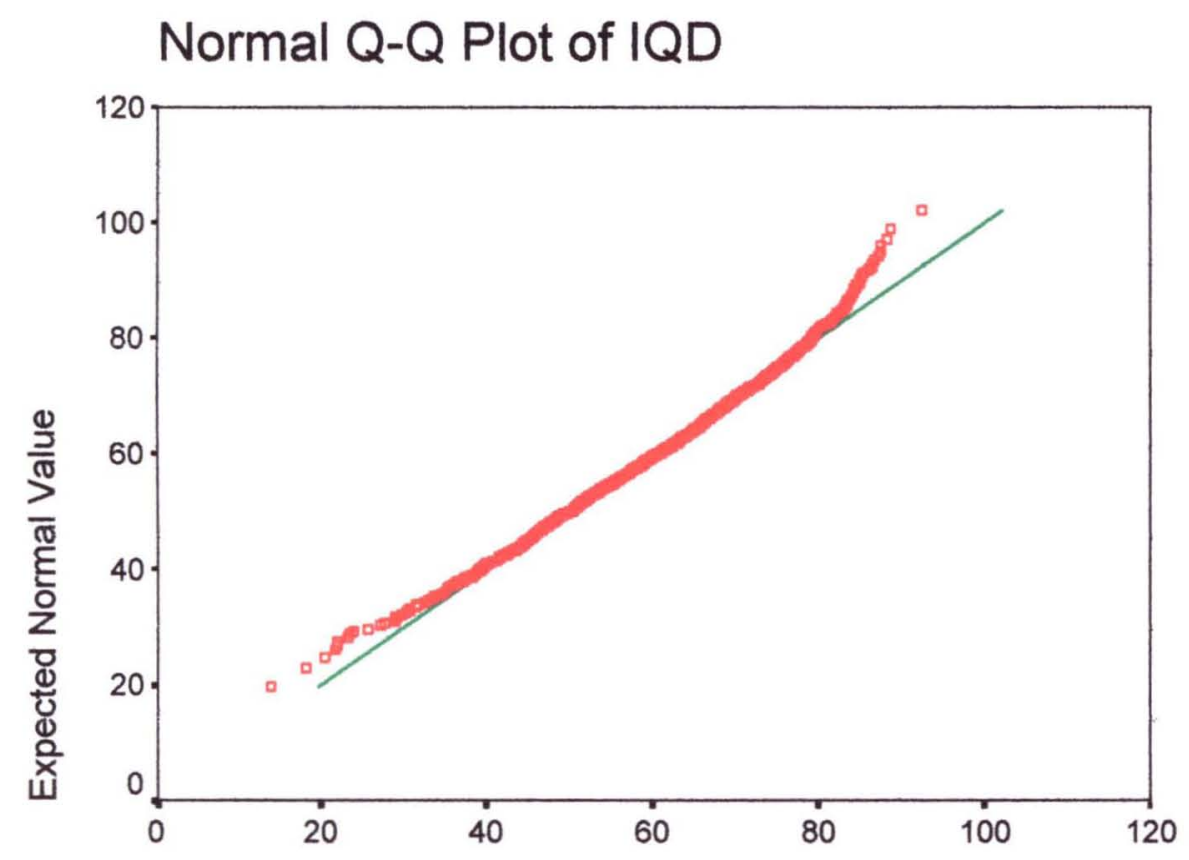

Observed Value 
ANEXO 4-HISTOGRAMAS DE DISTRIBUIÇÃO DAS VARIÁVEIS QUANTITATIVAS EM SUA UNIDADE ORIGINAL E TRANSFORMADAS EM SEU LOGARITMO NATURAL. 
Histogramas de distribuição das variáveis quantitativas em sua unidade original e transformadas em seu logaritmo natural.
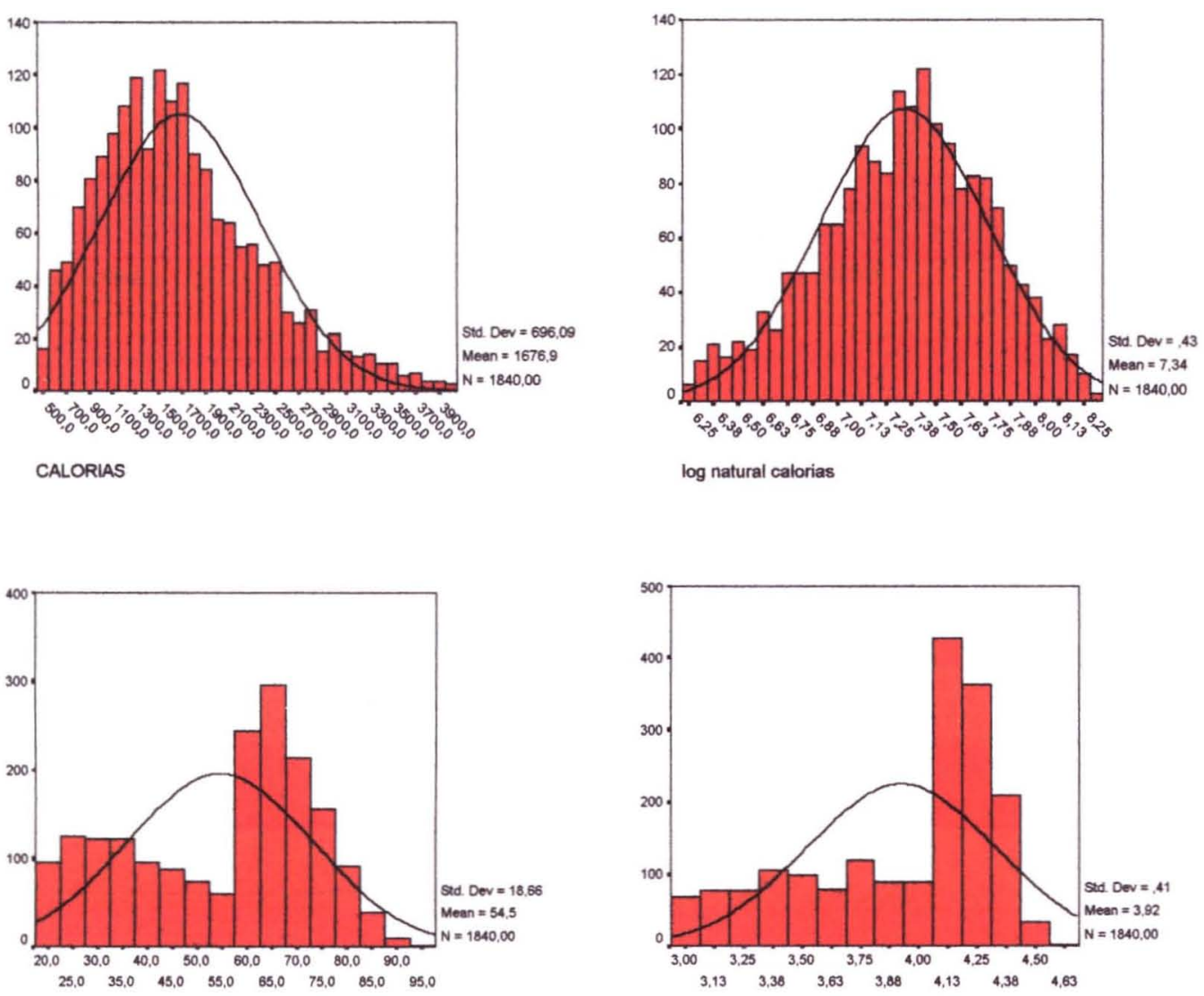

IDADE

$\log$ natural idade
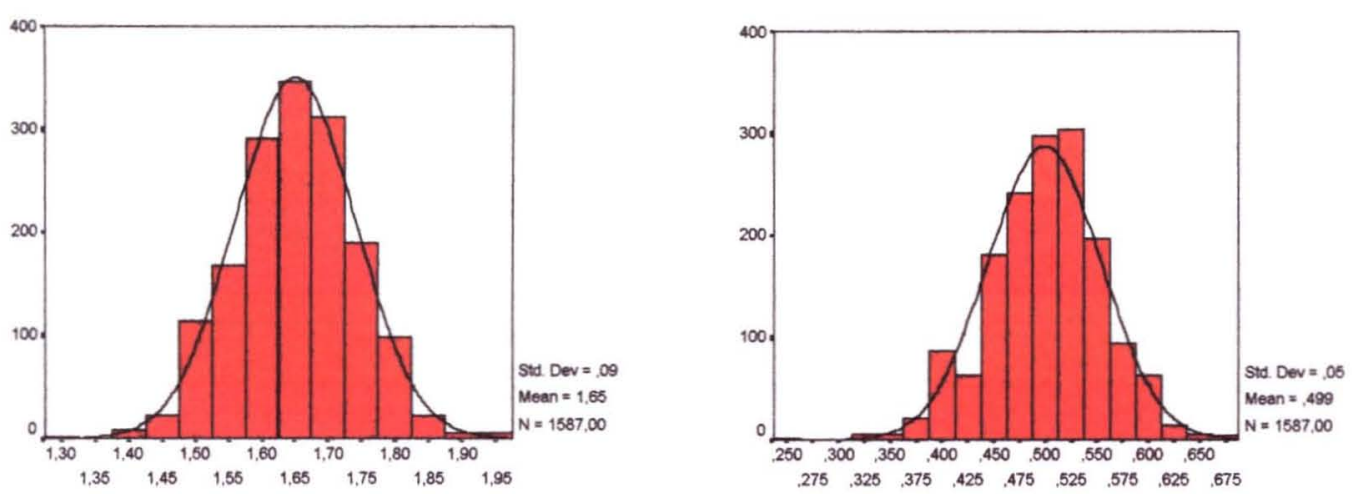

altura referida

$\log$ natural altref 

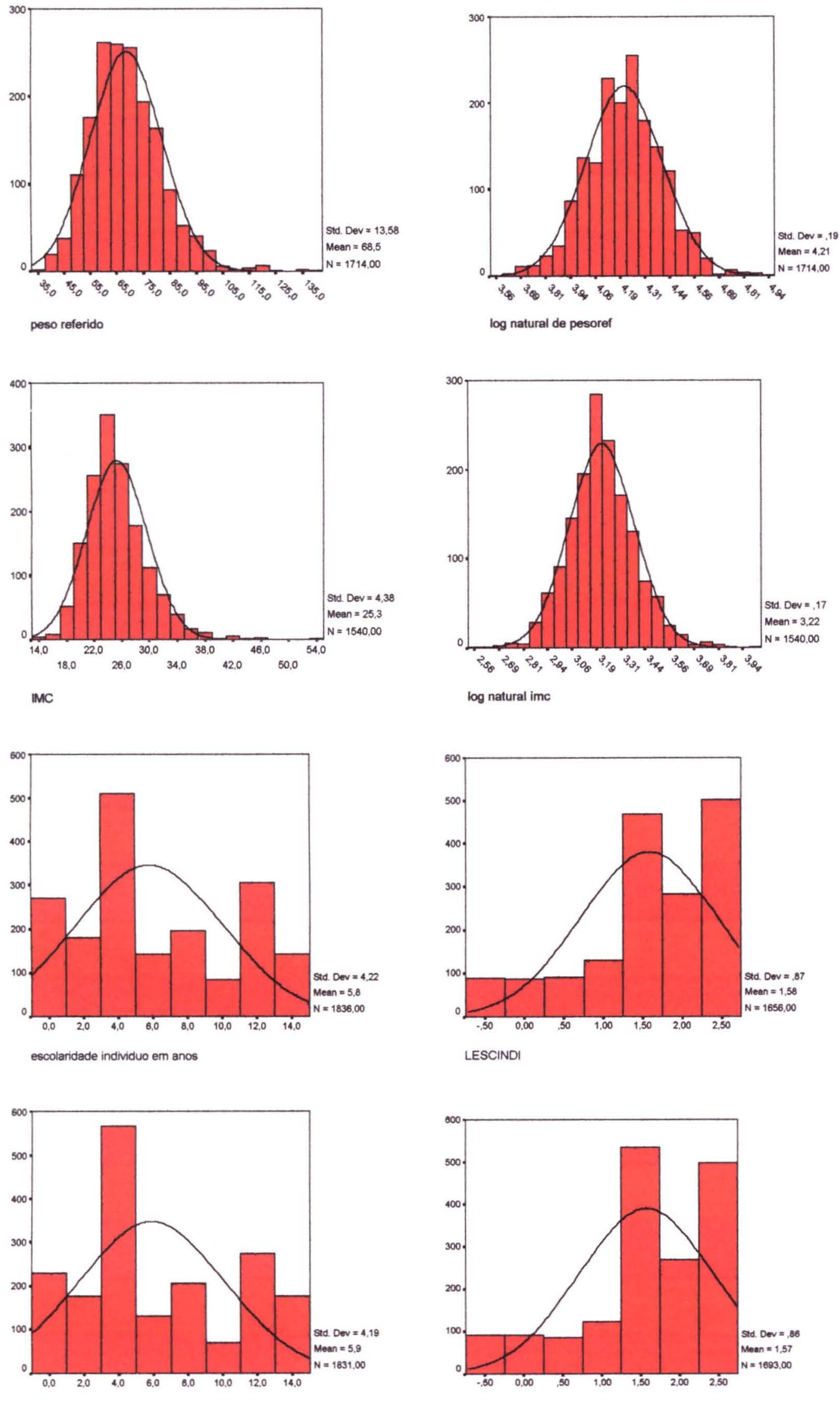

escolaridade do chefe em anos

LESCCHEF 


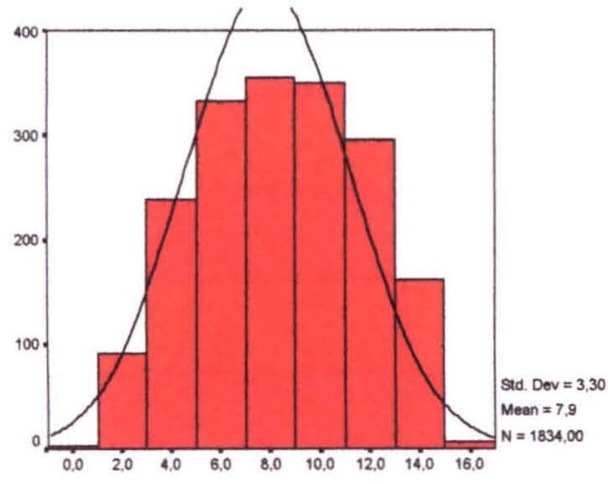

numero equipamentos

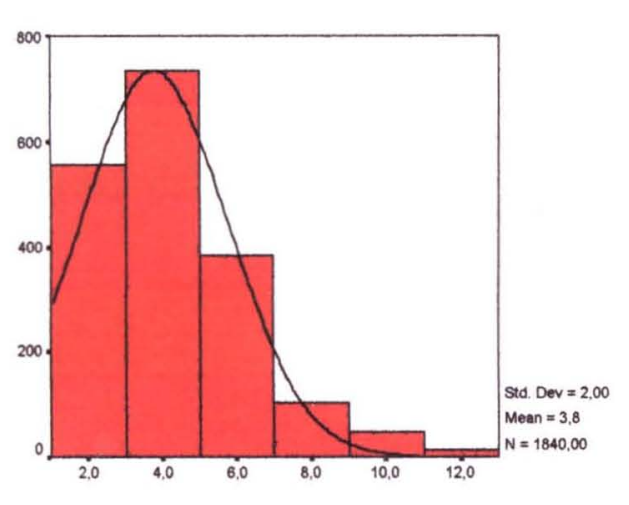

numero de moradores

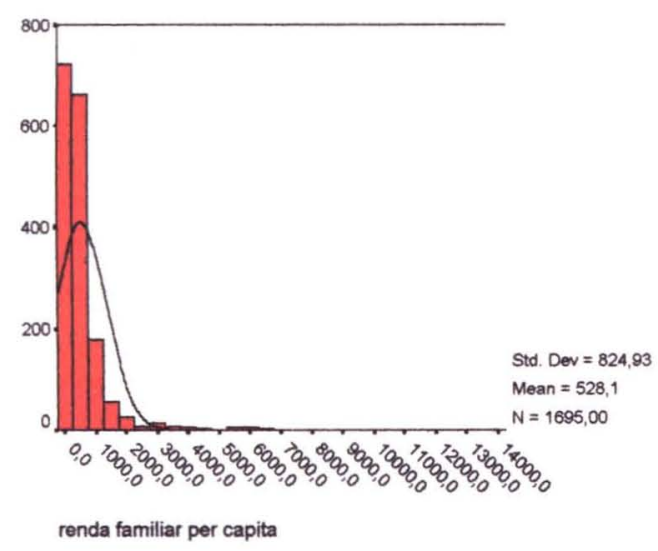

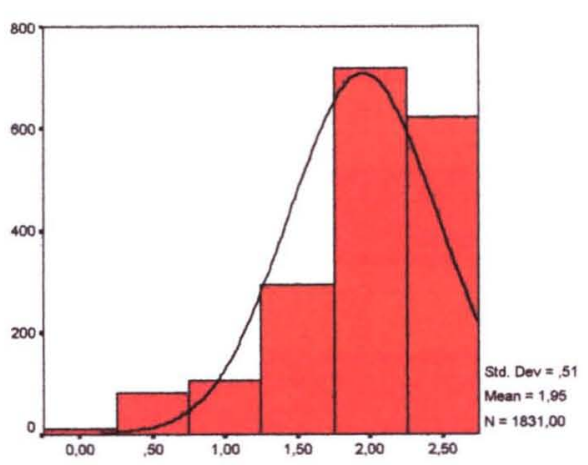

LNUMEQUI

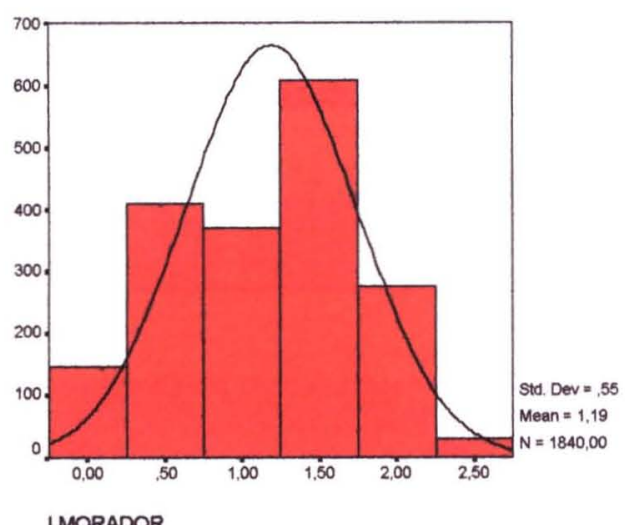

IMORADOR

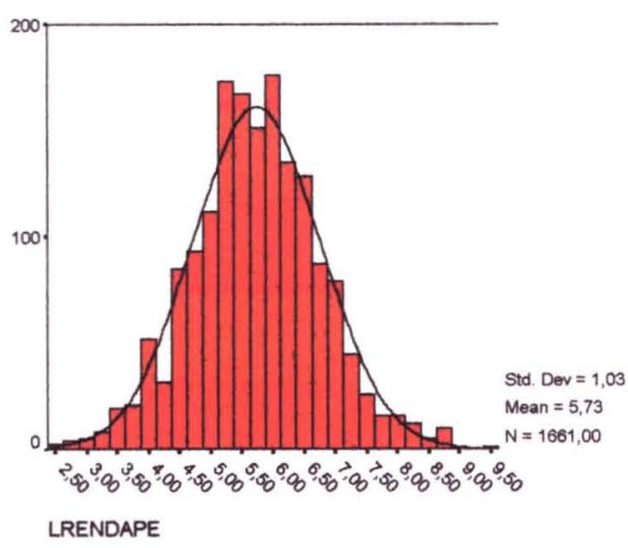




\section{ANEXO 5 - GRÁFICOS QQPLOTS DAS VARIÁVEIS QUANTITATIVAS.}


QQPLOTs das variáveis quantitativas.
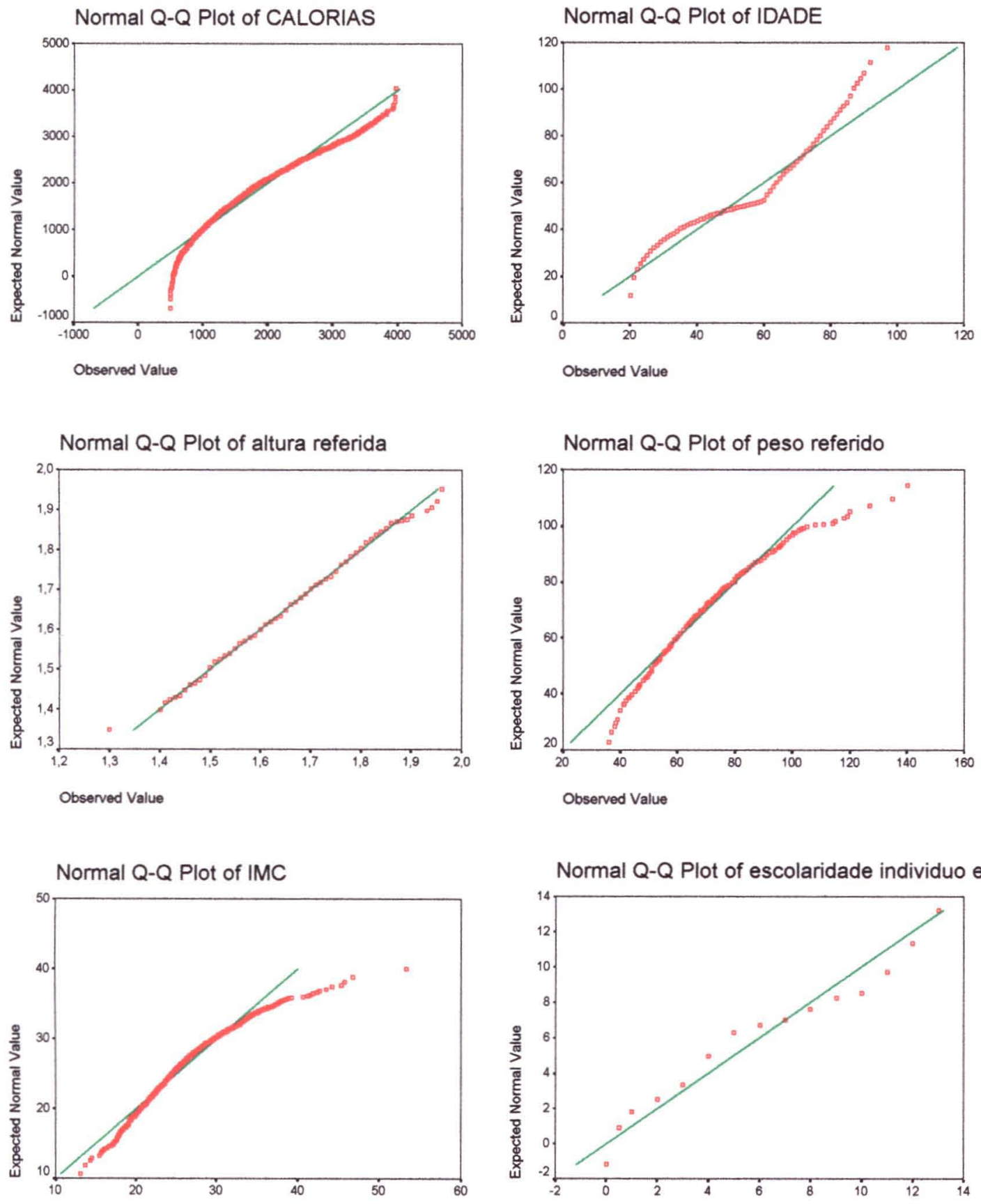

Observed Value

Observed Value

Normal Q-Q Plot of escolaridade do chefe e

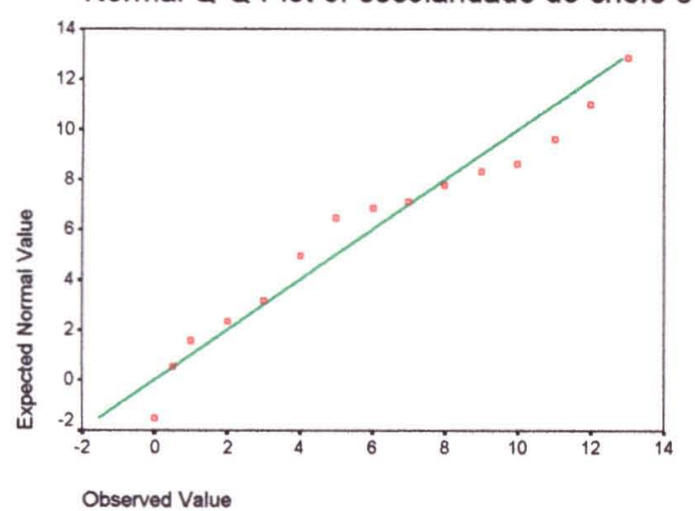

Normal Q-Q Plot of numero equipamentos

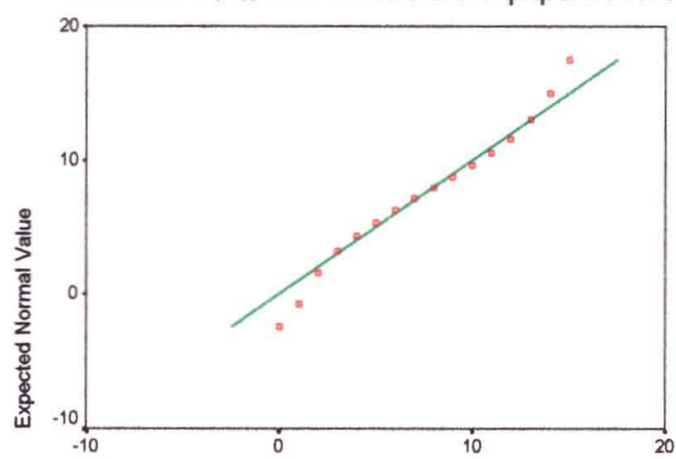

Observed Value 
Normal Q-Q Plot of renda familiar
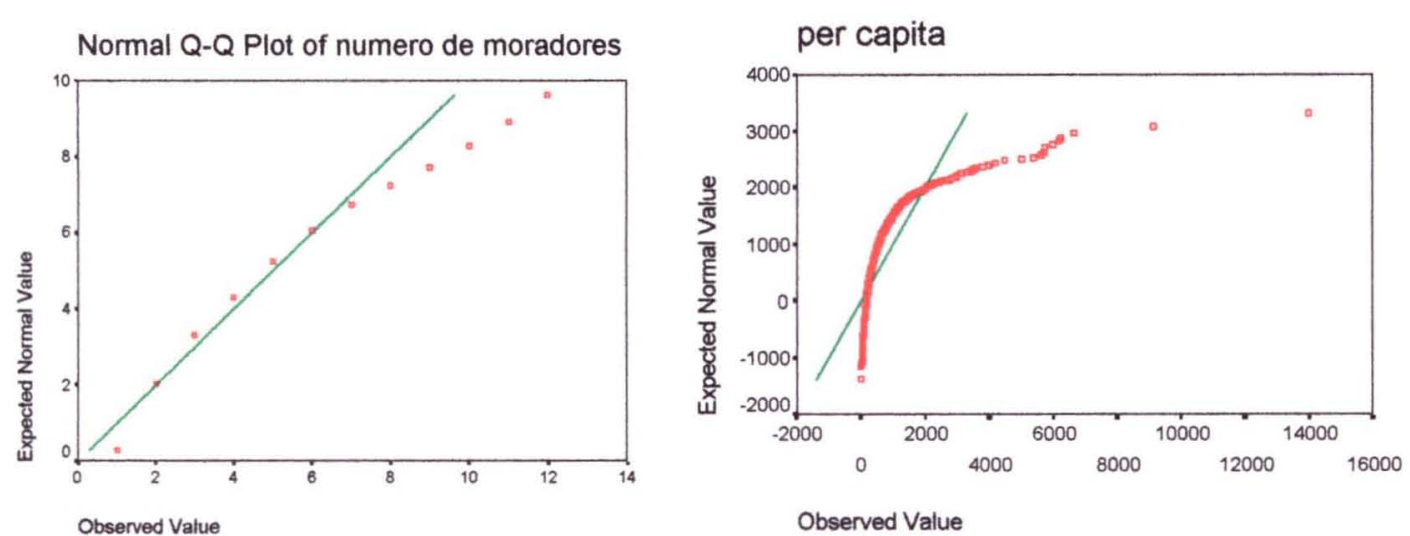
ANEXO 6-PARECER DO COMITÊ DE ÉTICA EM PESQUISA DA FSP/USP DO PROJETO DE PESQUISA PRINCIPAL "INQUÉRITO DE SAÚDE DO ESTADO DE SÃO PAULO - ISASP". 


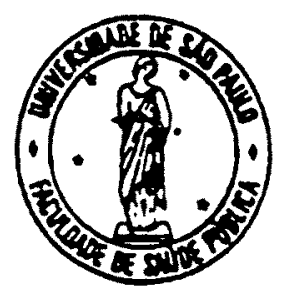

UNIVERSIDADE DE SÃO PAULO

FACULDADE DE SAUUDE PÚBLICA

COMITÉ DE ÉTICA EM PESQUISA-COEP

Av. DI. Annzido, 715 - sala 18 - sub-solo - Cerquezra césar

Sto Paulo-sP CP: 01246-904

Teletone (0x×11) 3066-7776 - e-marl: mogracaseusp.br

\section{Of.COEP/13/01}

14 de fevereiro de 2001

Pelo presente, informo que o Comitê de Ėtica em Pesquisa da Faculdade de Saúde Pública da Universidade de São Paulo-COEP, analisou e aprovou, em sua 1. ${ }^{2} / 00$ Sessão Ordinária, de 13.02.01, de acordo com os requisitos da Resolução CNS/196/96, o Protocolo de Pesquisa n. ${ }^{\circ}$ 381, intitulado: "INQUÉRITO DE SAÚDE NO ESTADO DE SÃO PAULO - INQUÉRITO DOMICILIAR DE SAÚDE, DE BASE POPULACIONAL, EM MUNICÍPIOS DO ESTADO DE SÃO PAULO", apresentado pelo pesquisador Chester Luiz Galvão Cesar.

Atenciosamente,

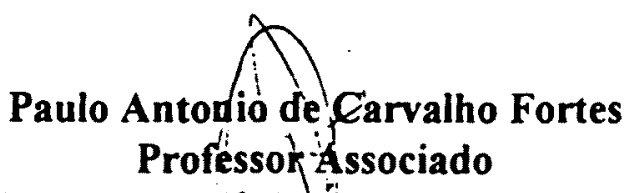

Vice-Coordenador do Comitê de lética em Pesquisa da FSP-COEP 
ANEXO 7-PARECER DO COMITÊ DE ÉTICA EM PESQUISA DA FSP/USP DESTE SUBPROJETO DE PESQUISA. 


\section{Universidade de São Paulo}

Faculdade de Saúde Pública

\section{COMITE DE ÉTICA-COEP}

Av. Dr. Arnaldo, 715 - CEP 01246-904 - São Paulo - Brasil

Telefones: (55-11) 3066- 7779 - fone/fax (55-11) 3064 -7314 - e-mail: mdgracas a usp. $n$

\section{Of.COEP/173/03}

15 de outubro de 2003

Pelo presente, informo que o Comitê de Ética em Pesquisa da Faculdade de Saúde Pública da Universidade de São Paulo-COEP, analisou e aprovou o protocolo de pesquisa n. ${ }^{\circ}$ 1032, intitulado "QUALDADE DA DIETA SEGUNDO ESTRATOS SOCIOECONÔMICOS DE ADULTOS DA RF:SLÃO METROPOLITANA DE SÃO PAULO", apresentado pela pesquisadora Juliana Masami Morimoto.

O projeto faz parte de uma pesquisa mais ampla, intitulada: "INQUÉRITO DE SAÚdE NO ESTADO DE SÃO PAULO - INQUÉRITO DOMICILIAR DE SAÚDE, DE BASE POPULACIONAL, EM MUNICIPIOS DO ESTADO DE SÃO PAULO", já analisada e aprovada por este Comitê em sua 1.a/00 reunião realizada em 13.02.01, não havendo modificações relativas ao conteúdo da pesquisa original.

Atenciosamente,

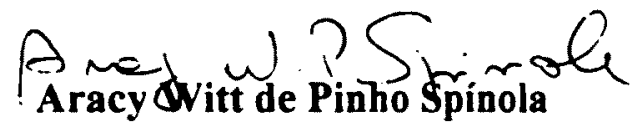

Professora Titular

Vice-Coordenadora do Comitê de Ética em Pesquisa da FSP-COEP 
ANEXO 8 - TERMO DE CONSENTIMENTO LIVRE E ESCLARECIDO DO PROJETO DE PESQUISA PRINCIPAL. 


\section{Inquérito de Saúde no Estado de São Paulo}

\section{USP, UNICAMP, UNESP C SES-SP}

TERMO DE CONSENTIMENTO

Eu, residente à rua $n^{0}$ bairTo afirmo meu consentimento para participar da

pesquisa "Inquérito de Saúde no Estado de São Paulo".

Fui informado(a) do objetivo da pesquisa que é o de conhecer melhor as condiçōes de vida e saúde dos moradores de alguns municípios e áreas do Estado de São Paulo, entre eles o Distrito do Butantã, no Municipio de São Paulo, e os Municipios de Taboão da Serra, Embu, e Itapecerica da Serra, na Grande São Paulo, além de Botucatu e Campinas, no interior do Estado. Esta pesquisa é um estudo conjunto das Universidades Públicas Paulistas com a Secretaria de Estado da Saúde.

Fui informado que na divulgação dos dados não haverá a identificação dos entrevistados e ninguém, além dos pesquisadores, terá acesso aos nomes dos entrevistados nesta pesquisa.

Também fui informado(a) que serão coletadas informações sobre a minha saúde, meus comportamentos relacionados à saúde, o uso que faço de serviços de saúde bem como sobre as minhas condiçōes sócio-econômicas. Estou ciente de que a minha participação é voluntária e que os pesquisadores responsáveis por este trabalho estarão à disposição para qualquer esclarecimento e informaçōes adicionais.

São Paulo de de 2001

Assinatura do(a) entrevistado(a) ou responsável:

Assinatura do entrevistador:

Responsáveis pela pesquisa nos municipios estudados:

Prof. Dr. Chester Luiz Galvão Cesar

Departamento de Epidemiologia - Faculdade de Saúde Pública da USP - Telefone 30835738

Prof. Dr. Moisés Goldbaum

Departamento de Medicina Preventiva - Faculdade de Medicina da USP - Telefone 3066-7444 
ANEXO 9-ANÁLISE DE RESÍDUOS DO MODELO FINAL DE REGRESSÃO LINEAR MÚLTIPLA PARA O ÍNDICE DE QUALIDADE DA DIETA NA POPULAÇÃO TOTAL ESTUDADA E SEGUNDO SEXO. 
Análise de resíduos do modelo final de regressão linear múltipla para o índice de Qualidade da Dieta.

Resíduo do modelo final de regressão linear múltiplo para a população total segundo valores estimados do Índice de Qualidade da Dieta.

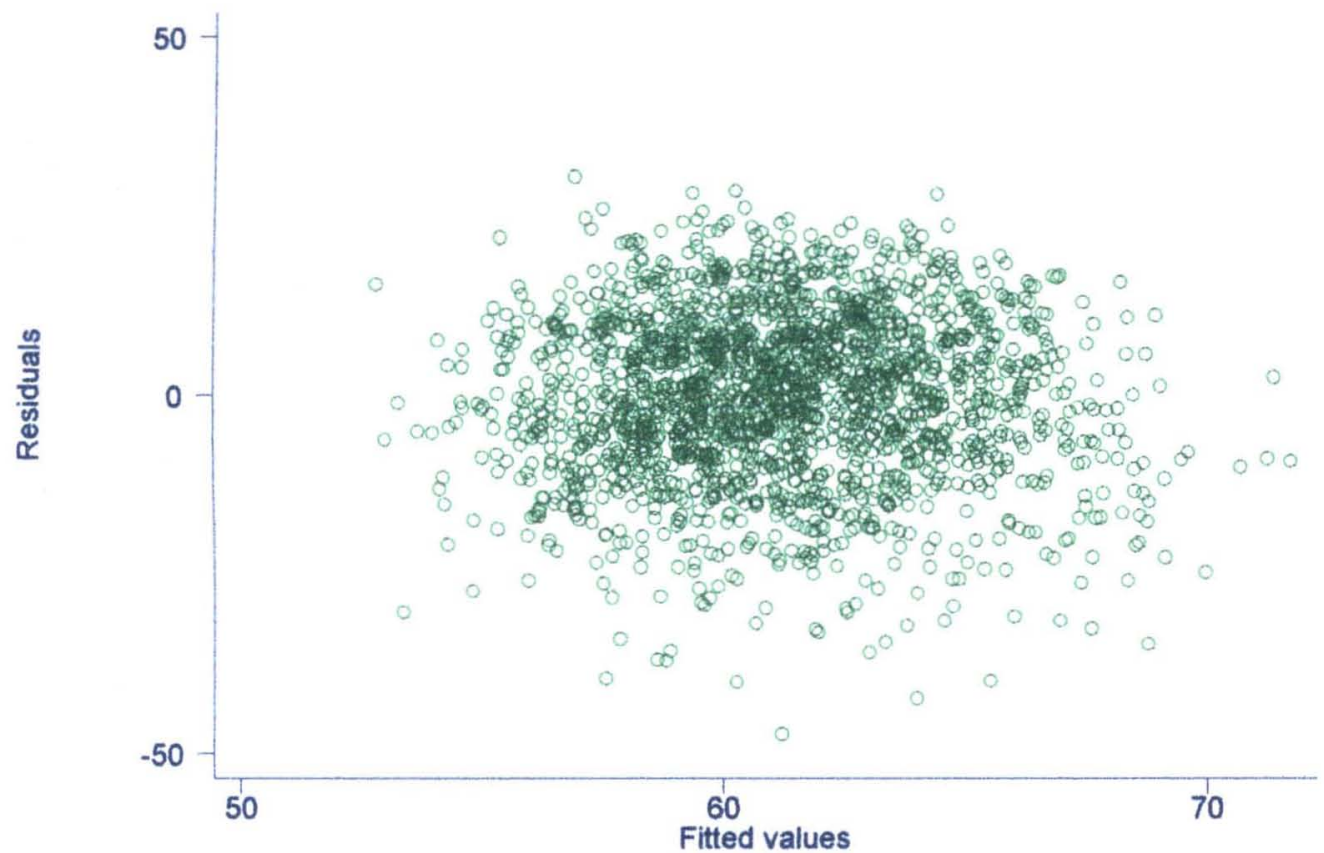

QQPLOT do resíduo do modelo final de regressão linear múltiplo para a população total.

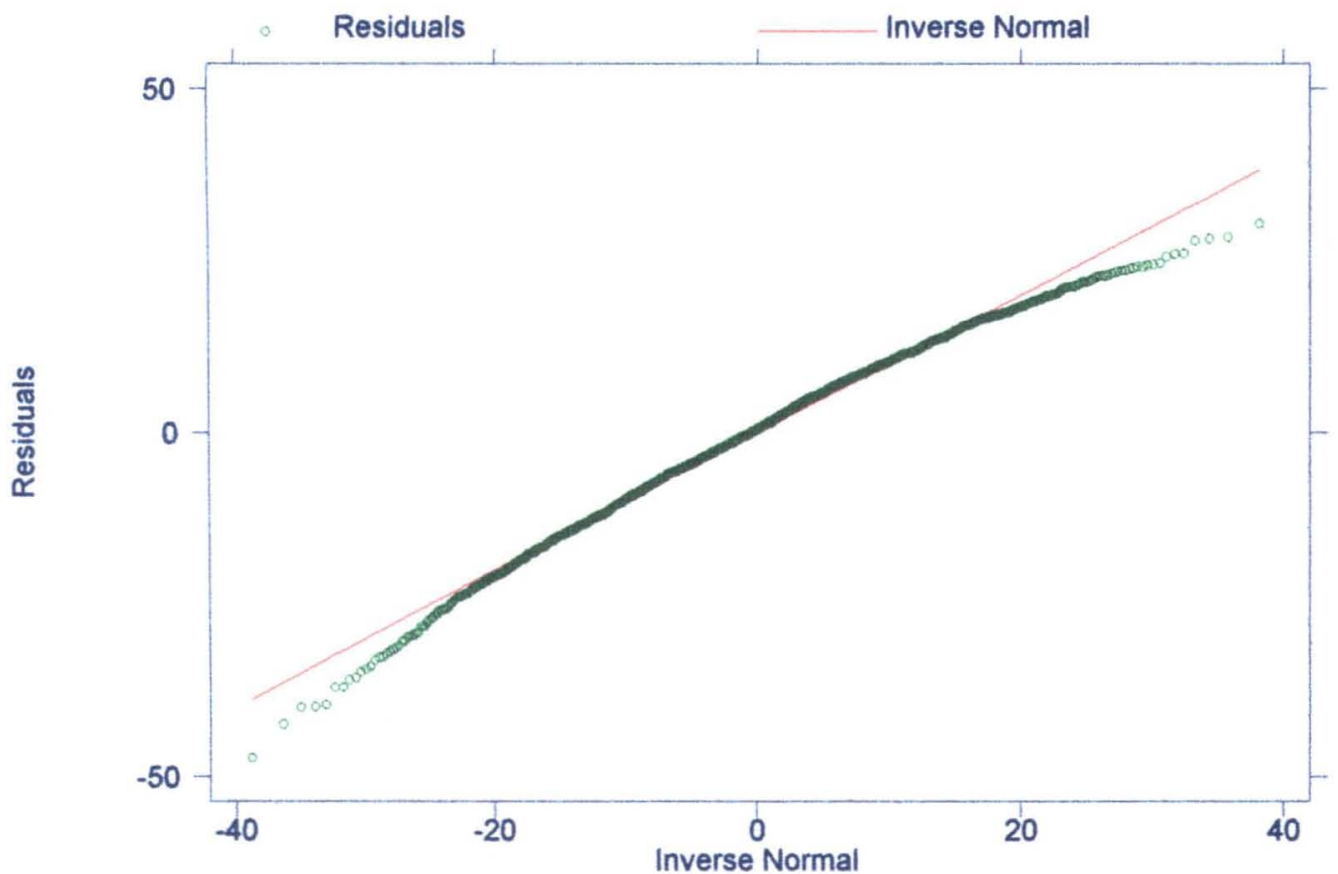


Resíduo do modelo final de regressão linear múltiplo segundo valores estimados do Índice de Qualidade da Dieta para o sexo masculino.

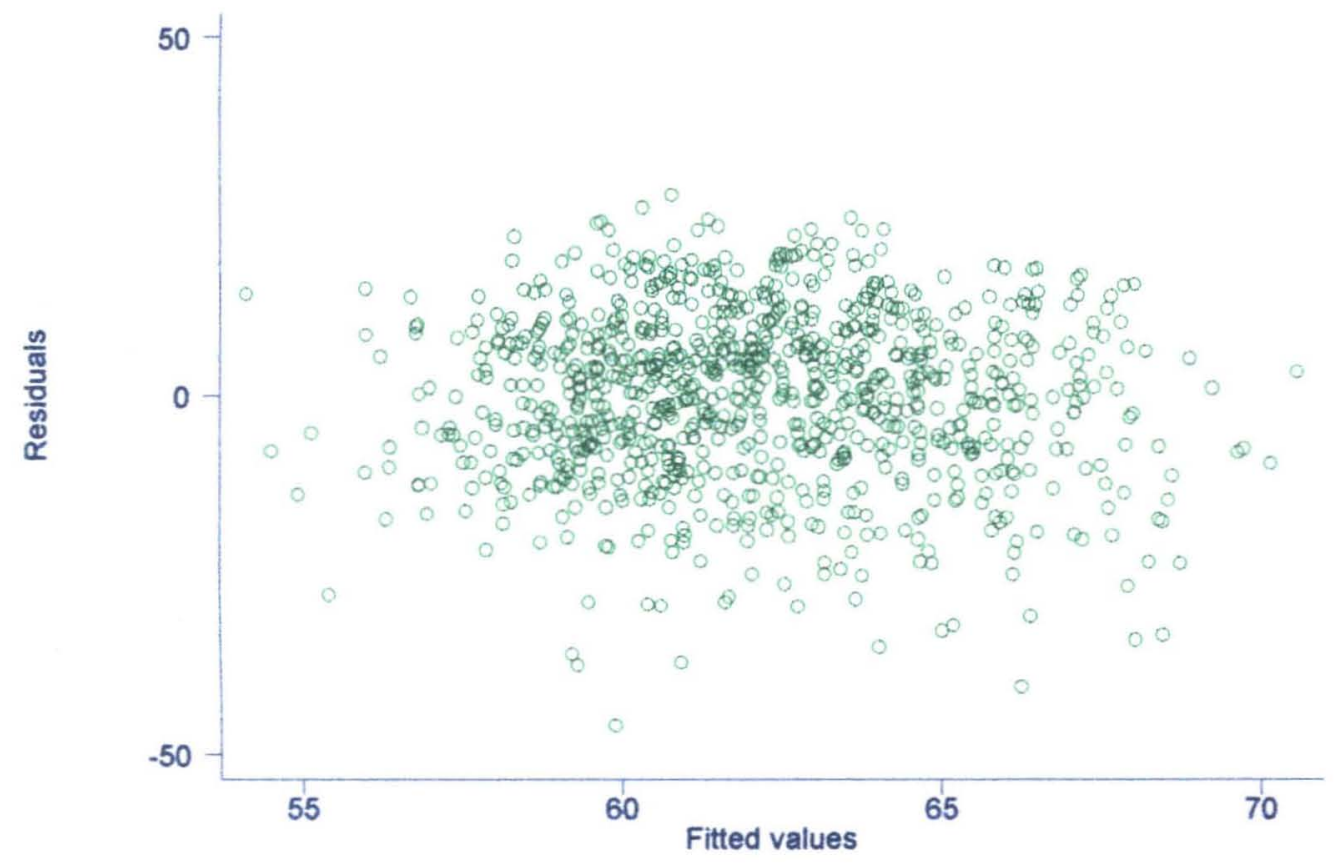

QQPLOT do resíduo do modelo final de regressão linear múltiplo para o sexo masculino.

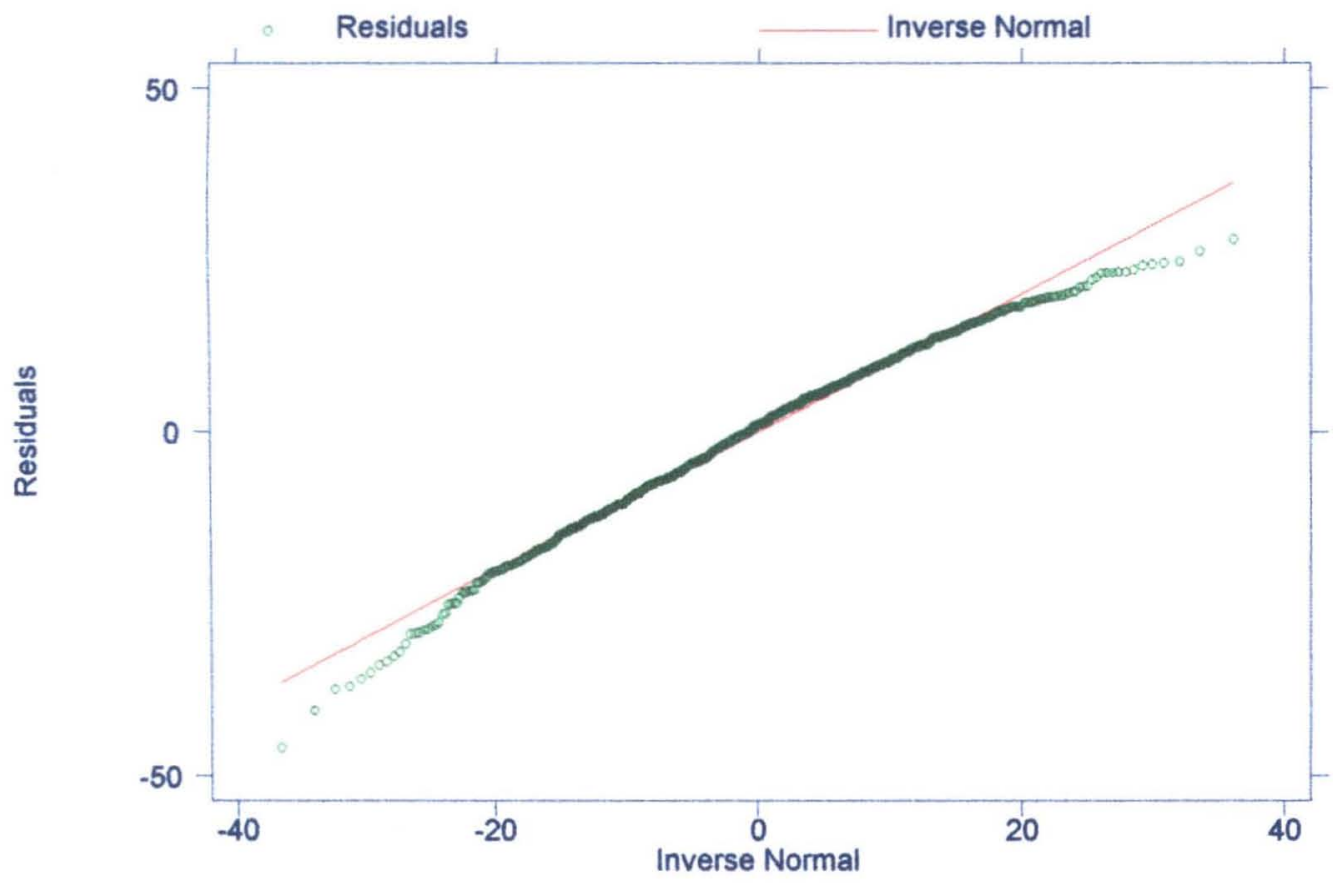


Resíduo do modelo final de regressão linear múltiplo segundo valores estimados do Índice de Qualidade da Dieta para o sexo feminino.

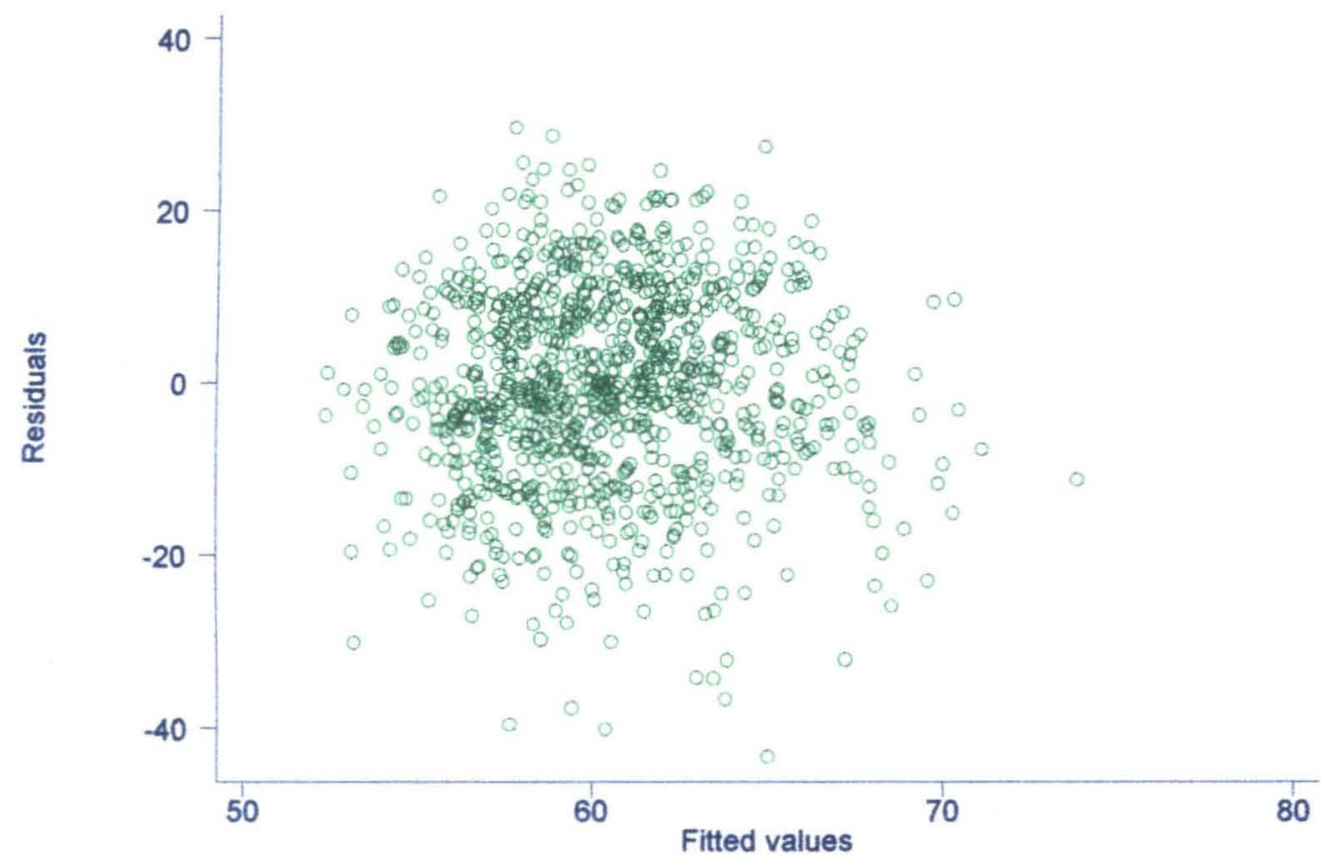

QQPLOT do resíduo do modelo final de regressão linear múltiplo para o sexo feminino.

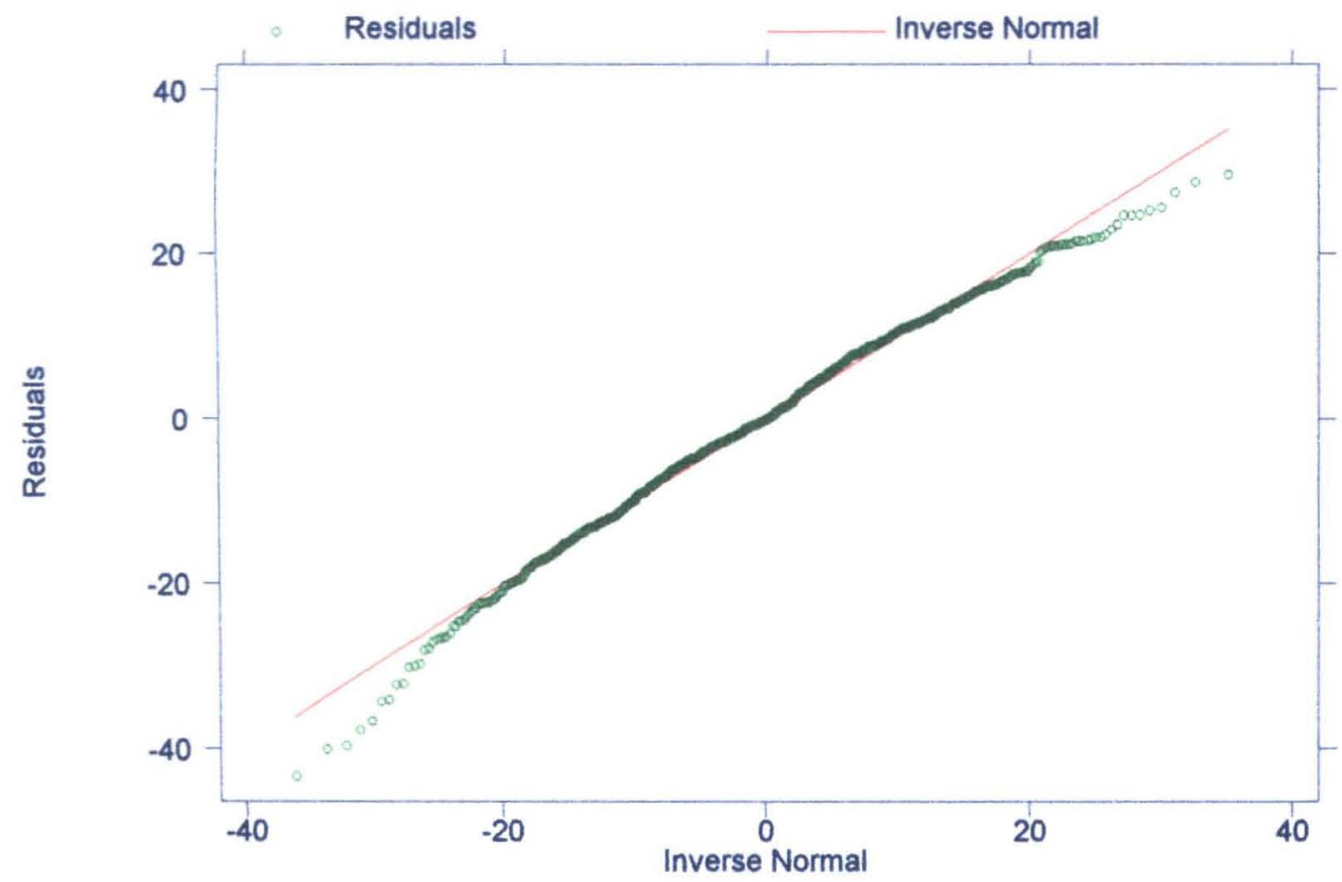

